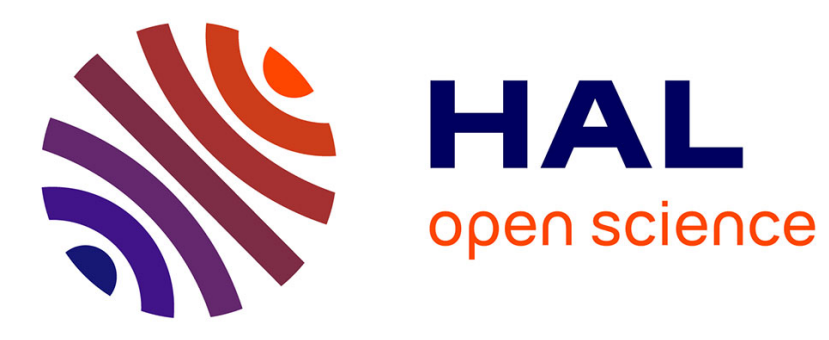

\title{
Humid Ageing of Organic Matrix Composites
}

\author{
Xavier Colin, Jacques Verdu
}

\section{To cite this version:}

Xavier Colin, Jacques Verdu. Humid Ageing of Organic Matrix Composites. Solid Mechanics and Its Applications, 208, Springer, pp.47-114, 2014, 978-94-007-7416-2. 10.1007/978-94-007-7417-9_3 . hal-02625990

\section{HAL Id: hal-02625990 \\ https://hal.science/hal-02625990}

Submitted on 26 May 2020

HAL is a multi-disciplinary open access archive for the deposit and dissemination of scientific research documents, whether they are published or not. The documents may come from teaching and research institutions in France or abroad, or from public or private research centers.
L'archive ouverte pluridisciplinaire HAL, est destinée au dépôt et à la diffusion de documents scientifiques de niveau recherche, publiés ou non, émanant des établissements d'enseignement et de recherche français ou étrangers, des laboratoires publics ou privés. 


\title{
Humid Ageing of Organic Matrix Composites
}

\author{
X. Colin and J. Verdu
}

\begin{abstract}
In this chapter, several aspects of the ageing phenomena induced by water in organic matrix composites are examined, essentially from the physicochemical point of view. It is first important to recognize that there are two main categories of humid ageing. First there are physical processes, mainly linked to the stress state induced by matrix swelling and sometimes matrix plasticization. This kind of ageing can occur in matrices of relatively high hydrophilicity (affinity with water). Highly crosslinked amine cured epoxies are typical examples of this behavior. The second category of humid ageing involves a chemical reaction (hydrolysis) between the material and water. Unsaturated polyesters are typical examples of this category. They display a low to moderate hydrophilicity, swelling and plasticization have minor effects, but hydrolysis induces a deep polymer embrittlement and, eventually, osmotic cracking. Whatever the ageing mechanism, it needs the water to penetrate into the material and depends on the water concentration and its distribution in the sample thickness. This is the reason why the first and second sections are respectively dedicated to water solubility and diffusivity in matrices, interphases and composites. In each case, the elementary processes are distinguished, to examine the effects of temperature and stress state and to establish structure-property relationships. It is shown that, in most of these aspects, research remains largely open. The last section is devoted to hydrolysis, its kinetic modeling, including the case of diffusion controlled hydrolysis, and its consequences on polymer properties. Structure reactivity relationships are briefly presented. The very important case of osmotic cracking, which can be considered as a consequence of hydrolysis, is also examined.
\end{abstract}

\footnotetext{
X. Colin $(\bowtie) \cdot J$. Verdu ARTS ET METIERS ParisTech, PIMM (UMR CNRS 8006), 151 boulevard de l'Hôpital 73013 Paris, France e-mail: Xavier.COLIN@ensam.eu
} 


\section{Introduction}

It is well known, for over half a century, that organic matrix composites (OMCs) can fail by "humid ageing", i.e. irreversible interaction with water in (atmospheric) vapor or liquid state. Two particular cases resulted in a considerable amount of research: (1) the case of high performance epoxy-carbon composites in military airplanes used in wet tropical environments, especially in Vietnam in the 1960-1975 period [1]; (2) the case of polyester-glass fiber boat hulls in the 1970s-1980s when pleasure sailing developed extensively. In principle, ageing problems in OMCs can involve one or several of the three components: the fibers, the matrix or the interface. It was immediately shown that, in both cases, fibers are impermeable to water and stable in the natural environments under consideration. Interfacial failure can occur but here, the weakest component is, no doubt, the matrix. It was also rapidly recognized that both cases correspond to two distinct modes of polymer-water interaction. Amine crosslinked epoxies do not react chemically with water, they fail by loss of mechanical processes linked to the water penetration and its swelling effect on the matrix. Polyesters react with water, the hydrolysis of ester groups cuts the network strands, that leads to polymer embrittlement, but the main consequence of hydrolysis is to generate small organic molecules eventually responsible for osmotic cracking (the blistering process, well known to boat users).

Considering now the whole family of OMCs, one can envisage three cases: For relatively highly hydrophilic matrices, e.g. high performance epoxies able to absorb up to $7 \%$ by weight of water, failure is expected to result mainly from stresses induced by differential swelling linked to water concentration gradients in transient absorption or desorption regimes. For polymers of relatively low hydrophilicity but containing hydrolysable groups, e.g. linear or tridimensional polyesters, anhydride cured epoxies, polycarbonates, certain polyamides, etc., failure must result from hydrolysis. For non-hydrolysable polymers of low hydrophilicity, e.g. polyethers, polysulfones, hydrocarbon polymers, etc., failure can eventually result from interfacial degradation. Whatever the mechanism of OMC-water interaction, it involves water penetration, that leads to two series of questions which will constitute the subjects of two sections of this chapter. The first section deals with the polymer-water equilibrium: the experimental determination of equilibrium water concentration, its variation with water activity and temperature, the structure-hydrophilicity relationships, the effect of absorbed water on main polymer physical properties. The second and third sections deal with kinetic aspects of water sorption, the experimental approaches, the diffusion mechanisms and the corresponding kinetic laws, the effect of temperature and stress state on diffusivity, the structure-diffusivity relationships, the role of reinforcing agents, especially fibers on diffusion, and the stress state induced by diffusion. The fourth section deals with hydrolysis processes: experimental approaches, mechanisms and kinetics, diffusion control on kinetics, consequences on mechanical properties, osmotic cracking and interfacial hydrolysis. 


\section{Polymer-Water Equilibrium Characteristics}

\subsection{Measurement of Water Concentration in a Polymer}

There is a wide variety of experimental approaches for the measurement of water concentration in a polymer (or composite) matrix. The simplest and most popular one is based on sample weighing in wet $(\mathrm{w})$ and dry $\left(\mathrm{w}_{0}\right)$ states from which one can determine the water mass fraction: $\mathrm{m}=\left(\mathrm{w}-\mathrm{w}_{0}\right) / \mathrm{w}$ and the water concentration: $\mathrm{C}=\mathrm{m} \rho / 18$, where $\rho$ is the density of the wet polymer expressed in $\mathrm{g} .1^{-1}$. This method can be routinely used to determine mass fractions higher than $0.1 \%$. Lower values can be accessible with high performance scales using precautions to suppress electrostatic interactions between the sample and the scale. It has been possible to reach concentrations of few dozens of ppm of water in polyethylene [2]. Low concentrations can also be determined using Karl Fisher chemical titration [3].

In the range of higher concentrations, various spectro-chemical methods are available, especially proton NMR (see e.g. Li and Chen. [4] for polyimides and Zhou and Lucas [5] for epoxies). Popineau et al. [6] also used NMR, but with deuterated water, to study water absorption by an epoxy resin. NMR allows distinguishing between free and bonded water or between two distinct populations of bonded water thanks to their distinct relaxation times. Dielectric spectroscopy is also abundantly used, it also allows distinguishing between free and bonded water, as shown e.g. by Reid et al. [7] or Grave et al. [8] in the case of epoxies, and by Lim et al. [9] in the case of polyimides. Infrared spectroscopy also allows both types of sorbed water to be distinguished since free water displays a sharp peak at about $3,650 \mathrm{~cm}^{-1}$, whereas hydrogen bonded water displays a broader band at a lower frequency depending on the strength of the hydrogen bond and the number of associated molecules. Examples of IR studies can be found in the literature, e.g. Illinger and Schneider [10], Grave et al. [8] or Cotugno et al. [11] in the case of epoxies, but the use of IR for quantitative studies appears difficult and would need very careful preliminary analyses.

The coexistence of free and bonded water creates many problems because free water can exist in various forms: pockets linked to the initial presence of macroscopic pores and nano-pockets. In the case of macroscopic pores, differential calorimetry allows to distinguish free water by its melting endotherm at $0{ }^{\circ} \mathrm{C}$. In small pores, this endotherm can be shifted towards low temperatures owing to confinement effect. Let us recall that in composites, porosity can be interfacial or induced by mechanical damage. In the case of nano-pockets, it is not easy to distinguish between those linked to initial nano-pores and those resulting from clustering in an initially homogeneous matrix. Preexisting pores can in principle be detected from density changes linked to water absorption at low to moderate activities. As a matter of fact, the density of a polymer-water mixture can vary between two limits $\rho_{\min }$ and $\rho_{\max }$ corresponding respectively to the case where water is fully soluble in the polymer (i.e. does not form a separate phase and both 
volumes are additive) and the case where water is insoluble in the polymer and fills only the pores. Assuming that water density is equal to unity, one obtains:

$$
\begin{gathered}
\rho_{\text {min }}=\frac{\rho_{p}}{1+m\left(\rho_{p}-1\right)} \\
\rho_{\text {max }}=\rho_{p}\left(1+\frac{m}{1-m}\right)
\end{gathered}
$$

where $\rho_{\mathrm{p}}$ is the polymer density in dry state. For all matrices of interest except hydrocarbon ones (polyolefins), $\rho_{\mathrm{p}}>1$.

Since clusters are formed only at high activities, one expects that, at low activities, density increases with the water mass fraction when water fills the pores, and decreases when water is dissolved in the matrix. Such methods are, indeed, very difficult to use in polyolefins where the density is lower than unity and where hydrophilicity is extremely low. The existence of preexisting nano-pores can be eventually detected using other penetrating fluids than water, e.g. nitrogen [12], BET [13], BJH or polarized xenon 129 [14]. It is necessary, here, to make the difference between surface (adsorption) and bulk properties, which could need the comparison of samples of different thicknesses.

\subsection{Effect of Water Activity on Equilibrium Water Concentration}

The curve of water mass (or molar) fraction against water activity $a$ at a fixed temperature $\mathrm{T}$ is called the "sorption isotherm". Let us recall that the water activity is defined by:

$$
\mu=\mu_{0}+\mathrm{RT} \operatorname{Ln}(\mathrm{a})
$$

where $\mu$ and $\mu_{0}$ are the respective values of the chemical potential in the system under study and a reference state.

The activity of a component is linked to:

- Its molar fraction $\mathrm{X}$ in a liquid state: $\mathrm{a}=\gamma \mathrm{X}$, where $\gamma$ is the activity coefficient. In an ideal solution, $\gamma=1$.

- Its partial pressure $\mathrm{p}$ in gaseous phase: $\mathrm{a}=\mathrm{F}$, where $\mathrm{F}$ is the fugacity. In an ideal gas, $\mathrm{F}=\mathrm{p}_{\mathrm{S}}^{-1}$, where $\mathrm{p}_{\mathrm{S}}$ is the component partial pressure at saturation.

The equilibrium corresponds to the equality of water chemical potentials in both the medium and polymer. Considering only cases of water sorption by homogeneous, non-porous samples, we can distinguish four basic processes corresponding to the isotherm shapes represented in Fig. 1.

Isotherms of type $H$ correspond to the case where the equilibrium concentration is proportional to activity over the whole activity range (Henry's law). This 
Fig. 1 Shape of main sorption isotherms for homogeneous, bulky polymer samples

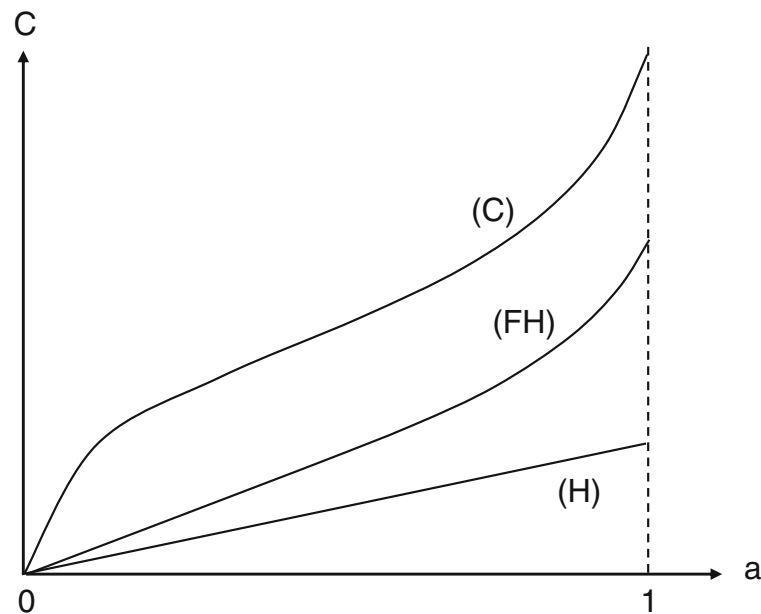

behavior can be observed in many polymers of relatively low hydrophilicity. Their equation is thus:

$$
\mathrm{W}=\mathrm{S} \mathrm{p}
$$

where $\mathrm{S}$ is the solubility coefficient and $\mathrm{p}$ the water partial pressure in the atmosphere or in equilibrium with the bath in the case of an exposure in liquid. According to the above definitions:

$$
\mathrm{W}=\frac{\mathrm{v}}{18} \frac{1-\mathrm{m}}{1-\mathrm{v}}
$$

i.e. $\mathrm{W} \approx \mathrm{v} / 18$ for low hydrophilicities. Since $\mathrm{p}=\mathrm{a} \mathrm{p}_{\mathrm{S}}$, it comes:

$$
\mathrm{v} \approx \mathrm{H} \mathrm{a}
$$

where $\mathrm{H}=18 \mathrm{p}_{\mathrm{S}}$ for low to moderate hydrophilicities.

Isotherms of type FH (Flory-Huggins) correspond to the following law:

$$
\operatorname{Ln}(\mathrm{a})=\operatorname{Ln}(\mathrm{v})+(1-\mathrm{v})+\chi(1-\mathrm{v})^{2}
$$

Their initial slope is:

$$
\left(\frac{\mathrm{dv}}{\mathrm{da}}\right)_{0}=\exp (-(1+\chi))
$$

Isotherms of $C$ (clusters) are defined by the Zimm-Lundberg [15] function $\mathrm{f}_{\mathrm{ZL}}$ for $\mathrm{f}_{\mathrm{ZL}}>-1$ :

$$
\mathrm{f}_{\mathrm{ZL}}=-\mathrm{v}\left[\frac{\partial(\mathrm{a} / \mathrm{v})}{\partial \mathrm{a}}\right]-1
$$


Table 1 Coefficients of the empirical power law linking the equilibrium mass uptake to relative hygrometry for the resin NARMCO 5208 and its carbon fiber laminates

\begin{tabular}{llll}
\hline Material & $\mathrm{a}_{\mathrm{S}}$ & $\mathrm{b}$ & Authors \\
\hline Laminate & 0.0182 & 1.28 & Shen and Springer[74] \\
Laminate & - & 1.8 & Husman[154] \\
Laminate & - & 1.0 & Mc Kague et al. [155] \\
Resin & 0.004 & 1.36 & Mc Kague et al. [59] \\
\hline
\end{tabular}

They can be represented, at least in a first approach, by a power law:

$$
\mathrm{v}=\mathrm{ba}^{\mathrm{m}}
$$

In the 1970s-1980s, most authors, in the composite field, used this type of power law to represent the activity effect on mass uptake: $\mathrm{m}_{\mathrm{S}}=\mathrm{a}_{\mathrm{S}}(\mathrm{HR})^{\mathrm{b}}$, where $\mathrm{m}_{\mathrm{S}}$ and HR (relative humidity) are expressed in percents. Some literature values of the proportionality factor as and exponent $b$ have been compiled for the highly crosslinked epoxy resin NARMCO $5208^{\circledR}$ and its carbon fiber laminates in Table 1.

However it is difficult to imagine, in homogeneous, non-porous samples, clustering without some water solubility in the polymer. In other words, isotherms of type $\mathrm{C}$ must always coexist with isotherms of type $\mathrm{H}$. The whole isotherm, which will be called $\mathrm{HC}$ corresponds to the equation:

$$
\mathrm{v}=\mathrm{Ha}+\mathrm{ba}^{\mathrm{m}}
$$

FH and HC isotherms display a positive curvature. Application of the ZimmLundberg criterion shows that, for the FH isotherm also, $f_{\mathrm{ZL}}>-1$. There is thus a risk of confusion between both isotherms. The parameters of HC equation (11) can be determined from experimental data, as follows: The initial slope $\mathrm{H}$ is determined graphically on the isotherm. Then, one calculates the function y:

$$
\mathrm{y}=\mathrm{v}-\mathrm{Ha}
$$

As it it will be seen, y is generally close to a power law as expected from Eq. 11. The same procedure can be applied to a FH isotherm. Here:

$$
\mathrm{H}=\exp (-(1+\chi))
$$

So that:

$$
\mathrm{y}=\mathrm{v}-\mathrm{a} \exp (-(1+\chi))
$$

A numerical application was made for $\chi=0.5$. $\mathrm{v}$ was calculated from Eq. 10 and y from Eq. 14. Then y was plotted against a in Fig. 2.

As can be seen, y cannot be represented in a satisfactory way by a power law. In the same way, it is clear that if experimental isotherms are well approximated by Eq. 14, they do not correspond to the Flory-Huggins law. 
Fig. $2 \mathrm{y}=\mathrm{f}(\mathrm{a})$ (see text). Points: values calculated from Flory-Huggins law; Curve: best fitting by a power law

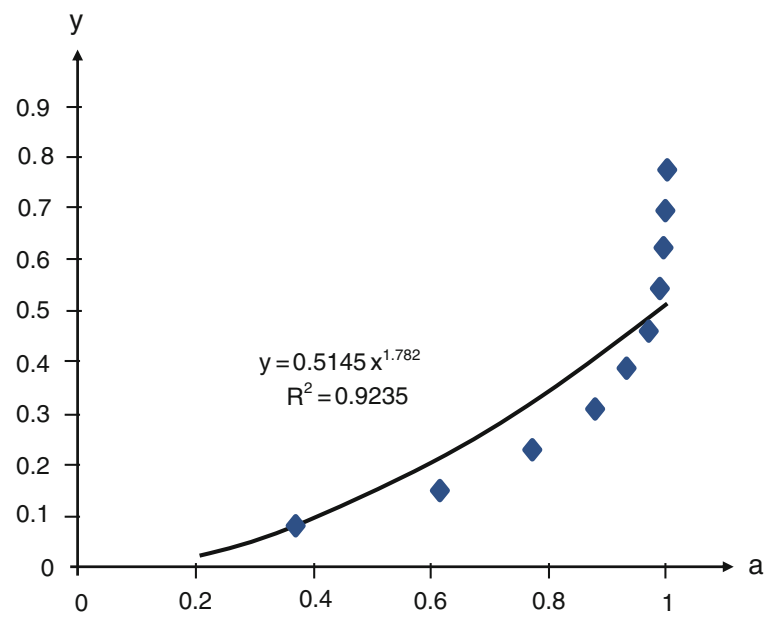

Isotherms of type L (Langmuir) have the following equation:

$$
\mathrm{W}=\frac{\mathrm{W}_{\mathrm{H}} \mathrm{hp}}{1+\mathrm{hp}}
$$

which can be written:

$$
\mathrm{v}=\frac{\mathrm{v}_{\mathrm{H}} \mathrm{ra}}{1+\mathrm{ra}}
$$

These equations come from the assumption that water is trapped in sites of maximum capacity, $\mathrm{W}_{\mathrm{H}}$ corresponding to the isotherm asymptote. The coefficient $h$ is named affinity constant of water vapor for Langmuir sites. In fact, as for isotherms of type $\mathrm{C}$, isotherms of type L generally coexist with Henry's process so that experimental isotherms are of type LH of equation [16]:

$$
\mathrm{v}=\mathrm{Ha}+\frac{\mathrm{v}_{\mathrm{H}} \mathrm{ra}}{1+\mathrm{ra}}
$$

This process can be recognized by the presence of a negative curvature in the region of low activities, followed by a linear part.

Finally, H, C and L phenomena can occur in the same sorption process. This case has been named, maybe abusively, a "dual" sorption whereas, in fact, the three processes coexist. Note that all the above mechanisms operate in the whole volume of homogeneous samples.

\subsection{Effect of Temperature}

In the past, most of the investigations in this field started from two apparently obvious assumptions: the water equilibrium concentration in the saturated state $\mathrm{W}_{\mathrm{S}}$ 
can be used as a fundamental quantity to discuss temperature and structure effects, and ii) $\mathrm{W}_{\mathrm{S}}$ is basically temperature independent (the case for many amine cured epoxies) or slightly temperature dependent with a small activation energy (case of polyesters for instance), so that a study of temperature effects would be of little utility. Both assumptions are in fact questionable.

Concerning the use of a single quantity to characterize hydrophilicity, it is eventually an acceptable point of departure in the case of $\mathrm{H}$ isotherms defined by a single parameter $\mathrm{H}$ or $\mathrm{S}$. In contrast, in the case of $\mathrm{HC}$ or $\mathrm{HL}$ isotherms, there are at least three parameters: $\mathrm{H}, \mathrm{b}$ and $\mathrm{m}$ for $\mathrm{HC}$ isotherms; $\mathrm{H}, \mathrm{v}_{\mathrm{H}}$ and $\mathrm{r}$ for $\mathrm{LH}$ isotherms, for which there is no reason to suppose that they are influenced in the same way by temperature or structure variations. Furthermore, in the cases of HC and LH isotherms, where the whole water concentration results from the sum of elementary components, the fact that the temperature dependence of the whole water concentration obeys Arrhenius law would result from a surprising coincidence. As a matter of fact, we know that the sum of terms obeying Arrhenius law does not obey Arrhenius law.

At this stage of our knowledge, we are only able to discuss the temperature effect on Henry's component, which is often the major component of water sorption. Let us recall that, in Henry's law (Eq. 4), the (single) parameter characterizing the polymer-water interaction is the solubility $\mathrm{S}$. Let us call $\mathrm{W}_{1 \mathrm{~S}}$ the water concentration corresponding to the Henry's component in the saturated state $[17,18]$ :

$$
\mathrm{W}_{1 \mathrm{~S}}=\mathrm{S} \mathrm{p}_{\mathrm{S}}
$$

In the simplest approach, $\mathrm{S}$ is expected to obey an Arrhenius law with an activation energy $E_{S}$ also called heat of dissolution:

$$
\mathrm{S}=\mathrm{S}_{0} \exp \left(-\frac{\mathrm{E}_{\mathrm{S}}}{\mathrm{RT}}\right)
$$

We see that the number of quantities to take into account in a study of structure-property relationships is at least 6 since, for each parameter of the isotherm, we have the pre-exponential factor and the activation energy to consider separately. There are many equations to represent the temperature dependence of the water saturated pressure $\mathrm{p}_{\mathrm{S}}$ but, in a first approximation, we can use the Arrhenius equation:

$$
\mathrm{p}_{\mathrm{S}}=\mathrm{p}_{\mathrm{S} 0} \exp \left(-\frac{\mathrm{E}_{\mathrm{P}}}{\mathrm{RT}}\right)
$$

where $\mathrm{E}_{\mathrm{P}} \approx 43 \mathrm{~kJ} \cdot \mathrm{mol}^{-1}$ can be called the heat of water vaporization.

From the combination of Eqs. 18-20, one obtains:

$$
\mathrm{W}=\mathrm{W}_{0} \exp \left(-\frac{\mathrm{E}_{\mathrm{W}}}{\mathrm{RT}}\right)
$$


where $\mathrm{W}_{0}=\mathrm{S}_{0}$ p $\mathrm{p}_{\mathrm{s}}$ and $\mathrm{E}_{\mathrm{W}}=\mathrm{E}_{\mathrm{S}}+\mathrm{E}_{\mathrm{P}}$.

One can now understand why $\mathrm{E}_{\mathrm{W}}$ is always low and can be either positive (e.g. in polyesters and, more generally, in all polymers of low to moderate polarity) or negative (e.g. in highly polar (and hydrophilic) epoxies or polyimides). This can be achieved if the heat of dissolution $\mathrm{E}_{\mathrm{S}}$ is negative, i.e. the water-polymer interaction is exothermic, and if the absolute value of $E_{S}$ is not very far from $43 \mathrm{~kJ} \mathrm{~mol}^{-1}$, i.e., in other words, if water establishes strong hydrogen bonds ( $\mathrm{H}$ bonds) with the polymer. When these bonds are stronger than water-water $\mathrm{H}$ bonds, $\mathrm{E}_{\mathrm{S}}<-\mathrm{E}_{\mathrm{P}}$ and the water concentration is a decreasing function of temperature (e.g. in highly hydrophilic epoxies). The reverse is true when $E_{S}>-E_{P}$ (e.g. in polyesters).

As will be shown below, the "Arrhenius model" is probably an oversimplification, but it is convenient to understand the trends of temperature effects on equilibrium concentration. Concerning the parameters specific to clustering or Langmuir absorption, the research domain is almost virgin.

\subsection{Effect of Stresses}

The water equilibrium concentration is linked to the equality of water chemical potentials in the environment and in the material. The chemical potential depends on thermodynamic parameters, among which are stresses. Stress effects on water solubility can therefore be derived from a thermodynamic approach (e.g. [19-21]). From an expression of the chemical potential of water, for the case of small, isotropic deformations with negligible changes of material elastic properties, these latter authors obtained a simple relationship for the equilibrium mass uptake $\mathrm{m}$ (see Sect. 2.9).

\subsection{Effect of Structure on Henry's Sorption Process}

First, it is important to note that structure-solubility relationships make sense only if we consider a unique sorption mechanism. This precaution was never taken in the literature, thus making the synthesis of published data difficult. In the following, the reasoning is applicable to Henry's sorption process where water concentration and its elementary components are proportional to activity.

The idea that water must fill the free volume and that hydrophilicity is linked totally or partially to the free volume fraction $\mathrm{f}$ is intuitive and has seduced many authors in the 1980s [22-25]. This theory calls however for three main criticisms:

1. In glassy polymers, there is no undisputable definition of the free volume fraction $f$. According to the theory of viscoelasticity, $f=f_{g}+\alpha\left(T-T_{g}\right)$, where $f_{g}$ is the free volume fraction at $T_{g}$ and $\alpha$ is the expansion coefficient of free volume. Typically, $\mathrm{f}_{\mathrm{g}} \sim 0.025$ and $\alpha \sim 5 \times 10^{-4} \mathrm{~K}^{-1}$, which means that 
$\mathrm{f}=0$ at $\mathrm{T}<\mathrm{T}_{\mathrm{g}}-50 \mathrm{~K}$. For various authors, the "free volume" is an arbitrary fraction of the penetrable volume (the volume in excess relatively to the Van der Waals volume $\mathrm{V}_{\mathrm{W}}$ ). The fractional free volume FFV is often defined by: $\mathrm{FFV}=\left(\mathrm{V}-1.3 \mathrm{~V}_{\mathrm{W}}\right) / \mathrm{V}$. There are, however, structural series, e.g. amine cured epoxies, for which the hydrophilicity is a decreasing function of FFV.

2. There are free volume rich substances of very low hydrophilicity, e.g. liquid hydrocarbons, silicone rubbers, etc.

3. Water displays a relatively high plasticizing power on polymers, furthermore its absorption is highly exothermic.

These features are incompatible with the hypothesis of a sorption mechanism mainly linked to free volume occupancy by water.

Since water is able to establish strong $\mathrm{H}$ bonds with polar sites in the polymer, its equilibrium concentration must be first linked to these interactions. From simple hydrophilicity comparisons, it is easy to observe that there are three kinds of chemical groups:

- The non-hydrophilic groups: $\mathrm{C}-\mathrm{H}, \mathrm{C}-\mathrm{C}, \mathrm{C}=\mathrm{C}, \mathrm{C}-\mathrm{F}, \mathrm{Si}-\mathrm{CH}_{3}$, phenylenes etc. Polymers containing only these groups, e.g. polyethylene, polypropylene, polybutadiene, polytetrafluorethylene, polydimethylsiloxane, etc., absorb generally less than $0.1 \mathrm{wt} \%$ water.

- The moderately hydrophilic groups: ethers, ketones, esters, etc. Polymers containing only these groups and those of the preceding category, e.g. polyoxyphenylene, polyetheretherketone, polycarbonate, linear and tridimensional polyesters, etc., absorb generally less than $3 \mathrm{wt} \%$ water.

- The strongly hydrophilic groups: alcohols, acids, amides, etc. Polymers containing these groups can be water soluble if they are in high concentrations, e.g. polyvinyl alcohol, polyacrylic acid, polyacrylamide, etc. All these polymers have industrial applications but, indeed, not in the composite field. In this latter, water absorptions in the saturated state are generally limited to values lower than $10 \mathrm{wt} \%$. Polyamides such as polyamide 6, 6-6 or 4-6, in which the hydrophilicity is limited by crystallinity (the crystalline phase is impermeable to water), are among the most hydrophilic linear polymers used as composite matrices. In the domain of thermosets, amine cured epoxies based on trifunctional (triglycidyl p-amino phenol, TGAP) or tetrafunctional (tetraglycidyl derivative of diamino diphenyl methane, TGDDM or TGMDA) epoxides can absorb up to $7 \mathrm{wt} \%$ water. In these matrices, the most hydrophilic group is the alcohol resulting from the amine-epoxide condensation, it is thus not surprising to find that hydrophilicity tends to be an increasing function of the crosslink density.

Starting from the above observations, it is tempting to suppose the existence of simple quantitative relationships between water absorption and the nature and concentration of polymer groups. The simplest relationship is a molar additive law [26-29] for epoxies, [30] for polyesters and [31] for vinyl esters). 
The principle can be summarized as follows: One defines a constitutive repeat unit CRU representative of the polymer structure. This unit, of molar mass $\mathrm{M}$, contains a groups $\mathrm{A}$ for which the molar contribution to water absorption is $\mathrm{H}_{\mathrm{A}}$, b groups $\mathrm{B}$ having a contribution $\mathrm{H}_{\mathrm{B}}$, etc. The group molar contributions are assumed independent of the neighboring structural groups. If the water uptake at saturation is $m$ (expressed in weight percent), the number of water molecules absorbed by the CRU is $\mathrm{H}$ :

$$
\mathrm{H}=\frac{\mathrm{m} \mathrm{M}}{1,800}
$$

The molar additive law stipulates:

$$
\mathrm{H}=\mathrm{aH}_{\mathrm{A}}+\mathrm{b} \mathrm{H}_{\mathrm{B}}+\text { etc. }
$$

This approach works relatively well in limited structural series if the chosen CRUs are large enough to take into account eventual group intramolecular interactions (intramolecular $\mathrm{H}$ bonds, inductive effects, etc.). The drawback is that the diversity of CRU structures imposes a large variety of elementary contributions, that reduces the practical interest of the approach. Anyhow, in wide polymer families, it appears that the contribution of a given group is an increasing function of its concentration, as seen for the alcohol group in epoxies [18] or for the sulfone group in polysulfones [32] (Fig. 3).

Starting from a suggestion of Tcharkhtchi et al. [18] and from analytical observations by NMR (e.g. [5]), IR [10] or dielectric spectroscopy (e.g. [7, 33]), Gaudichet et al. [32] proposed a theory according to which, since water molecules are doubly $\mathrm{H}$ bonded, this imposes restrictions on the distance between polar groups in the polymer. As a matter of fact, the length $\mathrm{x}$ of $\mathrm{OH}$ hydrogen bonds cannot be lower than the distance of a Van der Waals contact, about $0.15 \mathrm{~nm}$, and

Fig. 3 Henry's solubility of aromatic polysulfones against sulfone concentration

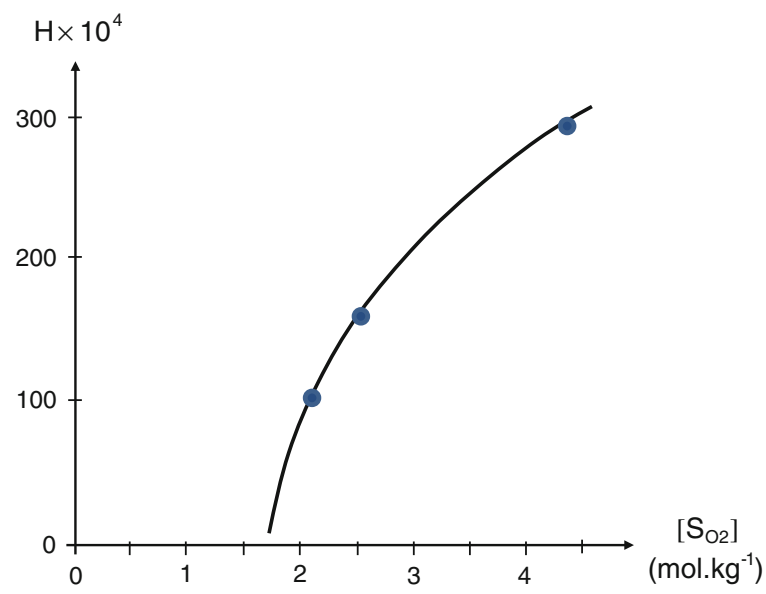


higher than about $0.24 \mathrm{~nm}$ [34]. Two polar groups can constitute a hydrophilic site if their distance $r$ is given by:

$$
\mathrm{r}=2(\mathrm{x}+l) \sin (\theta / 2)
$$

where $1(0.096 \mathrm{~nm})$ is the length of the $\mathrm{O}-\mathrm{H}$ bond in water and $\theta\left(104^{\circ}\right)$ is the $\mathrm{HOH}$ valence angle in water.

Thus, $0.39<\mathrm{r}<0.53 \mathrm{~nm}$. Indeed these limits are approximations. The potential of the water-polymer bond versus interatomic separation of polar groups is expected to have the shape of Fig. 4.

Let us now consider all the pairs of polar groups in the polymer. Only a fraction of these pairs will fulfill the distance requirements to be a hydrophilic group and this fraction will generally be an increasing function of the polar groups concentration. Let us consider, for instance aliphatic polyamides. The average distance between amide groups is $0.66 \mathrm{~nm}$ in PA 11, and $0.55 \mathrm{~nm}$ in PA6. Since the highest limit for a hydrophilic site is about $0.53 \mathrm{~nm}$, we see that the proportion of active amide groups in water absorption will be lower in PA 11 (equilibrium water mass uptake $\mathrm{m}_{\mathrm{S}} \sim 1.4 \%$ at $\left.50{ }^{\circ} \mathrm{C}\right)$ than in PA6 $\left(\mathrm{m}_{\mathrm{S}} \sim 8 \%\right.$ at $\left.50{ }^{\circ} \mathrm{C}\right)$. This theory provides thus an explanation that all the polar groups are not active, that was formerly interpreted in terms of group accessibility (see, for instance, [35]), but without any possibility to give a quantitative counterpart to this concept.

Fig. 4 Hydrogen bond potential for three cases of distribution of distances between polar groups. The dashed zone corresponds to the fraction of polar groups able to establish double $\mathrm{H}$ bonds with water. Top: Nonhydrophilic polymer. Middle: Moderately hydrophilic polymer. Bottom: Highly hydrophilic polymer

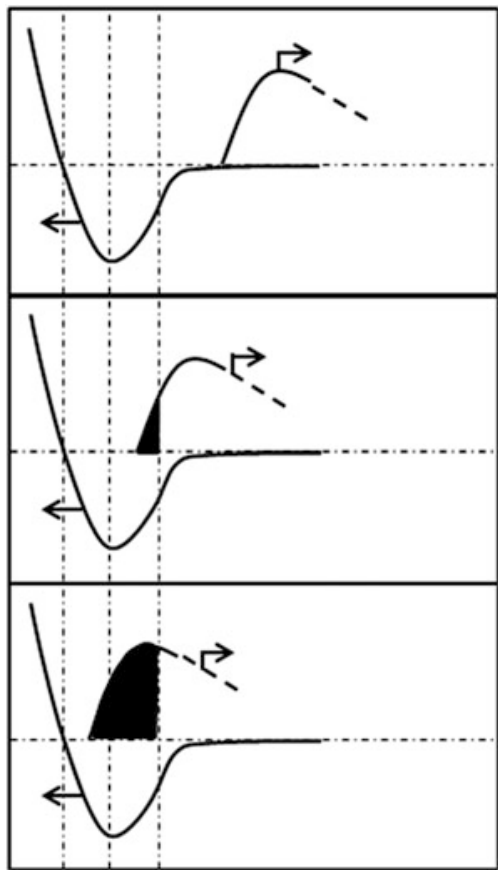


In the classical theories in which the hydrophilic site was a single polar group, the fact that, in a given structural series where hydrophilicity depends mainly on the concentration of a given group (e.g. sulfone in polysulfones or amide in polyamides), the absolute value of the heat of dissolution $\mathrm{E}_{\mathrm{S}}$ is an increasing function of the group concentration cannot be explained. $E_{S}$ is linked to the strength of the $\mathrm{H}$ bond. It must depend only on the nature of the group while the pre-exponential factor must be proportional to the group concentration. According to the new theory, there is a variety of $\mathrm{H}$ bonds differing by their length and thus, by their strength. Except in scarce cases, useless in the domain of composites, the average pair distance is higher than the distance corresponding to the minimal $\mathrm{H}$ bond potential, i.e. to the maximum activation energy. This carries two main consequences:

1. The temperature dependence of solubility results from the sum of an infinity of arrhenian elements, each one corresponding to a $\mathrm{H}$ bond distance.

2. The proportion of strongest $\mathrm{H}$ bonds and thus, the whole apparent activation energy, is expected to increase with the concentration of polar groups as observed.

It is noteworthy that many authors suggested the existence of a dual sorption process able to explain also the non-arrhenian character of the solubility $[2,5,36]$.

It must be recognized, however, that, although theoretically possible, a quantitative prediction of water concentration by the above theory remains especially difficult because both basic elements of the reasoning: the distribution of distances between pairs of polar groups and the real shape of the hydrogen bond potential are not easily accessible. At this stage of our knowledge, only the main trends of the solubility-structure relationships can be predicted. Molecular dynamics simulations will probably bring some light in the near future (see, for instance [37]), but water solubility determinations in this way remain difficult and studies of the spatial distribution of water molecules in the polymer give results difficult to reconcile with classical physical approaches (see below).

\subsection{Clustering}

Van Krevelen and Te Nijenhuis [28] developed the molar additive approach and reported $\mathrm{H}_{\mathrm{i}}$ values for several groups frequently found in polymers. It appeared that molar contributions vary nonlinearly with water activity, in other words that water sorption does not obey Henry's law. Some important molar contributions reported by Van Krevelen and Te Nijenhuis [28] are plotted against water activity in Fig. 5. All the curves display the shape expected for a $\mathrm{HC}$ isotherm. In other words, one can suspect the presence of clusters at high activities, in polymers used for determining molar increment values. This non-linear character of isotherms invalidates, in our opinion, the molar additivity approach since the best test for molar additivity would be precisely the proportionality between molar contributions $\mathrm{H}_{\mathrm{i}}$ and activity a. 
Fig. 5 Molar increments of water absorption against water activity for four chemical groups: alcohols (triangles), acids (crosses), esters (lozenges) and ethers (squares) according to Van Krevelen and Te Nijenhuis [28]

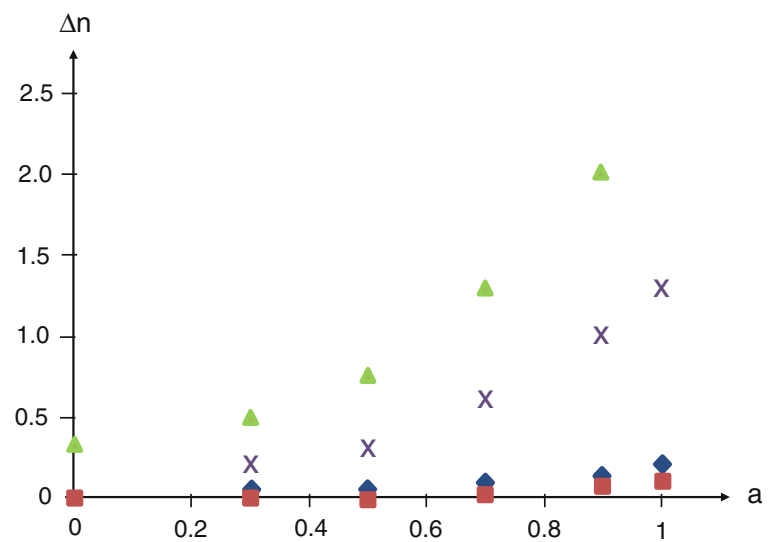

Zimm-Lundberg's theory

The curves of Fig. 5 can be well approximated by Eq. 11. Let us apply ZimmLundberg's theory $[15,38]$ to this equation:

$$
\mathrm{f}_{\mathrm{ZL}}=-\mathrm{v} \frac{\partial(\mathrm{a} / \mathrm{v})}{\partial \mathrm{a}}-1=\frac{-(\mathrm{m}-1)(\mathrm{v}-\mathrm{Ha})}{\mathrm{v}^{2}}-1
$$

One can arbitrarily define a critical activity $\mathrm{a}_{\mathrm{c}}$ above which the cluster contribution begins to be significant, for instance when:

$$
\mathrm{b} \mathrm{da}_{\mathrm{c}}^{\mathrm{m}}=\mathrm{dHa}_{\mathrm{c}}
$$

i.e.

$$
\mathrm{a}_{\mathrm{c}}=(\mathrm{dH} / \mathrm{b})^{1 / \mathrm{m}-1}
$$

where $\mathrm{d}$ is the relative error on $\mathrm{v}$ measurement.

We see in Eq. 30 that, as long as $a<a_{c}, f_{Z L}$ remains close to -1 and the probability of clustering is low. When $a>a_{c}, f_{Z L}$ becomes significantly lower than -1 and clustering must occur. The average cluster size (number of water molecules in the cluster) $\mathrm{s}$ is given by:

$$
\mathrm{s}=\mathrm{vf}_{\mathrm{ZL}}+1
$$

The Zimm-Lundberg's theory can be applied to FH isotherms [39]. Generally, the quantitative analysis of sorption isotherms of composite matrices reveals the presence of small clusters, with few water molecules.

\section{ENSIC theory}

Zimm and Lundberg considered the problem from the point of view of statistical mechanics. The ENSIC theory (Engaged Species Induced Clustering), proposed by Pitkethly et al. [40], considers the problem from a physico-chemical point of view. A water molecule penetrating in the polymer can establish bonds with the polymer 
or with previously sorbed water molecules. The probability of each mode of binding depends on the number of available sites and the strength of both bonds represented by an "affinity parameter" $\mathrm{k}_{\mathrm{p}}$ for water-polymer bonds and $\mathrm{k}_{\mathrm{w}}$ for water-water bonds. For a small increase of water vapor pressure $\mathrm{dp}$, the number $\mathrm{dn}_{\mathrm{w}}$ of water molecules entering the polymer is given by:

$$
d \mathrm{n}_{\mathrm{w}}=\left(\mathrm{k}_{\mathrm{p}} \mathrm{n}_{\mathrm{p}}+\mathrm{k}_{\mathrm{w}} \mathrm{n}_{\mathrm{w}}\right) \mathrm{dp}
$$

where $n_{p}$ and $n_{w}$ are the respective numbers of polymer sites and sorbed water molecules.

The integration of this equation leads to:

$$
\mathrm{v}=\frac{\mathrm{k}_{\mathrm{p}}}{\left(\mathrm{k}_{\mathrm{w}}-\mathrm{k}_{\mathrm{p}}\right)}\left[\exp \left(\mathrm{k}_{\mathrm{w}}-\mathrm{k}_{\mathrm{p}}\right) \mathrm{a}-1\right]
$$

Indeed, clustering can occur only if water has more affinity for itself than for the polymer $\left(\mathrm{k}_{\mathrm{w}}>\mathrm{k}_{\mathrm{p}}\right)$. Elberaïchi et al. [41] compiled some values of $\mathrm{k}_{\mathrm{p}}$ and $\mathrm{k}_{\mathrm{w}}$ for polymers of high, medium and low hydrophilicity. $\mathrm{k}_{\mathrm{w}}$ ranges between 3.1 and 5.8, whereas $\mathrm{k}_{\mathrm{p}}$ ranges between $6 \times 10^{-4}$ and $8.1 \times 10^{-2}$. In other words, water has always more affinity for itself than for polymers. The difference would be considerably smaller in the framework of the theory of doubly bonded water.

\section{Effect of structure}

Very little is known about structure-clustering relationships. Some interesting trends appear in the series studied by Gaudichet-Maurin [32] in Table 2. These results seem to indicate the existence of three domains of hydrophilicity separated by two boundaries at $57 \times 10^{-4}<\mathrm{H}_{1}<102 \times 10^{-4}$ and $297 \times 10^{-4}<\mathrm{H}_{2}$ $<567 \times 10^{-4}$. Clusters seem to be formed only for very low hydrophilicity samples $\left(\mathrm{H}<\mathrm{H}_{1}\right)$ where they are composed of about two water molecules, or very high hydrophilicity samples $\left(\mathrm{H}>\mathrm{H}_{2}\right)$ where they are composed of about three water molecules. In the intermediary domain, there is no clustering: Water absorption obeys Henry's law over the entire activity range.

The presence of clusters in polymers of very low hydrophilicity is not surprising because water is considerably more "attractive" for itself than for polymer segments. They can also exist in polymers of high hydrophilicity as predicted by the ENSIC theory. In highly hydrophilic polymers, plasticization by water induces a rearrangement of the polymer structure favorable to a hydrophilicity increase. In the case of PA 6 for instance, the amorphous phase, initially in glassy state at $\mathrm{T}<60{ }^{\circ} \mathrm{C}$, becomes rubbery that modifies its response to water penetration. Clustering and plasticization can in principle be distinguished from diffusion coefficients (see below). These latter are a decreasing function of activity in the case of clustering and an increasing function of activity in the case of plasticization.

A generalization of the results of Gaudichet-Maurin et al. [32] seems to us premature at this stage of our knowledge. The fact that clustering begins at relatively low activities is not easy to explain. A demixing of the polymer-water mixture is unlikely because it would then be difficult to explain the existence of 
Table 2 Henry's solubility coefficient and clustering characteristics for some polymers at $50{ }^{\circ} \mathrm{C}$ according to Gaudichet-Maurin et al. [32]

\begin{tabular}{lcclll}
\hline Polymer & $\mathrm{H} \times 10^{4}$ & $\mathrm{~b} \times 10^{4}$ & $\mathrm{~m}$ & $\mathrm{~s}$ & References \\
\hline PVC & 18 & 4 & 5.16 & 1.7 & $\mathrm{GM}$ \\
PC & 42 & 12 & 3.95 & 1.6 & $\mathrm{GM}$ \\
PA 12 & 51 & 23 & 4.66 & 2.1 & $\mathrm{~L}$ \\
PLA & 57 & 19 & 6.41 & 2.2 & GM \\
PSU & 102 & 0 & 0 & 1 & GM \\
BPA-IA & 134 & 0 & 0 & 1 & $\mathrm{~L}$ \\
PA 11 & 137 & 0 & 0 & 1 & GM \\
PET & 148 & 2 & 0 & 1 & GM \\
PPSU & 156 & 0 & 0 & 1 & GM \\
PEI & 186 & 2 & 0 & 1 & GM \\
PES & 297 & 2 & 0 & 1 & GM \\
PA 6 & 567 & 239 & 7.13 & 3 & GM \\
PHEMA & 2,010 & 1,190 & 7.04 & 3.2 & L \\
\hline
\end{tabular}

Remark s value determined at saturation. "GM": results obtained by Gaudichet-Maurin using a Dynamic Vapor Sorption apparatus. "L": literature, references quoted by "GM"

sorption equilibrium. The hypothesis that water fills nanopores can be set out, at least for polymers of low polarity. As a matter of fact, for these polymers, the absolute value of the heat of dissolution is noticeably lower than the heat of water vaporization. In the case where the water vapor would penetrate in the polymer and recondense in pores, the thermodynamic balance of the process would be null and the water equilibrium concentration would be temperature independent.

A possible mechanism can be based on the theory of Gaudichet-Maurin et al. [32]. It is schematized by Fig. 6 where one sees a pair of polar groups able to establish a $\mathrm{H}$ bond with one water molecule. There is in its immediate vicinity another group, too isolated to be associated to another group to form a hydrophilic site. However, it can form a site with the water molecule when this latter takes place on the former site.

\section{Molecular dynamics}

Clustering is probably the point of major discrepancy between conventional physics [15] and molecular dynamics (MD) simulation. As a matter of fact, simulations of hydrated polymers reveal the presence of clusters even at low water concentrations, even in polymers such as polysulfones which obey Henry's law over the entire activity range. These clusters can be large and appear often as chains of water molecules rather than more or less isotropic "globules" [42]. This point is discussed in detail in the above paper. The discussion remains open in our opinion. 
Fig. 6 Schematization of the sorption mechanism proposed by Gaudichet-Maurin et al. [32]. Top: dry state; Middle: Henry's sorption; Bottom: cluster formation, a new water molecule establishes a link between an isolated polar group and the oxygen of a Henry's sorbed molecule; black circle: polar sites

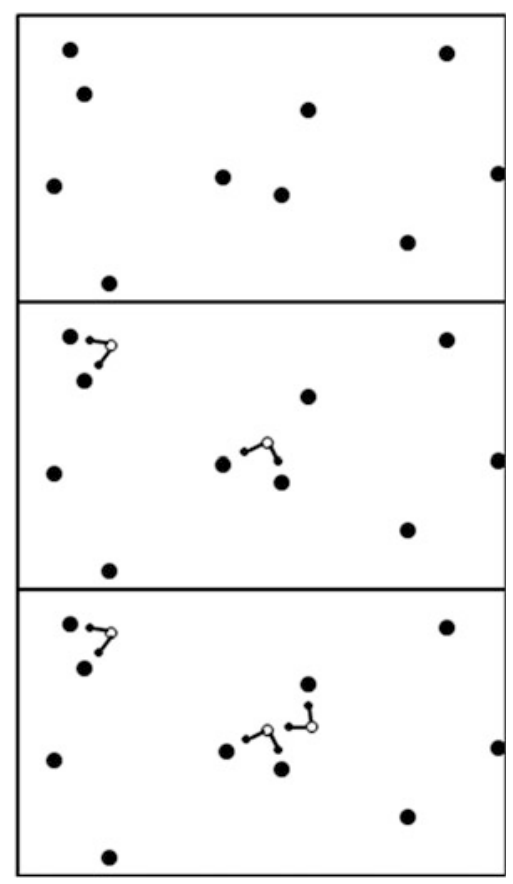

\subsection{Langmuir Sorption}

Examples of Langmuir sorption are common in samples of complex morphology, for instance in the domain of food engineering [43-45]. In the domain of engineering polymers, they are relatively scarce, except in samples of very peculiar morphology as, for instance, polyimide membranes with ionic domains [46]. Certain epoxy resins and their composites constitute a noticeable exception. The Langmuir process was first observed on sorption kinetic curves for composites [47]. It is noteworthy that, generally, sorption isotherms were not reported, the authors observed the consequences of the Langmuir sorption process on the water diffusion kinetics. This is why this problem will be analyzed in the next section. Sorption "anomalies" attributable to Langmuir process were soon observed in certain unreinforced epoxy samples, but they were attributed to other hypothetical mechanisms, for instance resin oxidation [48]. It seems now well established that a Langmuir process occurs only when unreacted epoxy groups are present, i.e. in insufficiently cured stoichiometric samples [48] or non-stoichiometric samples having an excess of epoxide groups [18]. More details on this phenomenon will be given in the section devoted to Langmuir's diffusion process.

Now, we are tempted to suppose that, when a sorption anomaly having the equilibrium and kinetic characteristics of a Langmuir process is observed in a polar polymer, it can be interpreted in terms of reversible chemical reaction of 
water with certain reactive groups present in the polymer. As a matter of fact, it is difficult to imagine physical bonds stronger than water (double) bonds with highly polar groups. If this generalization was valid, and that remains to be demonstrated, it would open the way for a (quantitative or semi-quantitative) prediction of the Langmuir process for a given polymer.

\subsection{Interfacial Water Absorption}

It must be first recalled that the interface is a bi-dimensional entity which cannot, in principle, be a locus of water absorption or chemical reaction. If there is a lack of adhesion between fiber and matrix, dewetting, mechanical or thermal stresses can induce the formation of interfacial voids and these latter can be filled by liquid water at high activities. Then, the interfacial water pockets can act as initiation sites for further interfacial crack propagation by osmotic processes [49], thermal spikes in supersonic flights [50] or water freezing as in the well-known mechanism of rock erosion. The non-empirical kinetic modeling of these processes would first need a precise description of the initially present interfacial defects, which is not obvious owing to the discrepancies between the available experimental methods $[40,51]$.

Coupling agents are generally used to facilitate processing but also to improve the composite resistance to humid ageing. Trifunctional alkoxy silanes (Alk-O- $)_{3} \mathrm{Si}-$ $\left(\mathrm{CH}_{2}\right)_{\mathrm{i}}$ - R (Fig. 7) are often used.

These differ mainly by the fourth group (-R) which is expected to establish a bond with the matrix. For instance, vinyl silanes can be used in unsaturated polyesters where they are expected to copolymerize with styrene or fumarate double bonds. In the same way, amino-silanes or epoxy-silanes are expected to react with amine cured epoxy matrices. The coupling agents are generally associated with other additives such as lubricants, antistatic agents or adhesive agents

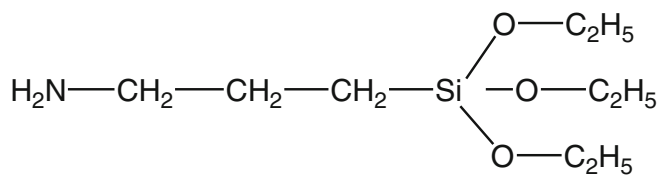

Aminopropyl triethoxy silane

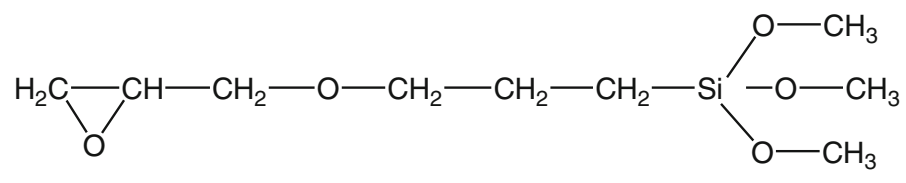

3 Glycidyloxy propyl trimethoxy silane

Fig. 7 Developed formulae of two common coupling agents 
aimed at facilitating processing. All these additives contribute to the formation of an intermediary layer between the fiber and matrix. This layer is called an "interphase". Its interaction with water can, indeed, play an important role in composite durability. It is well recognized that the interphase displays a more or less diffuse multi-layer structure [52-56]. In glass-polymer composites with silanes as coupling agents for instance, one expects the presence of three concentric layers:

1. An almost monomolecular layer containing mainly the Si-O-Si bonds formed by condensation of $\mathrm{Si}-\mathrm{OH}$ groups present at glass surface and Alk-O-Si- groups of the coupling agent.

2. A layer resulting of the hydrolytic condensation of alkoxysilane groups belonging to the coupling agent. This condensation forms a network.

3. A layer resulting of reactions between the coupling agent and reactive polymer groups in which the relative proportions of both components varies progressively with the distance to the fiber surface.

The thickness of layers (2) and (3) depends on the quantity of coupling agent deposited on fiber surface and processing conditions among other factors.

Let us consider, for instance, a glass fiber/polymer composite based on $24.4 \mathrm{w} \%$ matrix and $75 \mathrm{w} \%$ glass fibers of diameter $\mathrm{d}=10 \mu \mathrm{m}$ of density $\rho_{\mathrm{g}} \sim 2.5$ coated with $0.6 \mathrm{w} \%$ of an organic mixture of density $\rho_{\mathrm{c}} \sim 1.3$ forming a concentric layer of thickness $h$. The mass ratio:organic coating/glass, can be written:

$$
\frac{\mathrm{M}(\text { coating })}{\mathrm{M}(\text { glass })}=\frac{\pi(\mathrm{d}+\mathrm{h})^{2}}{\pi \mathrm{d}^{2}} \frac{\rho_{\mathrm{c}}}{\rho_{\mathrm{g}}}=\frac{0.6}{75}=8 \times 10^{-3}
$$

The solution of this second degree equation is:

$$
\mathrm{h} \approx 4 \times 10^{-3} \mathrm{~d}
$$

Thus, for $\mathrm{d} \sim 10 \mu \mathrm{m}, \mathrm{h} \sim 40 \mathrm{~nm}$.

This value is not very far from the one $(70 \mathrm{~nm})$ found by Wolff by atomic force microscopy on a glass-phenolic resin model system close to industrial materials [57]. In such materials, the coating agent corresponds to about $2-3 \%$ of the resin mass. It should not influence the overall water mass uptake in the composite, except in very rare cases. It is therefore necessary to use other methods than the gravimetric study of water absorption by the composite to appreciate the interphase hydrophilicity. Salmon et al. [58] chosen to prepare networks resulting of the condensation of pure triethoxysilanes (Fig. 5). The equilibrium water mass uptakes of these networks are given in Table 3.

In the case of amino-silane APS, however, hydrolysis is suspected to contribute to water absorption. Although very rare, these results indicate that the structurehydrophilicity relationships found for polymers seem to be also valid for the structures participating to the interphase in composites. One can note that water concentrations of several dozens of percents, as for APS, are expected to induce a 
Table 3 Water absorption at $20{ }^{\circ} \mathrm{C}$ and $75 \%$ HR by networks resulting of the hydrolytic condensation of triethoxysilanes. Influence of the organic group R. After Salmon et al. [58]

\begin{tabular}{lll}
\hline Code & Nature of group -R & Mass uptake (\%) \\
\hline APS & Amine & 35 \\
GPS & Epoxide & 3 \\
PS & Propyl & 0.1 \\
\hline
\end{tabular}

noticeable swelling of the interphase but, since this latter is confined, water absorption must generate hydrostatic pressure. This latter can have contradictory effects on composite durability: on one hand, by disfavoring hydrolysis and, on the other, by inducing interfacial damage.

\subsection{Main Consequences of Water Absorption on Polymer Physical Properties}

We will focus here on the properties which are important from a mechanical point of view, i.e. volumetric properties (essentially swelling) and glass transition temperature (plasticization).

\section{Swelling}

To study volumetric changes induced by solvent penetration in a polymer, it is first important to distinguish the case where the swollen polymer is in a rubbery state from the case, more frequent in the domain of composites, where the swollen polymer remains in glassy state.

In the first case, the sorption equilibrium results from the equality of two opposite forces: the expansion linked to the osmotic force induced by the presence of solvent in the polymer, and the retraction linked to the entropic elasticity of the network chains which are drawn by the swelling. The thermodynamic approach based on the Flory-Huggins theory, leaded Flory and Rehner [59] to establish the equation linking the swelling ratio to the concentration of elastically active chains (n) for an unfilled polymer:

$$
\mathrm{n}=\frac{-\left\{\ln (1-\mathrm{v})+\mathrm{v}+\chi \mathrm{v}^{2}\right\}}{\rho \mathrm{V}_{\mathrm{S}}\left(\mathrm{v}^{1 / 3}-\frac{2}{\mathrm{f}} \mathrm{v}\right)}
$$

where $\mathrm{v}$ is the polymer volume fraction in the swollen state, $\chi$ is the polymer-water interaction coefficient, $\mathrm{V}_{\mathrm{S}}$ is the molar volume of water, $\rho$ is the specific mass of the polymer and $\mathrm{f}$ is the crosslink functionality.

In the (more frequent) case where the polymer remains in a glassy state, there is, to our knowledge, no theory to predict the swelling ratio. What is sure is that the swelling ratio (swell) must always lie between the boundaries expressed by Eqs 1 and 2 , according to which: 
Table 4 Equilibrium mass uptake, volume increase $\left(\mathrm{y}=100\left(\mathrm{v}-\mathrm{v}_{0}\right) / \mathrm{v}_{0}\right)$ and "swelling yield" $(\mathrm{y} / \mathrm{m})$ for four styrene crosslinked unsaturated polyesters [60]

\begin{tabular}{lllll}
\hline Property & A & B & C & D \\
\hline $\mathrm{m}(\%)$ & 1.55 & 1.52 & 5.00 & 2.80 \\
$\mathrm{y}(\%)$ & 0.20 & 0.27 & 0.68 & 0.65 \\
$\mathrm{y} / \mathrm{m}$ & 0.13 & 0.18 & 0.14 & 0.23 \\
\hline
\end{tabular}

$$
1<\text { swell }<1+\text { m }\left(\rho_{\mathrm{p}}-1\right)
$$

where swell $=$ swollen volume/dry volume.

There is a large number of experimental data in the literature, for instance on polyesters ([60], Table 4).

The results can be summarized as follows: The swelling ratio is generally closer to the low boundary than to the higher one. In other words, water displays a relatively low swelling power. It appears that, for these networks, the volume increase is a small and almost constant fraction $(0.18 \pm 0.05)$ of the mass uptake. For highly crosslinked (and highly hydrophilic) epoxies at low activity, McKague et al. [61] found: $y / m \sim 0.51$. These authors expressed the volume change as a power law of mass change over the whole activity domain: $y=0.527 \mathrm{~m}^{1.17}$.

Marque et al. [62] studied the swelling ratio of three distinct polysulfones for various activity values and tried to compare its values with various theoretical values. In certain cases, it seems that the system adopts a swelling ratio in order to maintain the packing density constant, i.e. the fractional free volume (see Sect. 2.5) of the swollen polymer. This observation cannot, however, be generalized. The swelling mechanisms of glassy polymers are not well understood in our opinion and would merit supplementary research efforts.

In the case of unidirectional composites, swelling strains can develop only in the transverse direction to the fibres. In the case of absorption, compressive swelling stresses induce a certain self-limitation of deformations. In the case of desorption, in contrast, tensile forces resulting from swelling gradients (see below) have a dilatant effect. This is the reason why a significant hysteresis appears in swelling-deswelling curves, as shown for instance by Hahn [63]. Many authors have observed that the "swelling yield" $y / m$ defined above is low at low water activities and begins to increase at mass uptakes of the order of $0.5 \pm 0.2 \%$ where $y / m \sim 0.4-0.6$ for various epoxy-carbon composites $([64,65]$ reviewed in $[63,66])$.

\section{Swelling stresses}

Since swelling acts as a negative pressure $\mathrm{p}$ on the material, one can define a hygroelasticity coefficient $\mu$ expressing the swelling strain per mass [67-69]. These latter authors showed that:

$$
\mu=\frac{p(1-2 v)}{E \Delta \mathrm{V}^{+} / V_{0}}
$$


where $v$ is the Poisson's ratio, $\mathrm{E}$ is the Young's modulus and $\Delta \mathrm{V}^{+}$is the volume of diffused liquid (higher than the volume increase due to swelling).

The upper bound of $\mu$ would be $1 / 3$. Cracking would then occur for a critical volume of absorbed water:

$$
\frac{\Delta \mathrm{V}^{+}}{\mathrm{V}_{0}} \approx \frac{1-2 \mathrm{v}}{10 \mu}
$$

More sophisticated approaches are derived from thermodynamic considerations. Derrien and Gilormini [19] have derived an equation expressing the influence of a hydrostatic pressure $\mathrm{p}$ on the water equilibrium mass uptake $\mathrm{m}$ in a composite of specific mass $\rho_{\mathrm{p}}$, from an expression of the chemical potential:

$$
\mathrm{m}=\mathrm{Sp}(1-\mathrm{A} \eta \mathrm{p})
$$

where $\mathrm{S}$ is the solubility coefficient expressed in $\mathrm{Pa}^{-1}$, and $\eta$ is a lineic swelling coefficient ranging generally between 0.1 and 0.5 [21]. Coefficient $\mathrm{A}$ is given by:

$$
\mathrm{A}=\frac{3 \mathrm{M}}{\mathrm{RT} \rho_{\mathrm{p}}}
$$

where $\mathrm{M}$ is the water molar mass.

$\mathrm{A} \sim(1.8 \pm 0.4) \times 10^{-8} \mathrm{~Pa}^{-1}$ for most industrial polymers used as composite matrices. In composites, the polymer swelling is constrained by the (almost undeformable) reinforcing agent. Water absorption induces then a pressure increase into the matrix. The maximum radial stress $\sigma_{\mathrm{rr}}$ at the interface is then given by:

$$
\sigma_{\mathrm{rr}}=3\left(\frac{1-\mathrm{f}}{\mathrm{f}}\right) \mathrm{K} \eta \mathrm{m}
$$

where:

$$
K=\frac{f}{\frac{f}{K_{p}}+\frac{(1-f)}{K_{r}}+\frac{3}{4 G_{p}}}
$$

where $K_{p}$ and $K_{r}$ are the respective bulk moduli of polymer and reinforcing agent, $G_{p}$ is the shear modulus of polymer and $f$ is the weight fraction of reinforcing agent.

Indeed, the pressure induced by this constrained swelling will affect the water solubility according to Eq. 35. In other words, in the absence of such interaction, a composite is expected to absorb water. At equilibrium:

$$
\mathrm{m}_{\mathrm{c}}=(1-\mathrm{f}) \mathrm{m}_{\mathrm{p}}
$$

where $\mathrm{m}_{\mathrm{p}}$ is the mass uptake, in the same conditions, in the matrix.

Equation 37 shows that the real mass uptake will be in fact lower than $m_{c}$. Derrien and Gilormini [19] showed that, in this case, the system displays Langmuir's rather than Fick's behavior. 
The radial stress can cause interfacial decohesion at high swelling ratios.

\section{Plasticization}

The term "plasticization" is attributed to all the processes leading to a decrease in the glass transition temperature $\mathrm{T}_{\mathrm{g}}$. It can be justified by the existence of a relationship between the yield stress $\sigma_{\mathrm{y}}$ and $\mathrm{T}_{\mathrm{g}}$, according to which a $\mathrm{T}_{\mathrm{g}}$ decrease leads to a yield stress decrease and thus makes plastic deformation easier.

$$
\sigma_{\mathrm{y}}=\mathrm{C}\left(\mathrm{T}_{\mathrm{g}}-\mathrm{T}\right)
$$

where $\mathrm{C}$ is a parameter generally of the order of $1 \mathrm{MPa} \cdot \mathrm{K}^{-1}$.

In other words, a $\mathrm{T}_{\mathrm{g}}$ decrease of $1 \mathrm{~K}$ induces about $1 \mathrm{MPa}$ decrease of the yield stress. The water present in clusters cannot exert a plasticizing effect.

Solvent plasticization has stimulated an abundant literature. It can be approached by both the free volume and the entropy theories with certain simplifying assumptions more or less difficult to justify. For instance, the free volume theory starts from two hypotheses: (1) The free volumes of the polymer and the solvent are additive; (2) The free volume at $\mathrm{T}_{\mathrm{g}}$ is an universal constant.

It is then easy to show that [70]:

$$
\mathrm{T}_{\mathrm{g}}=\frac{(1-\mathrm{v}) \alpha_{\mathrm{p}} \mathrm{T}_{\mathrm{gp}}+\mathrm{v} \alpha_{\mathrm{w}} \mathrm{T}_{\mathrm{gw}}}{(1-\mathrm{v}) \alpha_{\mathrm{p}}+\mathrm{v} \alpha_{\mathrm{w}}}
$$

where $\alpha_{\mathrm{p}}$ and $\alpha_{\mathrm{w}}$ are the expansion coefficients of free volume (the difference between the expansion coefficient in the liquid/rubbery state and the expansion coefficient in the glassy state), $\mathrm{v}$ is the volume fraction of water and $\mathrm{T}_{\mathrm{gw}}$ is the glass transition temperature of water: $\mathrm{T}_{\mathrm{gw}} \sim 120 \mathrm{~K}$.

Equation 43 simplifies assuming that the Simha-Boyer rule is valid: $\alpha \times \mathrm{T}_{\mathrm{g}}=$ constant $=0.113$. Then:

$$
\frac{1}{T_{g}}=\frac{1}{T_{g p}}+A_{p} v
$$

where $A_{p}=T_{g w}^{-1}-T_{g p}^{-1}$.

$\mathrm{A}_{\mathrm{p}}$ ranges between $4.8 \times 10^{-3} \mathrm{~K}^{-1}$ and $6.0 \times 10^{-3} \mathrm{~K}^{-1}$ for most of the glassy polymers so that:

$$
588 \mathrm{~K}<\frac{\mathrm{dT}_{\mathrm{g}}}{\mathrm{d} v}<2,160 \mathrm{~K}
$$

In other words $\mathrm{T}_{\mathrm{g}}$ would decrease by about $6 \mathrm{~K}$ per percent water absorbed for polymers having a relatively low $\mathrm{T}_{\mathrm{g}}(350 \mathrm{~K})$. This decrease would be about $20 \mathrm{~K}$ per percent for polymers having the highest available $\mathrm{T}_{\mathrm{g}}$ values $(600 \mathrm{~K})$. The fact that $\mathrm{T}_{\mathrm{g}}$ depression increases with the quantity of absorbed water, its order of magnitude and the fact that, for equal concentrations of absorbed water, the $T_{g}$ depression is an increasing function of the polymer glass transition temperature are experimentally verified. Indeed, the above relationships suppose that water and polymer form a single phase. Zhou and Lucas [71] found, as previously reported, 
two kinds of bonded water in amine cured epoxies, and showed that both types of water molecules had distinct contributions to plasticization. Carfagna et al. [72] studied epoxy samples differing by the amine/epoxide functional ratio and compared the $T_{g}$ values of wet samples, using free volume and entropy theories. The former gave better results, but the chosen value for $\mathrm{T}_{\mathrm{gw}}(277 \mathrm{~K})$ was far from the value now accepted $(\sim 120 \mathrm{~K})$.

\section{Water Diffusion}

\subsection{Introduction. Experimental Approaches. Main Types of Sorption Curves}

In a bulk, non-porous polymer sample, water moves by molecular diffusion. Except in the case of interconnected pores or cracks, which will not be studied here, what penetrates the polymer is water vapor, i.e. each molecule is isolated from the others and moves by activated jumps in the direction of the concentration (chemical potential) gradient. There are basically four main diffusion processes: Fick's diffusion, Langmuir's diffusion, case II diffusion and coupled reactiondiffusion. This latter will be studied in the section devoted to hydrolysis. In all cases, diffusion kinetics can be studied from mass uptake or water concentration increase curves using the methods described previously, gravimetry being, by far, the most common. Diffusion kinetics can also be studied by measurement of water concentration thickness profiles during the sorption transient (before equilibrium), however, this latter approach is generally more difficult than the former one and is rarely used. The classical approach consists in making gravimetric measurements on microtome sections [73]. NMR imaging is a more promising solution, as illustrated by Ghi et al. [74] in the case of crosslinked PMMA, or by Braun et al. [75] in the case of polyurethane foams, where spatial resolutions of the order of $0.1 \times 0.1 \mathrm{~mm}$ were reached. This resolution is too low to permit precise quantitative studies, but there are fast developments in this field and NMR imaging could become an interesting tool for the study of water diffusion in the future.

In Fick's diffusion, the water transport mechanism can be characterized by a single quantity, the coefficient of diffusion or diffusivity $\mathrm{D}$. Then, one can define a characteristic time of diffusion for a sample of thickness $L: t_{D}=L^{2} / D$. Its meaning is the following: to determine $\mathrm{D}$ from experimental mass uptake curves, one must study the phenomenon for times of the order of $t_{D}$. If $t \ll t_{D}$, the mass uptake is too low to permit identification of $D$. If $t \gg t_{D}$, the sample is close to equilibrium and there is no way to determine $D$. The dependence of $t_{D}$ with the square of the sample thickness is to be noted: a sample which would take 10 years to reach equilibrium when its thickness is $2 \mathrm{~cm}$, would only take one day for a thickness of $0.1 \mathrm{~mm}$. One can deduce that decreasing the sample thickness (when it is possible) is the best way to accelerate Fickian diffusion. 
Table 5 The three main diffusion cases other than Fick's diffusion

\begin{tabular}{ll}
\hline Type & Second process \\
\hline Langmuir & $\begin{array}{l}\text { Trapping/untrapping of water by } \\
\text { strongly interactive polymer sites }\end{array}$ \\
(II) & $\begin{array}{l}\text { Polymer relaxation/devitrification } \\
\text { Diffusion-reaction }\end{array}$ \\
\hline
\end{tabular}

In all diffusion processes other than Fick's, Fickian diffusion is combined with another process for which the characteristic time is $t_{R}$ (Table 5). We see that if $t_{D} \ll t_{R}$, the sample is first filled by water according to Fick's law, an equilibrium can be observed for a limited time, but at long term, the second process becomes significant and a new mass change is observed. One can then say that Fick's diffusion and the second mechanism are decoupled. If on the contrary $t_{D} \geq t_{R}$, this means that both mechanisms cannot be decoupled, since Fickian diffusion occurs simultaneously with the second process.

\subsection{Fickian Diffusion}

\section{Kinetic equations}

In the simplest case of unidirectional diffusion (no edge effects), the equilibrium mass uptake $\mathrm{m}_{\mathrm{s}}$ is independent of the sample thickness $\mathrm{L}$ and, for an initially dry material in given exposure conditions, the water diffusion obeys Fick's second law:

$$
\frac{\partial \mathrm{C}}{\partial \mathrm{t}}=D \frac{\partial^{2} \mathrm{C}}{\partial \mathrm{z}^{2}}
$$

where $\mathrm{C}$ is the local water concentration and $\mathrm{z}$ the depth of the layer in the sample thickness.

For a parallelepipedic sample of dimensions $\mathrm{L}$ (in the diffusion direction), $\mathrm{H}_{\mathrm{L}}$ and $\mathrm{H}_{\mathrm{T}}$, a correction must be made [76]:

$$
\mathrm{D}=\mathrm{D}_{0}\left(1+\frac{\mathrm{L}}{\mathrm{H}_{\mathrm{L}}}+\frac{\mathrm{L}}{\mathrm{H}_{\mathrm{T}}}\right)^{2}
$$

The resolution of this differential equation gives:

$$
\frac{\mathrm{C}(\mathrm{z}, \mathrm{t})}{\mathrm{C}_{\mathrm{s}}}=1-\frac{4}{\pi} \sum_{\mathrm{n}=1}^{\infty} \frac{1}{2 \mathrm{n}-1} \sin \left[(2 \mathrm{n}-1) \pi \frac{\mathrm{z}}{\mathrm{L}}\right] \exp \left\{-(2 \mathrm{n}-1) \pi^{2} \frac{\mathrm{Dt}}{\mathrm{L}^{2}}\right\}
$$

where $\mathrm{C}_{\mathrm{s}}$ is the equilibrium concentration.

The whole mass uptake at time $\mathrm{t}$ is given by: 
Fig. 8 Shape of a Fick's diffusion curve in reduced coordinates

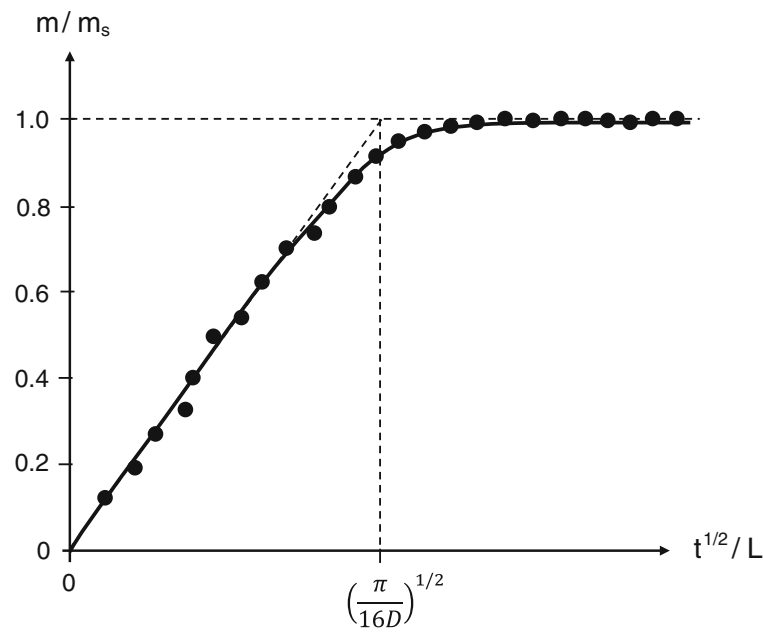

For a semi-infinite plate, the solution is:

$$
\frac{\mathrm{C}(\mathrm{z}, \mathrm{t})}{\mathrm{C}_{\mathrm{s}}}=\operatorname{erfc}\left[\frac{\mathrm{z}}{2 \sqrt{\mathrm{Dt}}}\right]
$$

As long as the water concentration on the back surface remains low, i.e. the whole mass uptake remains lower than about $60 \%$ of the equilibrium mass uptake, the above equations can be well approximated by the following equation:

$$
\frac{\mathrm{m}_{\mathrm{t}}}{\mathrm{m}_{\mathrm{s}}}=\mathrm{y}=\frac{4}{\sqrt{\pi}} \sqrt{\frac{\mathrm{Dt}}{\mathrm{L}^{2}}}
$$

$\mathrm{D}$ can thus be determined from the slope of the relative mass uptake against square root of time (Fig. 8):

$$
\mathrm{D}=\frac{\pi \mathrm{L}^{2}}{16}\left(\frac{\mathrm{dy}}{\mathrm{d} \sqrt{\mathrm{t}}}\right)^{2}
$$

The fact that the mass uptake increases proportionally with the square root of time is usually considered as a proof that diffusion obeys Fick's law. In fact there are cases where sorption begins as a Fickian process but deviates from this law at high relative mass uptakes. In this latter case, for Fickian diffusion, the relative mass uptake must be approximated by an exponential function:

$$
\frac{\mathrm{m}_{\mathrm{t}}}{\mathrm{m}_{\mathrm{s}}}=1-\frac{8}{\pi^{2}} \exp \left(-\pi^{2} \frac{\mathrm{Dt}}{\mathrm{L}^{2}}\right)
$$


Table 6 Apparent activation energy of water diffusion in some polymers

\begin{tabular}{lll}
\hline Polymer & $\mathrm{E}_{\mathrm{D}}(\mathrm{kJ} / \mathrm{mol})$ & Source \\
\hline Polycarbonate (bisphenol A) & 26 & Ghorbel et al. [137] \\
Unsaturated polyester (45\% styrene) & $9-13$ & Jacquemet and Lagrange [77] \\
Vinyl ester (40-45\% styrene) & $22-50$ & Bellenger et al. [31] \\
Amine cured epoxy (DGEBA-DDM-PGE) & $40-70$ & Damian et al. [156] \\
Polyimide (kapton) & $42-46$ & Sacher and Susko [157] \\
\hline
\end{tabular}

Fick's law is obeyed by a large number of polymers and composites, at least in a limited temperature range.

\section{Influence of water activity and temperature on diffusivity}

In the simplest case, water diffusivity is independent of water activity and depends on temperature according to an Arrhenius law:

$$
\mathrm{D}=\mathrm{D}_{0} \exp \left(-\frac{\mathrm{E}_{\mathrm{D}}}{\mathrm{RT}}\right)
$$

Values of activation energy $\mathrm{E}_{\mathrm{D}}$ range generally between 10 and $100 \mathrm{~kJ}^{\mathrm{mol}}{ }^{-1}$ (Table 6). It appears difficult to make a coherent synthesis of published data because they reveal great discrepancies. For instance, for polyesters of the orthophthalate-

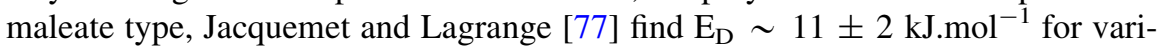
ous resins and composites, whereas Belan [78] find values of the order of $38 \mathrm{~kJ} . \mathrm{mol}^{-1}$ for networks of close structure. A possible explanation of this difference comes from the fact that the investigated temperature range was $5-40{ }^{\circ} \mathrm{C}$ in the first case and $30-70{ }^{\circ} \mathrm{C}$ in the second case, owing to the non-arrhenian character of the temperature dependence of water diffusivity, as already observed by Bellenger et al. [30]. A possible explanation of this behavior was given, in the case of water diffusion in polyethylene, by Mc Call et al. [2].

\section{Influence of the stress state}

In the transient regime of sorption, there are water concentration and thus, swelling ratio gradients in the sample thickness. This differential swelling induces a stress state and this latter can, in turn, influence diffusion. This problem was soon recognized by Crank [79]. Thermodynamic and mechanical aspects have been widely studied, both in resins and composites [20, 21, 80-84]. The domain profited from the contemporaneous advances in mechanics of heterogeneous solids, homogenization methods, etc.

Certain composites remain stable, i.e. undergo reversible changes during exposure to wet environments at ambient temperature, but undergo irreversible damage at high temperature where diffusion is faster, while the swelling ratio is almost unchanged. Irreversible damage modifies moisture uptake and induces sorption-desorption hysteresis.

Concerning molecular aspects of diffusion, it was for a long time supposed that it can be described by the free volume theory. In its simplest version, this theory considers that the diffusivity is linked to the molecular mobility and can receive 
the same treatment as viscosity in the glass transition region. According to Doolittle, one would have:

$$
\mathrm{D}=\mathrm{D}_{0} \exp \left(-\frac{\mathrm{b}}{\mathrm{v}}\right)
$$

where $\mathrm{v}$ is the free volume fraction and $\mathrm{b}$ a constant generally considered equal to unity. $\mathrm{D}_{0}$ is a parameter characteristic of the polymer-water couple.

The free volume fraction $\mathrm{v}$ is the sum of the "thermal free volume" $\mathrm{v}_{\mathrm{T}}$ linked to expansion and the "mechanical free volume" $v_{M}$ linked to the stress state. According to the classical free volume theory:

$$
\mathrm{v}_{\mathrm{T}}=\mathrm{v}_{\mathrm{g}}+\alpha\left(\mathrm{T}-\mathrm{T}_{\mathrm{g}}\right)
$$

where $\alpha=\alpha_{1}-\alpha_{\mathrm{g}}$ is the difference between the expansion coefficients in the liquid/rubbery state and in the glassy state. $\alpha$ is called the expansion coefficient of free volume. $v_{\mathrm{g}}$ is the free volume fraction at the glass transition temperature $\mathrm{T}_{\mathrm{g}}$. Pseudo universal values of these parameters are $\alpha=5.10^{-4} \mathrm{~K}^{-1}$ and $\mathrm{v}_{\mathrm{g}}=0.025$.

According to this model, the free volume vanishes at $\mathrm{T}_{\mathrm{g}}-\mathrm{v}_{\mathrm{g}} / \alpha \sim \mathrm{T}_{\mathrm{g}}-$ $50 \mathrm{~K}$. Indeed, according to this equation, there would not be diffusion below $\mathrm{T}_{\mathrm{g}}-$ $50 \mathrm{~K}$, which is contradicted by experimental data. In this theory, an elementary free volume could be defined as the lowest hole volume allowing a cooperative segmental motion. But, the water molecule is considerably smaller than the polymer segment undergoing a cooperative motion. The study of its diffusion would thus need a new definition of free volume. Many authors consider, however, that $v_{\mathrm{g}}$ corresponds to the free volume fraction "frozen" in glassy state, i.e. is temperature independent below $\mathrm{T}_{\mathrm{g}}$. This latter assumption lacks justification. The classical vision of small molecule diffusion is the following: water moves by activated jumps in temporary holes formed by segmental motions. Since cooperative motions seem to fail to explain the temperature dependence of water diffusivity, it is tempting to assume that this latter is linked with the residual mobility linked to local $\left(\beta, \gamma\right.$, etc.) motions. The "mechanical free volume" fraction $\mathrm{V}_{\mathrm{M}}$ is an algebraic quantity. It is positive under tensile conditions:

$$
\mathrm{v}_{\mathrm{M}}=\frac{\sigma}{\mathrm{E}}(1-2 \mathrm{v})
$$

where $\sigma$ is the tensile stress, E is the Young's modulus and $v$ is the Poisson's ratio. $\mathrm{v}_{\mathrm{M}}$ is a negative quantity under compressive conditions:

$$
\mathrm{v}_{\mathrm{M}}=-\frac{\sigma}{\mathrm{K}}
$$

where $\mathrm{K}$ is the bulk modulus.

The diffusion coefficient is thus expected to increase under tensile stresses and to decrease under compressive stresses. There is no reason to refute the global trends predicted by this approach. Some published data seem to confirm its validity $[85,86]$, but the experimental method chosen by the former authors involves a 
great quantity of simplifying assumptions and their choice of certain parameter values, for instance $b$, is questionable. The latter authors did not report diffusivity values, but mentioned that they disagree with the theory. Derrien and Gilormini [19] find almost undetectable stress effects on water diffusion in an amine crosslinked epoxy. As previously mentioned, results obtained on samples undergoing strong tensile stresses are difficult to interpret owing to the occurrence of creep and damage. Results obtained on samples exposed under high hydrostatic pressures would be more significant but also more difficult to obtain.

\section{Influence of clustering and plasticization}

When sorption occurs only by Henry's mechanism, the diffusivity is independent of activity. If a dependence of D on activity is observed, it indicates the presence of a complex sorption mechanism.

In the case of clustering, the water diffusivity tends to decrease at high activities [87]. There are many explanations of this behavior in the literature. For certain authors, clusters are considered as stable entities of which the diffusivity is a decreasing function of their size. For other authors, their low diffusivity is attributed to steric hindrance [46] without defining the meaning of this term. A simpler explanation could be that, since water-water interactions are stronger than water-polymer ones, the residence time of a water molecule in a cluster must be longer than in a polymer-water complex (see below). It seems that modeling of the clustering effect on diffusion is purely empirical as shown, for instance, by Detallante et al. [46] in the case of sulfonated polyimides.

In the case of plasticization, the water diffusivity is an increasing function of water activity, i.e. of water concentration. This is attributed to the plasticization effect of water on hydrophilic polymer glasses. Plasticization increases free volume and segmental mobility, at least in the temperature domain just below $\mathrm{T}_{\mathrm{g}}$, that favors diffusion. There is an abundant literature on this aspect [79, 88, 89]. The kinetic problem is often resolved using Fick's law with a concentration dependent diffusivity:

$$
\frac{\partial C}{\partial t}=\frac{\partial}{\partial z}\left(D(C) \frac{\partial C}{\partial z}\right)
$$

It is usual to take [90]:

$$
\mathrm{D}(\mathrm{C})=\mathrm{D}_{0} \exp (\gamma \mathrm{C})
$$

where $D_{0}$ is the diffusion coefficient extrapolated at zero concentration and $\gamma$ a "plasticization parameter".

For Van Krevelen and Te Nijenhuis [28], $\gamma=-0.08$ in the case of clustering and $\gamma=+0.08$ in the case of plasticization, $\mathrm{C}$ being expressed in percent of mass uptake. When plasticization and clustering coexist, D can increase with activity at low activities and decrease at high activities, as found in the case of polyimide Kapton where the water concentration value at the maximum diffusivity decreases when the temperature increases [91]. The problem becomes more complicated when polymer plasticization induces its phase change from glassy to rubbery state 
where molecular mobility is considerably higher. This case, named "case II" will be examined below.

\section{Mechanism(s) of Fickian diffusion}

As seen above, the basic free volume theory fails to explain experimental observations. More sophisticated theories consider not the average free volume but rather a distribution of hole sizes. The proportion of them allowing the transport of a given molecule would be a decreasing function of the molecule size. Indeed, water molecules, which are very small, would "profit" from a greater proportion of available holes [92].

Another possible explanation is that sub-glass motions ( $\beta$ motions) are sufficient to permit water diffusion. This is not easy to reconcile with the fact that water diffusivity is considerably higher in polyesters (very low activity of $\beta$ transition) than in amine cured epoxies (very active $\beta$ transition). Finally, it appears very difficult to correlate water diffusivity with molecular mobility or with any classical volumetric criterion (as well as free volume) as fractional free volume or packing density.

It seems obvious that considerations of molecular mobility and free volume are not sufficient to explain the structure-water diffusivity relationships. A new idea was proposed by McCall et al. [2] in their work on water transport properties in polyethylenes differing by the concentration of oxygen containing structural irregularities. They found that the temperature dependence of water solubility $S$ and diffusivity $\mathrm{D}$ did not obey an Arrhenius law, contrary to their product $\mathrm{D} \times \mathrm{S}$. They concluded that the solubility has two components, one corresponding to the apolar PE matrix with low activation energy, another corresponding to polar sites with a higher activation energy. Diffusion would be slowed down by the interactions between these polar sites and water molecules. This theory is not easy to confirm from literature raw data, where cluster contribution is generally not separated from Henry's contribution, and where sorption isotherms are not recorded. The trends seem however be confirmed by the results obtained by Bellenger et al. [29] on a series of aromatic amine cured epoxies (Table 7).

The results obtained on series $\mathrm{C}$ clearly show that water solubility is independent of crosslink density. In series $\mathrm{A}$ and $\mathrm{B}$, where crosslink density and packing density vary in the same way, diffusivity appears as a decreasing function of packing density, but with a slope four times higher for series A than for series B, (Fig. 9). It seems thus that diffusivity is not governed by packing density alone. Furthermore, if D was only dependent on free volume, its temperature dependence would display a discontinuity at $\mathrm{T}_{\mathrm{g}}$, as for permanent gases. Experiments showed that this discontinuity does not exist in the case of an amine cured epoxy [18].

Plotting $\mathrm{D}$ against $\mathrm{m}_{\mathrm{s}}$ (Fig. 10) reveals the same type of dependence as in Fig. 9, but with better correlation coefficients. This similarity can be explained by the fact that packing density depends mainly on cohesion, i.e. on polar groups concentration [93]. It is thus tempting to assume that water diffusivity is a decreasing function of water equilibrium concentration in the saturated state, i.e. a decreasing function of water solubility. The differences between epoxies and polyesters or vinylesters confirm, at least semi-quantitatively, this difference [31], 
Table 7 Glass transition temperature $\left(\mathrm{T}_{\mathrm{g}}\right)$, concentration of crosslink nodes $(\mathrm{X})$, packing density (Van der Waals volume/molar volume, $\mathrm{P}^{*}$ ), equilibrium water mass uptake $\left(\mathrm{m}_{\mathrm{s}}\right)$ and diffusion coefficient (D) determined at $100{ }^{\circ} \mathrm{C}$ under $100 \% \mathrm{RH}$.

\begin{tabular}{llllll}
\hline Code & $\mathrm{T}_{\mathrm{g}}(\mathrm{K})$ & $\mathrm{X}\left(\mathrm{mol}_{\mathrm{kg}} \mathrm{kg}^{-1}\right)$ & $\mathrm{P} *$ & $\mathrm{~m}_{\mathrm{s}}(\%)$ & $\mathrm{D}\left(\mathrm{m}^{2} \cdot \mathrm{s}^{-1}\right) \times 10^{13}$ \\
\hline A0 & 443 & 2.28 & 0.668 & 2.54 & 64 \\
A25 & 466 & 3.30 & 0.670 & 3.40 & 55 \\
A50 & 472 & 4.23 & 0.680 & 4.36 & 47 \\
A80 & 486 & 5.25 & 0.687 & 5.50 & 35 \\
A100 & 499 & 5.88 & 0.695 & 6.09 & 30 \\
C25 & 470 & 4.98 & 0.690 & 5.47 & 27 \\
C50 & 440 & 4.10 & 0.695 & 4.98 & 28 \\
C75 & 408 & 3.24 & 0.694 & 4.92 & 33 \\
C100 & 391 & 2.40 & 0.691 & 5.29 & 47 \\
B0 & 417 & 2.02 & 0.667 & 1.81 & 149 \\
B25 & 439 & 2.86 & 0.665 & 2.26 & 126 \\
B50 & 456 & 3.63 & 0.670 & 2.68 & 121 \\
B75 & 465 & 4.30 & 0.677 & 3.08 & 95 \\
B100 & 471 & 4.90 & 0.678 & 3.52 & 82
\end{tabular}

Epoxides are diglycidyl ether of bisphenol A (DGEBA) and triglycidyl derivative of p-amino phenol (TGAP). Amines are diaminodiphenylmethane (DDM), or DDM with hydrogens in 2-6 position substituted by ethyl groups (DDMe) and aniline (AN). Series A is based on DGEBATGAP mixtures, the number corresponds to molar fraction (\%) of TGAP, crosslinked by DDM. Series B is identical except that DDM is replaced by DDMe. Series C is based on TGAP crosslinked by a DDM-aniline mixture. The number corresponds to the molar fraction of aniline. After [Bellenger et al. [29]]

Fig. 9 Diffusivity against packing density for series A (triangles), B (lozenges) and $\mathrm{C}$ (squares)

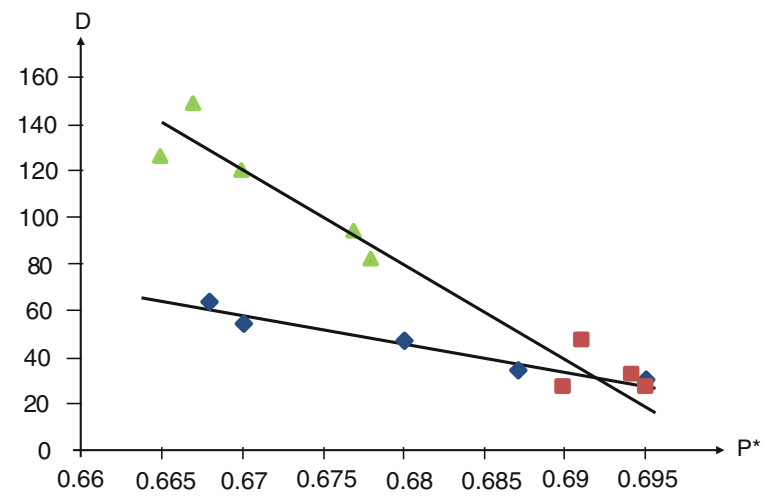

which is also confirmed in a series of aromatic polysulfones [94]. In all these structural series, including polyethylene, $\mathrm{D}$ is roughly inversely proportional to $\mathrm{m}_{\mathrm{s}}$.

$$
\mathrm{D} \sim \mathrm{Q} / \mathrm{m}_{\mathrm{s}}
$$




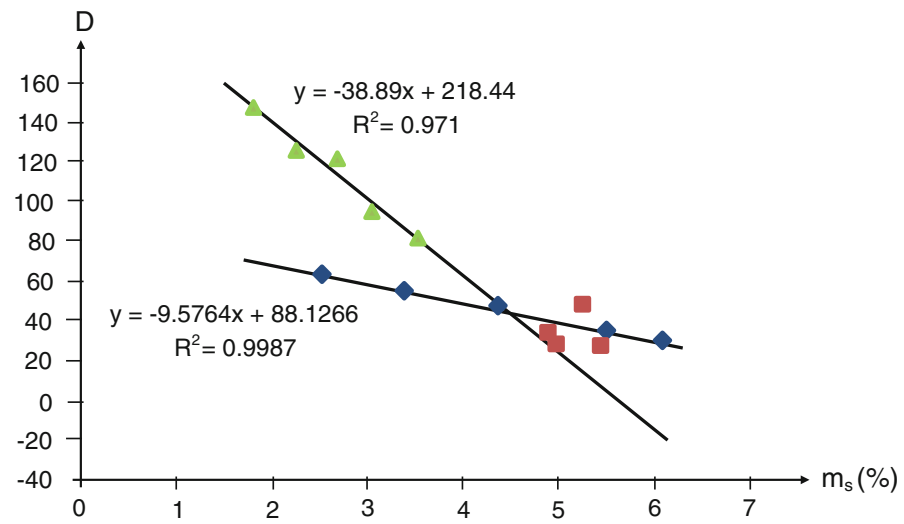

Fig. 10 Diffusivity against equilibrium water concentration for series A (triangles), series B (lozenges) and series $\mathrm{C}$ (squares)

where $\mathrm{Q}$ is of the order of $2 \times 10^{-12} \mathrm{~m}^{2} \cdot \mathrm{s}^{-1}$ for polymers of low polarity, such as polyethylene or polyesters at $50{ }^{\circ} \mathrm{C},(18 \pm 4) \times 10^{-12} \mathrm{~m}^{2} . \mathrm{s}^{-1}$ for aromatic polysulfones at $50{ }^{\circ} \mathrm{C}$ and $(25 \pm 6) \times 10^{-12} \mathrm{~m}^{2} \cdot \mathrm{s}^{-1}$ for amine cured epoxies [94].

Thus, the specificity of water diffusion would be due to the existence of strong $\mathrm{H}$ bonds between water molecules and polar groups of the polymer. These interactions would slow down diffusion which could be described as a succession of jumps from a polar site to another, the whole kinetics depending on two elementary times: the lifetime of the water-polar site complexes and the time to cross the distance 1 between polar sites, this latter being a decreasing function of their concentration. It can be assumed that this second elementary time is proportional to $1^{2}$, but depends also on free volume. In the current state of our knowledge, we see no possibility to envisage a water diffusion mechanism ignoring the role of water-polymer interactions, but its modeling remains to be established.

\subsection{Langmuir's Diffusion}

It was soon recognized that, in many cases, water absorption by composites seems to display a Fickian behavior (i.e. $\mathrm{m} \propto \mathrm{t}^{1 / 2}$ ) at low mass uptakes, but displays an inflection or a slow but continuous mass increase, instead of an equilibrium. This behavior has been clearly identified as a Langmuir process in certain cases, but it is probably abusively considered as a Langmuir process in other cases where the slow change is not reversible at all. As shown in the section devoted to water solubility, the Langmuir process involves the existence of sites able to establish relatively strong, but reversible, bonds with water, so that two populations of water molecules coexist in the material: the "free" molecules of which the transport in 
the matrix obeys Fick's law with a diffusivity D, and the "trapped" molecules temporarily retained at Langmuir sites by reversible bonds. The mathematics of Langmuir diffusion have been exposed in many articles, for instance in the widely cited paper of [Carter and Kibler [95]]. The "trapping-detrapping" process is the following:

$$
\begin{aligned}
& \mathrm{F}+\mathrm{P} \rightarrow \mathrm{F}-\mathrm{P}\left(\mathrm{k}_{\mathrm{t}}\right) \\
& \mathrm{F}-\mathrm{P} \rightarrow \mathrm{F}+\mathrm{P}\left(\mathrm{k}_{\mathrm{d}}\right)
\end{aligned}
$$

where $\mathrm{F}$ is a free (mobile) water molecule, $\mathrm{P}$ is a polar site of the polymer and $\mathrm{F}-\mathrm{P}$ is the water-polymer complex. $\mathrm{k}_{\mathrm{t}}$ and $\mathrm{k}_{\mathrm{d}}$ are the corresponding rate constants.

The kinetic law for free molecules in a elementary layer can be written:

$$
\frac{\partial \mathrm{F}}{\partial \mathrm{t}}=\mathrm{k}_{\mathrm{d}}[\mathrm{F}-\mathrm{P}]-\mathrm{k}_{\mathrm{t}}[\mathrm{F}][\mathrm{P}]
$$

Assuming that the number of occupied polymer sites is small compared to the whole number of sites, one can consider that $[\mathrm{P}]=$ constant, and thus that:

$$
\frac{\mathrm{dn}}{\mathrm{dt}}=\alpha \mathrm{N}-\beta \mathrm{n}+\mathrm{D} \frac{\partial^{2} \mathrm{n}}{\partial \mathrm{z}^{2}}
$$

where $\mathrm{n}$ and $\mathrm{N}$ are the respective numbers of mobile and immobilized water molecules, $\alpha$ and $\beta$ are the respective probabilities of detrapping (proportional to $\mathrm{k}_{\mathrm{d}}$ ) and trapping (proportional to $\mathrm{k}_{\mathrm{t}}[\mathrm{P}]$ ). $\mathrm{D}$ is the coefficient of diffusion of free molecules.

At equilibrium:

$$
\alpha \mathrm{N}_{\mathrm{s}}=\beta \mathrm{n}_{\mathrm{s}}
$$

The total number $\mathrm{w}_{\mathrm{s}}$ of sorbed water molecules is thus:

$$
\mathrm{w}_{\mathrm{s}}=\mathrm{n}_{\mathrm{s}}\left(1+\frac{\beta}{\alpha}\right)
$$

When the characteristic times of complex formation and dissociation $\left(\beta^{-1}\right.$ and $\alpha^{-1}$ ) are significantly longer than the characteristic time of diffusion $\left(\mathrm{L}^{2} / \mathrm{D}\right)$, both phenomena are distinguishable in sorption curves. These display two plateaus: the first one linked to the equilibrium concentration $n_{s}$ of free water molecules, the second one to the formation of water-polymer complexes Fig. 11.

It is noteworthy that if $\beta / \alpha \gg 1$ or $\beta / \alpha \ll 1$, or if $\mathrm{L}^{2} / \mathrm{D} \geq \alpha^{-1}$ and $\beta^{-1}$, the identification of Langmuir's mechanism and the determination of its parameters can appear difficult. Sorption anomalies (non-Fickian behavior) in composites have often been attributed to the Langmuir process without a rigorous proof of its existence. A first proof would be the characteristic shape (negative curvature) of the Langmuir sorption isotherm. In many cases, a positive curvature was observed, the equilibrium mass uptake was expressed as a power function of activity: 
Fig. 11 Shape of a Langmuir's sorption curve

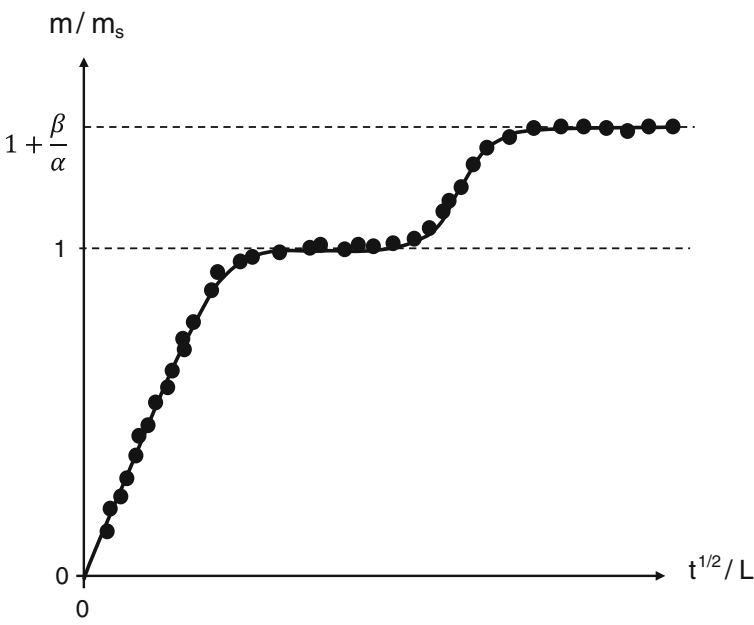

$\mathrm{m}_{\mathrm{s}} \propto \mathrm{a}^{\mathrm{m}}$ with $\mathrm{m}>1$, despite that sorption curves were fitted by the above set of equation. The number of adjustable parameters allows, indeed, good fittings.

The nature of Langmuir sites would merit a detailed discussion. In the literature, the main hypotheses for Langmuir loci are pores at interfaces or in the matrix, preexisting, linked to a lack of matrix/fiber adhesion or to matrix outgassing during processing, or inherent to the resin morphology [96], or induced by swelling stresses during exposure to wet environments. Various assumptions have been proposed to explain the role of pores: water adsorption on their surface, or simply high strength of water-water bonds in clusters. These assumptions lack justification in our opinion. As a matter of fact, there is a great diversity of clustering cases without Langmuir behavior.

In the 1980s, various authors, for instance Wong and Broutman [48], observed that sorption anomalies attributable to Langmuir's process appear in epoxideamine networks having unreacted epoxide groups. Tcharkhtchi et al. [18] studied the phenomenon on samples thin enough to separate the two plateaus, and observed that the increase of mass uptake corresponding to the second process was almost proportional to the concentration of unreacted epoxide groups. They concluded that the second process is the reversible hydrolysis of epoxide groups into 1-2 diols (Fig. 12).

As quoted in Sect. 2.7, we are now tempted to assume that, in matrices, Langmuir behavior is linked to the existence of a reversible polymer-water reaction. Let us consider the hydrolysis equilibrium:

Fig. 12 Hydrolysis of epoxide groups

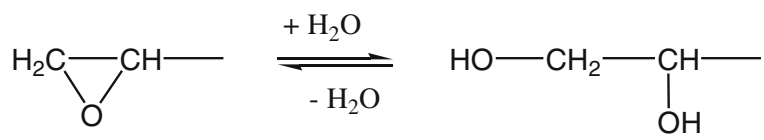




$$
\begin{gathered}
\mathrm{E}+\mathrm{W} \rightarrow \mathrm{D}\left(\mathrm{k}_{\mathrm{H}}\right) \\
\mathrm{D} \rightarrow \mathrm{E}+\mathrm{W}\left(\mathrm{k}_{\mathrm{R}}\right)
\end{gathered}
$$

where $\mathrm{W}$ is water, $\mathrm{E}$ is an unreacted epoxide and $\mathrm{D}$ is the corresponding diol.

The equilibrium corresponds to:

$$
\mathrm{k}_{\mathrm{H}}[\mathrm{W}][\mathrm{E}]=\mathrm{k}_{\mathrm{R}}[\mathrm{D}]
$$

If $[\mathrm{E}]_{0}$ is the epoxide concentration in dry state:

$$
[\mathrm{D}]+[\mathrm{E}]=[\mathrm{E}]_{0}
$$

Then:

$$
[\mathrm{D}]=\frac{[\mathrm{E}]_{0}}{1+\frac{\mathrm{k}_{\mathrm{H}}[\mathrm{W}]}{\mathrm{k}_{\mathrm{R}}}}
$$

Concerning water concentration [W], a simple hypothesis can be made: diols do not modify hydrophilicity, i.e. [W] $=$ constant. In this case, the relative mass uptake $\Delta \mathrm{m}$ corresponding to the second plateau is given by:

$$
\Delta \mathrm{m}=18 \rho[\mathrm{D}]
$$

where $\rho$ is the material density in $\mathrm{g} . \mathrm{L}^{-1}$ if $[\mathrm{D}]$ is in mol. $\mathrm{L}^{-1}$.

Two extreme cases can be distinguished:

- If $\mathrm{k}_{\mathrm{H}}[\mathrm{W}] \ll \mathrm{k}_{\mathrm{R}}$, then:

$$
[\mathrm{D}] \sim[\mathrm{E}]_{0} \text { almost all epoxides have reacted }
$$

- If $\mathrm{k}_{\mathrm{H}}[\mathrm{W}] \gg \mathrm{k}_{\mathrm{R}}$, then:

$$
[\mathrm{D}] \approx \frac{\mathrm{k}_{\mathrm{R}}[E]_{0}}{\mathrm{k}_{\mathrm{H}}[\mathrm{W}]}<<[\mathrm{E}]_{0}
$$

Experimental results seem to be in favor of the first case [18].

Let us now return to the mechanism of water diffusion slowed down by polymer-water interactions proposed in the previous section. It is, no doubt, a Langmuir mechanism since it involves a certain period of water molecules retention at polymer polar sites. In this case, it remains to be explained why sorption curves display, in many cases, a purely Fickian behavior. Inequality 71 gives a possible answer: the sorption curves have the shape of Fickian curves because the number of occupied Langmuir's sites is small compared to the number 
of potential Langmuir's sites, as a consequence of the fact that dissociation of water-polymer complexes is considerably slower than their formation.

\subsection{Case II Diffusion}

This case will be only briefly evoked here, because it should be avoided in practice by a proper matrix choice. As previously seen, water plasticizes the polymer, i.e. induces a decrease of its glass transition temperature $\mathrm{T}_{\mathrm{g}}$. Case II occurs when, for a critical mass uptake $m_{c} \leq m_{s}, T_{g}$ becomes equal to the test temperature, in other words when, in the sample layers where $\mathrm{m} \geq \mathrm{m}_{\mathrm{c}}$, the polymer becomes rubbery. Since there is a strong difference in water diffusivity values between glassy and rubbery states, there will be a quasi-discontinuity in the layer where $m=m_{c}$. This diffusion front will move from the surface to sample core at an almost constant rate, so that the mass uptake will vary proportionally with $t$ rather than $t^{1 / 2}$. After the pioneering work of Alfrey et al. [97], the theory of case II diffusion was established by Thomas and Windle [98]. For mechanical aspects of case II, one can cite the work of Argon et al. [99] and the references cited therein. Indeed, for an engineering composite having a mechanical function, the occurrence of case II would be catastrophic.

\subsection{Diffusion in Composites}

Diffusion laws were inspired by heat diffusion equations for homogeneous materials. The investigations on diffusion in heterogeneous media were inspired by the work of prestigious authors such as, for instance, Maxwell on electrical properties of heterogeneous materials. Barrer [100] summarized the first research on this topic at the beginning of the composite area. The discipline was then boosted by the advances in mechanics of heterogeneous materials and homogenization methods, but also by the emergence of powerful computation tools. Here, we will focus on long fiber composites.

Let us first consider the case of a unidirectional laminate with a fiber volume fraction $\mathrm{f}$. Water diffusivity is expected to depend on the direction of diffusion relative to the fiber direction. In the longitudinal direction, there is a simple situation: water diffuses only into the matrix with the same coefficient $D_{m}$ as into samples of pure resin (if this latter is in the same structural state). The water flux is thus expected to be proportional to the matrix cross section, i.e. to the matrix volume fraction $(1-f)$. The overall diffusivity in the longitudinal direction $D_{1}$ is:

$$
\mathrm{D}_{\mathrm{l}}=\mathrm{D}_{\mathrm{m}}(1-\mathrm{f})
$$


In the transverse direction, impermeable fibers impose a certain tortuosity to diffusion pathways. There are many expressions for the corresponding overall diffusivity $D_{t}$, the simplest one being derived from the Maxwell-Garnett approximation:

$$
\frac{\mathrm{D}_{\mathrm{t}}}{\mathrm{D}_{\mathrm{m}}}=\frac{1-\mathrm{f}}{1+\mathrm{f}}
$$

The equation of Kondo and Taki [101], assuming a cubic stacking of fibers, is widely used:

$$
\frac{\mathrm{D}_{\mathrm{t}}}{\mathrm{D}_{\mathrm{l}}}=\frac{1-\mathrm{f}}{1-2 \sqrt{\frac{\mathrm{f}}{\pi}}}
$$

In composites, there are many sources of complication linked to eventual interfacial diffusion and damage (pre-existing or swelling-induced). Their effects were progressively incorporated into diffusion models (see the references cited in Sect. 2.2.3, [102, 103]).

A peculiarity of diffusion in composites was shown by Derrien and Gilormini [80]. Since the matrix is swollen by water and this swelling is restrained by nondeformable fibers, a stress state appears in the matrix which modifies its water solubility and diffusivity. As a result, the diffusion behavior can take the appearance of Langmuir's diffusion while no specific sites for water-polymer interaction exist. This behavior appears however difficult to observe experimentally owing to the small contribution of the "mecano-sorptive" effects under consideration.

\section{Hydrolysis}

\subsection{General Aspects}

Hydrolysis is a chemical reaction between water and a reactive substrate leading to a bond rupture in the latter. The most general mode of writing of a hydrolysis reaction is:

$$
\mathrm{A}-\mathrm{B}+\mathrm{H}_{2} \mathrm{O} \rightarrow \mathrm{A}-\mathrm{H}+\mathrm{B}-\mathrm{OH}
$$

In industrial polymers, the most frequent reactive functions are esters in linear polyesters and copolyesters, polycarbonate, tridimensional polyesters based on unsaturated polyesters, or in anhydride cured epoxies. Amides (in linear polyamides), imides and some other groups, for instance epoxides as previously shown, are also more or less likely to react with water.

\section{Hydrolytic chain scission}

In polymers, two important cases can be distinguished: 
1. Ester groups belong to polymer backbone. In this case, each hydrolysis event is a chain scission that carries important consequences for polymer mechanical properties.

2. Ester groups belong to polymer lateral groups, for instance in linear polyacrylates, polymethacrylates, or in esters of polyvinylalcohol. In such cases, hydrolysis does not modify the chain length and will not influence, at reasonably low conversions, the polymer mechanical properties.

Attention will be focused here on the first category, in which hydrolysis modifies the molar mass or the crosslink density of the polymer.

Hydrolysis is a reversible but not a symmetric process, for instance in a linear polymer (-P is a macromolecular fragment):

$$
\begin{aligned}
& \mathrm{P}-\mathrm{A}-\mathrm{B}-\mathrm{P}+\mathrm{H}_{2} \mathrm{O} \rightarrow \mathrm{P}-\mathrm{A}-\mathrm{H}+\mathrm{HO}-\mathrm{B}-\mathrm{P}\left(\mathrm{k}_{\mathrm{H}}\right) \\
& \mathrm{P}-\mathrm{A}-\mathrm{H}+\mathrm{HO}-\mathrm{B}-\mathrm{P} \rightarrow \mathrm{P}-\mathrm{A}-\mathrm{B}-\mathrm{P}+\mathrm{H}_{2} \mathrm{O}\left(\mathrm{k}_{\mathrm{R}}\right)
\end{aligned}
$$

In the hydrolysis process, water is a small molecule able to diffuse rapidly in the polymer matrix (at least, for low sample thicknesses) and to accede easily to reactive sites. In contrast, in the reverse reaction, both reactants are macromolecular species with a diffusivity several orders of magnitude lower than that of water. Their condensation can thus be diffusion controlled in the time and temperature domains, where hydrolysis is not diffusion limited. From this point of view, linear and tridimensional polymers are not equivalent. In linear polymers, both groups resulting from hydrolysis can migrate far one from the other, thanks to cooperative and reptation chain motions (in rubbery state). In tridimensional polymers of relatively high crosslink density, especially in the glassy state, there is no possibility of long range migration for the (dangling) chain ends resulting from a chain scission, the reverse reaction is thus in principle favored.

\section{Equilibrium characteristics. Reversible hydrolysis}

Let us consider the above reactions with the following symbols and boundary conditions (Table 8).

The kinetic equation for substrate consumption can be written:

$$
\frac{\mathrm{ds}}{\mathrm{dt}}=\frac{\mathrm{dX}}{\mathrm{dt}}=\mathrm{k}_{\mathrm{H}}[\mathrm{W}][\mathrm{E}]-\mathrm{k}_{\mathrm{R}}[\mathrm{X}][\mathrm{Y}]
$$

i.e. with the chosen set of hypotheses:

Table 8 Symbols and boundary conditions for the study of hydrolysis equilibrium

\begin{tabular}{lll}
\hline Species & Concentration at time t & Initial concentration \\
\hline Water & {$[\mathrm{W}]$} & {$[\mathrm{W}]$} \\
Hydrolysable groups A-B & {$[\mathrm{E}]$} & {$[\mathrm{E}]_{0}$} \\
A-H groups & {$[\mathrm{X}]$} & 0 \\
B-OH groups & {$[\mathrm{Y}]=[\mathrm{X}]$} & 0 \\
\hline
\end{tabular}




$$
\frac{\mathrm{dX}}{\mathrm{dt}}=\mathrm{k}_{\mathrm{H}}[\mathrm{W}]\left([\mathrm{E}]_{0}-[\mathrm{X}]\right)-\mathrm{k}_{\mathrm{R}}[\mathrm{X}]^{2}
$$

At equilibrium:

$$
\mathrm{k}_{\mathrm{H}}[\mathrm{W}]\left([\mathrm{E}]_{0}-[\mathrm{X}]\right)-\mathrm{k}_{\mathrm{R}}[\mathrm{X}]^{2}=0
$$

From the solution of this equation one sees that:

- If $4 \mathrm{k}_{\mathrm{R}}[\mathrm{E}]_{0} / \mathrm{k}_{\mathrm{H}}[\mathrm{W}] \ll 1$, then $[\mathrm{X}]_{\text {equ }} \sim[\mathrm{E}]_{0}$, hydrolysis is almost total, the reverse reaction can be neglected. Polyesters often belong to this family. Polycarbonates correspond to an almost ideal case because the acid resulting from hydrolysis decomposes easily into alcohol (phenol) and volatile carbon dioxide. Thus the reverse reaction cannot occur:

$$
\begin{gathered}
\mathrm{P}-\mathrm{O}-\mathrm{CO}-\mathrm{O}-\mathrm{P}+\mathrm{H}_{2} \mathrm{O} \rightarrow \mathrm{P}-\mathrm{O}-\mathrm{CO}-\mathrm{OH}+\mathrm{HO}-\mathrm{P} \\
\mathrm{P}-\mathrm{O}-\mathrm{CO}-\mathrm{OH} \rightarrow \mathrm{P}-\mathrm{OH}+\mathrm{CO}_{2}
\end{gathered}
$$

- If $4 \mathrm{k}_{\mathrm{R}}[\mathrm{E}]_{0} / \mathrm{k}_{\mathrm{H}}[\mathrm{W}] \gg 1$, then $[\mathrm{X}]_{\mathrm{equ}} \sim\left(\mathrm{k}_{\mathrm{H}}[\mathrm{W}][\mathrm{E}]_{0} / 2 \mathrm{k}_{\mathrm{R}}\right)^{1 / 2}$, equilibrium occurs at a low conversion of the hydrolysis process. Polyamide 11 is a typical case of equilibrium at low hydrolysis conversion [104].

Effect of ionic species

Hydrolysis is an ionic process. It is catalyzed by acids or bases. Possible mechanisms are schematized in Fig. 13, for instance, in the case of polyester:

Experimental results of hydrolysis in hydrochloric acid solutions are available for both PET [105] and for PA 11 [106]. In both cases, it appears that diluted HCl has only a small effect on the hydrolysis rate (see for instance [107] for $\mathrm{HCl} 0.1 \mathrm{M}$

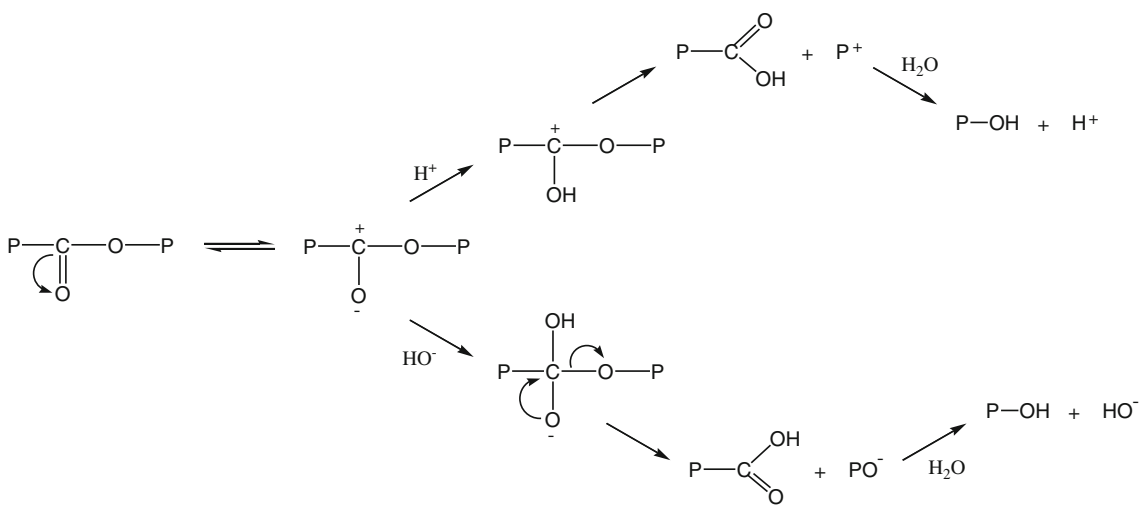

Fig. 13 Possible mechanisms of acid or base catalyzed ester hydrolysis 
in PET). But, the hydrolysis rate increases almost exponentially with the acid concentration. The explanation of this behavior was first proposed by Ravens [105]. Ionic species are highly polar and thus almost insoluble in polymers of low polarity. What can penetrate in a polymer is the non-dissociated form of the acid. Then, it can dissociate into the polymer matrix, the dissociation yield being an increasing function of the matrix polarity. These considerations led Merdas et al. [108] to the following relationship for the hydrolysis rate $r$, using the above notations with $[\mathrm{AH}]$ the non-dissociated acid concentration in the polymer:

$$
\mathrm{r}=\mathrm{K}[\mathrm{E}][\mathrm{W}]^{3 / 2}(1+\gamma[\mathrm{AH}])^{1 / 2}
$$

The pre-factor $\mathrm{K}$ is mainly linked to the hydrolysis rate constant and to the dissociation constant of water into the polymer matrix. The parameter $\gamma$ is defined by:

$$
\gamma=\frac{\mathrm{k}_{\mathrm{A}}}{\mathrm{k}_{\mathrm{w}}[\mathrm{W}]}
$$

where $\mathrm{k}_{\mathrm{A}}$ is the equilibrium constant of the acid $\mathrm{AH}$ dissociation and $\mathrm{k}_{\mathrm{w}}$ is the equilibrium constant of water dissociation, both in the polymer matrix.

These quantities are extremely difficult to determine experimentally, but the trends predicted by this equation can be checked experimentally. They allow the following cases to be distinguished:

(a) Weak acids in low concentration. In this case, both $\gamma$ and [AH] are small, $\gamma[\mathrm{AH}] \ll 1$, the catalytic effect is negligible. This is the case of terminal acid groups in polyamide 11 . If they had a catalytic effect, hydrolysis would be auto-accelerated, which is not the case [104]. Let us recall that the concentration of terminal acids is equal to the reciprocal of number average molar mass (see below).

(b) Weak acids in high concentration. This is the case of many organic acids. The proportion of dissociated acid $(\gamma)$ is small but the non-dissociated acid is highly soluble in the polymer ([AH] high), so that the catalytic effect can be important.

(c) Strong (e.g. mineral) acids. Here, the fraction of non-dissociated acid in the aqueous phase becomes significant only at high acid concentration (for instance, $\mathrm{pH} \leq 1$ ). The $\mathrm{AH}$ concentration in the polymer can be low, but $\gamma$ is high and the catalytic effect is noticeable at moderate $\mathrm{pH}$ values and can be strong at very low $\mathrm{pH}$ values.

NB: Catalytic species such as acids not only accelerate hydrolysis, but also shift equilibrium towards low conversions since they scavenge the terminal groups (e.g. alcohols in the case of polyesters, or amines in the case of polyamides) which, in their absence, would react with acid chain ends. Sometimes, for instance in the case of PA 11 hydrolysis in the presence of carbon dioxide [108], the accelerating effect is low, while the shift of equilibrium is noticeable. 


\section{Hydrolysis induced hydrophilicity changes}

In certain cases, for instance polyesters, hydrolysis substitutes a moderately polar group (ester) by a pair of strongly polar groups (alcohol + acid). Since hydrolysis rate is an increasing function of the water concentration in the polymer, this increase in hydrophilicity can induce an auto-acceleration of hydrolysis [109] in the absence of auto-catalysis. Assuming that, in a first approach, hydrophilicity is an additive molar function, one can modify the kinetic equation as follows:

$$
\frac{\mathrm{dE}}{\mathrm{dt}}=-\mathrm{k}_{\mathrm{H}}[\mathrm{E}]\left\{[\mathrm{W}]_{0}+\mathrm{b}\left([\mathrm{E}]_{0}-[\mathrm{E}]\right)\right\}
$$

where $[\mathrm{W}]_{0}$ is the initial water concentration and $\mathrm{b}$ a parameter expressing the increase in water concentration per hydrolysis event.

\subsection{Hydrolysis as a Chain Scission Process: Consequences and Experimental Approaches}

\section{In linear polymers}

In the simplest case, all the hydrolysable groups are equi-reactive, so hydrolysis is a random chain scission process. In this case, if $s$ is the number of moles of chain scissions per mass unit, $\mathrm{M}_{\mathrm{n}}$ and $\mathrm{M}_{\mathrm{w}}$ are the molar mass averages respectively in number and in weight, the following equations can be written $[110,111]$ :

$$
\begin{aligned}
& \frac{1}{M_{n}}-\frac{1}{M_{n 0}}=s \\
& \frac{1}{M_{w}}-\frac{1}{M_{w 0}}=\frac{s}{2}
\end{aligned}
$$

It can be deduced from these equations that, if the initial polydispersity ratio $\left(\mathrm{PI}_{0}=\mathrm{M}_{\mathrm{w} 0} / \mathrm{M}_{\mathrm{n} 0}\right)$ is higher than 2, it must decrease and tend towards 2 . If $\mathrm{PI}_{0}<2$, it must increase and tend towards 2 . If $\mathrm{PI}_{0}=2$, it must remain constant. The change of PI during hydrolysis is the best way to check the random (or nonrandom) character of hydrolysis.

Non-random character can result from various causes:

- Specific reactivity of certain groups, for instance at chain ends;

- Loss of small fragments extracted by liquid water or evaporated;

- Limitation of hydrolysis by crystallites (see below).

In the two former cases, the non-random character is revealed by a gravimetric study [112]. In a purely random process, each hydrolysis event induces a mass increase: 


$$
\frac{\mathrm{dm}}{\mathrm{dt}}=18 \frac{\mathrm{ds}}{\mathrm{dt}}
$$

where $\mathrm{m}$ is the mass uptake expressed in $\mathrm{g} \cdot \mathrm{g}^{-1}$ and $\mathrm{s}$ is the number of moles of chain scissions per gram.

For a polymer of initial $\mathrm{M}_{\mathrm{n} 0}=50 \mathrm{~kg} \cdot \mathrm{mol}^{-1}$ undergoing a decrease of $10 \%$ after hydrolysis, the number of chain scissions would be about $2 \times 10^{-3} \mathrm{~mol}^{-1}$ and the mass uptake (for the dry sample) would be $36 \mathrm{mg}$ per gram. Gravimetry is thus an interesting tool for investigating hydrolysis. Chemical or spectrochemical titration of terminal groups can be used in the domain of relatively low molar masses, where these methods are sensitive enough. In the same way, spectrochemical titration of hydrolysable groups, for instance NMR titration of ester groups, can be used, provided it is precise enough.

For linear polymers, molar mass measurements are however the best way to determine the number of chain scissions using the above equations. Molar mass can be determined by viscosimetry. From viscosity measurements on dilute polymer solutions one can determine the reduced viscosity $\eta_{\text {red }}$ from which one can obtain, by extrapolating to zero concentration, the intrinsic viscosity $[\eta]$. This latter is linked to the average molar mass by a power law. The intrinsic viscosity can also be obtained from a single value of the reduced viscosity:

$$
\begin{gathered}
\eta_{\text {red }}=\frac{\eta-\eta_{0}}{\eta_{0}} \\
{[\eta]=\lim _{\mathrm{C} \rightarrow 0}\left(\frac{\eta_{\mathrm{red}}}{\mathrm{C}}\right)} \\
{[\eta]=\frac{1}{2 \mathrm{k}_{\mathrm{H}} \mathrm{C}}\left[-1+\left(1+4 \mathrm{k}_{\mathrm{H}} \eta_{\mathrm{red}} \mathrm{C}\right)^{1 / 2}\right]} \\
{[\eta]=\mathrm{KM}^{a}}
\end{gathered}
$$

where $\eta$ and $\eta_{0}$ are the viscosities of the polymer solution and the pure solvent respectively, $\mathrm{C}$ is the polymer concentration and $\mathrm{k}_{\mathrm{H}}$ is the Huggins coefficient generally of the order of $0.5 \pm 0.2$. $\mathrm{K}$ depends of the nature of solvent and polymer, and temperature; $\mathrm{a}$ is an exponent of the order of $0.7 \pm 0.2 \mathrm{M}$ is an average molar mass closer to $\mathrm{M}_{\mathrm{w}}$ than to $\mathrm{M}_{\mathrm{n}}$. In a first approach, one can consider that: $\mathrm{M}=\mathrm{M}_{\mathrm{w}}$.

There is also another viscosimetric approach using the Newtonian viscosity $\eta_{\mathrm{N}}$ determined from rheometric experiments in the molten state. It can be linked to the weight average molar mass using a universal scaling law:

$$
\eta_{\mathrm{N}}=\mathrm{KM}^{3.4}
$$

This method is, indeed, very sensitive, but must be used with caution because the measurements are made at relatively high temperature where the polymer can be reactive (for instance, the reverse reaction of hydrolysis can occur) in the 
timescale of experiments. The latter can require a prior neutralization of chain ends.

Steric exclusion chromatography (SEC or GPC for gel permeation chromatography) or mass spectrometry (MALDI TOF), but only when the polymer is polar and the molar mass is not too high (typically $\leq 25 \mathrm{~kg} \cdot \mathrm{mol}^{-1}$ ), allow the molar mass distribution to be established, from which all the average values can be determined. These methods give access to the polydispersity index which allows detecting eventual non-random characteristics.

\section{In semi-crystalline polymers}

Since water is insoluble in the crystalline phase, hydrolysis concerns only the amorphous phase. Chain scissions in this latter liberate initially entangled chain segments which have then sufficient mobility (in the rubbery state) to join the crystalline phase. This process of secondary crystallization has been called chemicrystallization. The amorphous phase is thus destroyed by two phenomena: the "chemi-crystallization" induced by chain scissions [113], which is expected to occur without significant mass change, and the eventual loss of small chain fragments by extraction or evaporation (involving mass loss).

When all the amorphous phase has been destroyed, hydrolysis stops. The kinetic curves of molar mass changes then display an asymptote at a molar mass corresponding to the lamella thickness. In PET, for instance, total hydrolysis leads to an increase in density from 1.413 to 1.453 (theoretically, the density of a $100 \%$ crystalline PET is 1.457), and an increase in the melting point from about $265{ }^{\circ} \mathrm{C}$ to more than $270{ }^{\circ} \mathrm{C}$. The degree of polymerization, initially about 70 , decreases to an asymptotic value of about 9. The polydispersity index, initially about 2.2, decreases to about unity [114]. Hydrolytic etching (at $\mathrm{T}_{\mathrm{f}}>\mathrm{T}>100{ }^{\circ} \mathrm{C}$ under pressure, $\mathrm{T}_{\mathrm{f}}$ being the melting point) is an interesting way to determine the lamella thickness in hydrolysable semi-crystalline polymers.

\section{Case of networks}

Let us first consider an ideal network in which all the chains are elastically active, i.e. connected at both ends to the network. In this case, each chain scission destroys $\zeta$ elastically active chains (EACs). $\zeta=3$ for a network node functionality $\mathrm{f}=3$ (number of chains starting from a node) and $\zeta=1$ for $\mathrm{f}>3$ [115]. If $\mathrm{s}$ is the number of chain scissions per mass unit, one can thus express the crosslink density $v$ (EACs concentration) at low conversions of the degradation process by:

$$
v=v_{0}-\zeta s
$$

For ideal or quasi-ideal networks, we dispose of essentially two methods: (1) rubber elasticity and glass transition temperature for thermosets; (2) rubber elasticity and equilibrium swelling in solvents for rubbers. Concerning swelling, we dispose of the Flory-Rehner theory (paragraph 1.9.1), but it must be used with caution because structural changes (increase in polarity) induced by hydrolysis can modify the polymer-solvent interaction parameter $\chi$ and lead to erroneous crosslink density values. 
Rubber elasticity

In the simplest approach [116], the stress $\sigma$ is linked to the draw ratio $\lambda$ by:

$$
\sigma=\operatorname{RT} \rho \nu\left(\lambda^{2}-\lambda^{-1}\right)
$$

The tangent shear modulus $G$ or the tangent Young's modulus $E$ are linked to the crosslink density by:

$$
\begin{gathered}
\mathrm{G}=\mathrm{RT} \rho \nu \\
\mathrm{E}=3 \mathrm{G}
\end{gathered}
$$

Thus the number s of chain scissions is given by:

$$
\mathrm{s}=\frac{1}{\zeta \mathrm{RT} \rho}\left(\mathrm{G}_{0}-\mathrm{G}\right)
$$

\section{Glass transition temperature}

The glass transition temperature $\mathrm{T}_{\mathrm{g}}$ is linked to the crosslink density by the $\mathrm{Di}$ Marzio relationship [117]:

$$
\mathrm{T}_{\mathrm{g}}=\frac{\mathrm{T}_{\mathrm{gl}}}{1-\mathrm{KF} v}
$$

where $\mathrm{K}$ is an universal constant, $\mathrm{T}_{\mathrm{gl}}$ and $\mathrm{F}$ are parameters linked to the (dynamic) chain stiffness.

The derivation gives:

$$
\frac{\mathrm{dT}_{\mathrm{g}}}{\mathrm{d} v}=\frac{\mathrm{KFT}_{\mathrm{gl}}}{(1-\mathrm{KFv})^{2}}
$$

The numerator can be typically of the order of $10^{4} \mathrm{~K} \cdot \mathrm{g} \cdot \mathrm{mol}^{-1}$ for flexible (aliphatic) chains and of $3 \times 10^{4} \mathrm{~K} \cdot \mathrm{g} \cdot \mathrm{mol}^{-1}$ for stiff (aromatic) chains. It appears that the glass transition temperature is sensitive to chain scissions for stiff chain (thermosets), but almost insensitive for flexible chain networks (rubbers).

There are, however, many possible causes of non-ideality. The first one comes from interactions between neighboring EACs. This is taken into account in the Mooney-Rivlin equation [118, 119] which expresses the stress $\sigma$ against the draw ratio $\lambda$ :

$$
\sigma=\operatorname{RT} \rho v\left(1+\mathrm{c}_{2} \lambda^{-1}\right)\left(\lambda^{2}-\lambda^{-1}\right)
$$

In the case of long EACs (rubbers in general), the parameter of non-ideality $c_{2}$ can be of the order of unity and must be taken into account. In networks swollen by solvents, $\mathrm{c}_{2}$ decreases and tends towards zero when the swelling ratio increases. It can thus be interesting to perform mechanical measurements on swollen samples. In dense networks (generally thermosets), $c_{2}$ is small and can be often neglected.

The most important cause of non-ideality, in the context of degradation studies, is that chain scission transforms an ideal network into a non-ideal one. A non-ideal 
network is constituted of EACs connected on both ends to the network, dangling chains (DC) linked by only one end to the network, and free chains (FC) not linked to the network. A chain scission in an EAC creates two DCs. A chain scission in a FC creates two smaller FCs. A very simple kinetic model can be based on the following considerations:

- The whole concentration [E] of hydrolysable groups (HG) is the sum of the concentrations $[\mathrm{E}]_{\mathrm{e}}$ of HGs present in EAC and $[\mathrm{E}]_{\mathrm{b}}$ of HGs belonging to nonelastically active chains (DCs and FCs). One EAC contains $\mathrm{N}_{\mathrm{e}} \mathrm{HGs}$.

- The reverse reaction is negligible and all HGs are equi-reactive so that:

$$
\begin{gathered}
\frac{\mathrm{d}[\mathrm{E}]}{\mathrm{dt}}=-\mathrm{k}[\mathrm{W}][\mathrm{E}] \\
{[\mathrm{E}]=[\mathrm{E}]_{0} \exp (-\mathrm{k}[\mathrm{W}] \mathrm{t})} \\
\frac{\mathrm{d}[\mathrm{E}]}{\mathrm{dt}}=-\mathrm{k}[\mathrm{W}][\mathrm{E}]_{0} \exp (-\mathrm{k}[\mathrm{W}] \mathrm{t})
\end{gathered}
$$

Moreover:

$$
\begin{gathered}
{[E]_{\mathrm{b}}=[\mathrm{E}]-[\mathrm{E}]_{\mathrm{e}}=[\mathrm{E}]-v \mathrm{~N}_{\mathrm{e}}} \\
\frac{\mathrm{d}[\mathrm{E}]_{\mathrm{b}}}{\mathrm{dt}}=\frac{\mathrm{d}[\mathrm{E}]}{\mathrm{dt}}-\mathrm{N}_{\mathrm{e}} \frac{\mathrm{d} v}{\mathrm{dt}}
\end{gathered}
$$

Let us consider the HGs belonging to non-elastically active chains: they are destroyed by hydrolysis events occurring on DCs or FCs, but each hydrolysis event on an EAC creates $\left(\mathrm{N}_{\mathrm{e}}-1\right)$ new "non-elastically active" HGs, thus:

$$
\frac{\mathrm{d}[\mathrm{E}]_{\mathrm{b}}}{\mathrm{dt}}=-k[\mathrm{~W}][\mathrm{E}]_{\mathrm{b}}+\left(\mathrm{N}_{\mathrm{e}}-1\right) \frac{\mathrm{d} v}{\mathrm{dt}}
$$

Combining Eqs 101 and 102 leads to:

$$
\mathrm{k}[\mathrm{W}] \mathrm{N}_{\mathrm{e}} v+\left(2 \mathrm{~N}_{\mathrm{e}}-1\right) \frac{\mathrm{d} v}{\mathrm{dt}}=0
$$

With pertinent boundary conditions, this differential equation leads to:

$$
v=v_{0}\left(2 \mathrm{~N}_{\mathrm{e}}-1\right) \exp (-\mathrm{Kt})-2 v_{0}\left(\mathrm{~N}_{\mathrm{e}}-1\right)
$$

where $\mathrm{K}=\frac{k[\mathrm{~W}] \mathrm{N}_{\mathrm{e}}}{\left(2 \mathrm{~N}_{\mathrm{e}}-1\right)}$.

The theories linking a given physical property to the crosslink density $v$ have been established for ideal networks. Do these theories remain valid for non-ideal ones? There is no clear answer to this question. It is simply assumed that, at least at low departures from ideality, they are applicable, but their limits of validity remain unknown. 
In the case of styrene cured unsaturated polyesters, there are, in principle, two kinds of dangling chains: those resulting from terminations and transfer reactions during the styrene-fumarate copolymerization, and those corresponding to the acidic and alcoholic chain ends of the polyester prepolymer. The concentration of the latter is directly linked to the prepolymer molar mass. Furthermore, the corresponding acid and alcohol functions are the same as those created by hydrolysis. In other words, schematically, a polyester of molar mass $\mathrm{M}$ is equivalent to a polyester of infinite length having undergone $\mathrm{M}^{-1}$ chain scissions per mass unit. It is therefore possible to use polyester networks of known structure to calibrate crosslink density determinations from elastic modulus measurements [120].

\subsection{Effect of Structure}

Structure-hydrolytic stability relationships have been abundantly investigated in the case of ester-containing polymers. In the simplest case of linear polymers, the initial rate $R_{s}$ of chain scission is:

$$
\mathrm{R}_{\mathrm{s}}=\frac{\mathrm{ds}}{\mathrm{dt}}=k[\mathrm{~W}][\mathrm{E}]_{0}
$$

Some values of $\mathrm{R}_{\mathrm{s}}$ at $100{ }^{\circ} \mathrm{C}$, compiled by Bellenger et al. [121], are reported in Table 9.

It appears that hydrolysis is not slower in networks than in linear polymers. VE are considerably more stable than UP, that can be attributed to the lower reactivity

Table 9 Initial rate of hydrolysis. Data compiled by Bellenger et al. [121]

\begin{tabular}{lll}
\hline Polymer & $\mathrm{R}_{\mathrm{s}} \times 10^{10}\left(\mathrm{~mol} \cdot \mathrm{L}^{-1} \mathrm{~s}^{-1}\right)$ & Activation energy $\left(\mathrm{kJ} . \mathrm{mol}^{-1}\right)$ \\
\hline Polycarbonate bisphenol A (PC) & 67 & 75 \\
Polyethylene terephthalate (PET) & 600 & 107 \\
Unsaturated polyesters (UP) & $2,000-15,000$ & $70 \pm 10$ \\
Vinyl esters (VE) & $20-100$ & - \\
\hline
\end{tabular}

Table 10 Hydrolysis characteristics of some linear polyesters modeling unsaturated polyesters according to [60]

\begin{tabular}{lccl}
\hline Code & {$[\mathrm{E}]_{0}\left(\mathrm{~mol} \cdot \mathrm{kg}^{-1}\right)$} & {$[\mathrm{W}]\left(\mathrm{mol}_{\mathrm{kg}}^{-1}\right)$} & $\mathrm{K} \times 10^{8}\left(\mathrm{~kg} \cdot \mathrm{mol}^{-1} \mathrm{~s}^{-1}\right)$ \\
\hline I-NPG & 8.7 & 2.6 & 2.7 \\
I-PG & 9.7 & 6.7 & 2.8 \\
I-EG & 9.4 & 3.2 & 40 \\
I-DEG & 8.5 & 7.2 & 2.5 \\
M-NPG & 10.9 & 3.3 & 41 \\
M-PG & 12.4 & 9.5 & 38 \\
M-EG & 14.1 & 3.9 & 192 \\
M-DEG & 9.4 & 10.5 & 50 \\
\hline
\end{tabular}


of methacrylates (VE) compared to fumarates or phthalates (UP). A detailed study of model compounds of UPs $[60,78]$ gave more information about the reactivity of the various kinds of esters which may be present in UPs (Table 10). The substrates are homopolymers resulting from the polycondensation of two diacids: isophthalic acid (I) or maleic acid (M) with four diols: neopentyl glycol (NPG), propylene glycol (PG), ethylene glycol (EG) or diethylene glycol (DEG).

These results call for the following comments: In both isophthalate and maleate series, NPG, PG and DEG have close reactivity; esters of ethylene glycol are one order of magnitude more reactive. This is presumably due to the fact that ethylene segments allow interactions between an acid group resulting from hydrolysis and the neighboring ester, which is forbidden with the other diols. One can note that, if NPG systems have the same reactivity as PG ones, they are 2-3 times less hydrophilic. Since the initial rate is proportional to water concentration, NPG systems are 2-3 times more stable than PG ones. In networks, the effect of the diol on hydrophilicity is "diluted" by the presence of $40 \pm 5 \mathrm{w} \%$ styrene, but its influence on hydrolysis rate is still not negligible.

But, the most striking fact is the difference of reactivity between maleates and isophthalates. Indeed, in a network, maleate units are saturated by styrene, but the aliphatic esters remain relatively highly reactive and constitute, no doubt, the "weak points" of the network.

Styrene cured unsaturated polyesters are, by far, the most important composite matrices undergoing hydrolysis. Among other polymers in which problems of hydrolytic ageing have been observed, one can cite: polyamides, including aromatic ones (for instance, Kevlar) [122], anhydride cured epoxies, polyurethanes based on polyesters, vinyl esters, polyvinyl acetate used as low profile additive in polyester sheet molding compounds or bulk molding compounds, etc. There is not, to our knowledge a theoretical tool able to predict the hydrolysis rate of a given group in a given polymer.

\subsection{Diffusion Controlled Hydrolysis}

Let us consider the simplest case of almost irreversible hydrolysis where the rate of water consumption $r_{w}$ is proportional to the water concentration [W]:

$$
\frac{\mathrm{dW}}{\mathrm{dt}}=-\mathrm{k}[\mathrm{E}]_{0}[\mathrm{~W}]=-\mathrm{K}[\mathrm{W}]
$$

where $\mathrm{K}$ is a pseudo first order rate constant depending only on temperature.

One can define a characteristic time $t_{R}$ of this reaction:

$$
\mathrm{t}_{\mathrm{R}}=\mathrm{K}^{-1}
$$

For a bulk sample of thickness $\mathrm{L}$, one can define a characteristic time $\mathrm{t}_{\mathrm{D}}$ for water diffusion: 


$$
\mathrm{t}_{\mathrm{D}}=\mathrm{L}^{2} / \mathrm{D}
$$

where $\mathrm{D}$ is the coefficient of water diffusion into the material.

One can then consider the ratio of characteristic times:

$$
\mathrm{J}=\mathrm{t}_{\mathrm{R}} / \mathrm{t}_{\mathrm{D}}
$$

- If $\mathbf{J} \gg 1$, diffusion is faster than reaction and homogenizes the distribution of water concentration in the sample thickness. Hydrolysis is homogeneous.

- If $\mathbf{J} \ll 1$, hydrolysis consumes all the available water in a superficial layer, the water concentration in the sample core is lower than in superficial layers. Hydrolysis is diffusion controlled and degradation is heterogeneous.

The kinetic problem of diffusion controlled hydrolysis in polyesters was first solved by Golike and Lasoski [123]. When the reverse reaction is negligible, the kinetic equation can be written:

$$
\frac{\partial W}{\partial t}=D \frac{\partial^{2} W}{\partial z^{2}}-k[E][W]
$$

At low conversions, $[\mathrm{E}]$ can be considered constant and $\mathrm{k}[\mathrm{E}]=\mathrm{K}=$ constant. If a steady state is rapidly reached, $\delta \mathrm{W} / \delta \mathrm{t}=0$ and, if the sample is exposed on both sides:

$$
\mathrm{D} \frac{\partial^{2} \mathrm{~W}}{\partial \mathrm{z}^{2}}=\mathrm{K}[\mathrm{W}]
$$

This equation can be solved taking, for instance, the origin of $\mathrm{z}$ at a surface:

$$
[\mathrm{W}]=[\mathrm{W}]_{\mathrm{s}} \frac{\cosh \mathrm{B}\left(\mathrm{z}-\frac{\mathrm{L}}{2}\right)}{\cosh \mathrm{B} \frac{\mathrm{L}}{2}}
$$

where $\mathrm{B}=(\mathrm{K} / \mathrm{D})^{1 / 2}$

One sees that, if $\mathrm{L} \ll \mathrm{B}^{-1}$, hydrolysis is almost homogeneous. In contrast, if $\mathrm{L} \gg \mathrm{B}^{-1}$, the sample core will remain non-degraded, hydrolysis will affect only a superficial layer whose thickness is of the order of $3 \mathrm{~B}^{-1}$. It is noteworthy that, in this model, the shape of the water concentration profile in superficial layers is exponential (Fig. 14) and the thickness of the degraded layer is independent of hydrolysis conversion. In a polyester composite at $20{ }^{\circ} \mathrm{C}$, the coefficient of water diffusion is of the order of $10^{-13} \mathrm{~m}^{2} \cdot \mathrm{s}^{-1}$, and the extrapolated first order rate constant of hydrolysis is about $10^{-11} \mathrm{~s}^{-1} . \mathrm{B}^{-1}$ is therefore of the order of $0.1 \mathrm{~m}$. Hydrolysis is thus expected to be almost homogeneous in samples of thicknesses of few $\mathrm{cm}$.

Note that, if $\mathrm{K}$ and $\mathrm{D}$ obey an Arrhenius law with respective activation energies $\mathrm{H}_{\mathrm{K}}$ and $\mathrm{H}_{\mathrm{D}}$, then $\mathrm{B}^{-1}$ also obeys an Arrhenius law: 
Fig. 14 Shape of the water concentration profile in reduced coordinates $\frac{w}{w_{s}} \quad \frac{w}{w_{s}}$

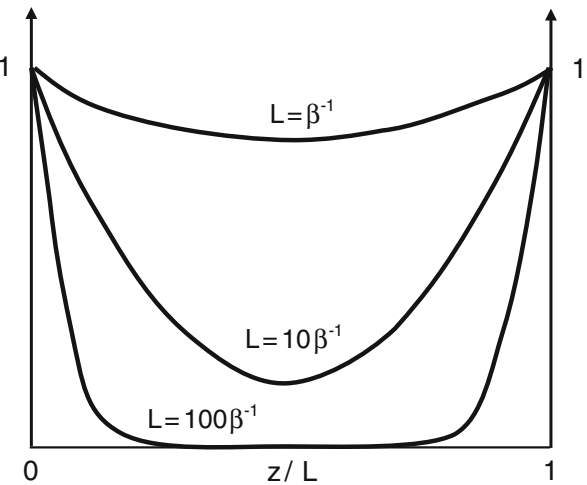

$$
\mathrm{B}^{-1}=\mathrm{B}_{0}^{-1} \exp \left[\frac{1}{2}\left(\mathrm{H}_{\mathrm{K}}-\mathrm{H}_{\mathrm{D}}\right)\right]
$$

Since, generally, $\mathrm{H}_{K}>\mathrm{H}_{\mathrm{D}}, \mathrm{B}^{-1}$ is expected to decrease when the temperature increases. A hydrolytic ageing can thus be homogeneous in service conditions and diffusion controlled under accelerated ageing conditions. Typically, for polyester composites, $\mathrm{B}^{-1}$ would be of the order of $1 \mathrm{~cm}$ at $100{ }^{\circ} \mathrm{C}$.

If hydrolysis is equilibrated, as in the case of PA 11 [104], the hydrolysis rate decreases progressively and $\mathrm{B}^{-1}$, which is inversely proportional to $\mathrm{K}$, increases. Water invades the sample thickness and hydrolysis tends to become homogeneous.

\subsection{Osmotic Cracking}

In the 1970s-1980s, blistering appeared worldwide on polyester composite boat hulls and seriously affected the manufacturers. Blisters are cracks propagating parallel to the surface in the back-up layer, between the gel-coat and the first fiber reinforced layer. Blistering also appeared in other structures based on polyester matrix composites: tanks, swimming pools, etc. It was soon diagnosed as an osmotic cracking process for which the mechanism can be briefly resumed as follows [124-126]: microcavities of unknown origin are initially present, they are filled by water. Small molecules or salts, initially present in the matrix (for instance, catalyst residues) or formed during hydrolysis, are dissolved by water and accumulate into microcavities. The material layer separating a microcavity and the water bath is permeable to water, but considerably less permeable to larger molecules. It thus works as a semi-permeable membrane and an osmotic pressure 
develops into the cavity. According to Van't Hoff (1882) [127] the osmotic pressure is given by:

$$
\mathrm{p}=\mathrm{RT} \sum \mathrm{C}_{\mathrm{i}}
$$

where $\mathrm{C}_{\mathrm{i}}$ is the concentration of the $i$ th solute in the microcavity.

Using the classical fracture mechanics concepts, one can determine the critical pressure $\mathrm{p}_{\mathrm{c}}$ to initiate crack propagation [49]:

$$
\mathrm{p}_{\mathrm{c}}=\left(\frac{3 \mathrm{EW}_{\mathrm{s}}}{2 \mathrm{~h}}\right)^{1 / 2}
$$

where $\mathrm{E}$ is the Young's modulus, $\mathrm{W}_{\mathrm{s}}$ is the surface energy and $\mathrm{h}$ is the cavity diameter.

Taking the following orders of magnitude: $\mathrm{E}=3 \mathrm{GPa}, \mathrm{W}_{\mathrm{s}}=1 \mathrm{~J} . \mathrm{m}^{-2}$ and $\mathrm{h}=10 \mu \mathrm{m}$, one obtains: $\mathrm{p}_{\mathrm{c}} \sim 20 \mathrm{MPa}$, a value not very far from the ultimate strength of the polyester matrix. Using now the Van't Hoff relationship, one obtains $\Sigma \mathrm{C}_{\mathrm{i}}=8000$ mol.m $\mathrm{m}^{-3}$, i.e. 8 mol. $\mathrm{L}^{-1}$.

The osmotic cracking process can be revealed using gravimetric curves of relatively thin samples (typically $\leq 1 \mathrm{~mm}$ ), where the characteristic time of diffusion is lower than the characteristic time of osmotic damage. The kinetic curves of mass variation have a typical shape (Fig. 15) [128].

Four elementary times can be distinguished:

- $0<\mathrm{t}<\mathrm{t}_{1}$ : physical water sorption. The system reaches an equilibrium linked to water solubility at $\mathrm{t}_{1}$.

- $\mathrm{t}_{1}<\mathrm{t}<\mathrm{t}_{2}$ : the system stays in pseudo-equilibrium. It undergoes hydrolysis, but the conversion ratio remains low, on this side of the sensitivity of the measuring method.

- $\mathrm{t}>\mathrm{t}_{2}$ : propagation of osmotic cracks begin at $\mathrm{t}_{2}$. The increase of mass uptake corresponds to the increase of volume created by cracking. $t_{2}$ is a quantity well

Fig. 15 Typical shape of the gravimetric curve of a thin sample undergoing osmotic cracking

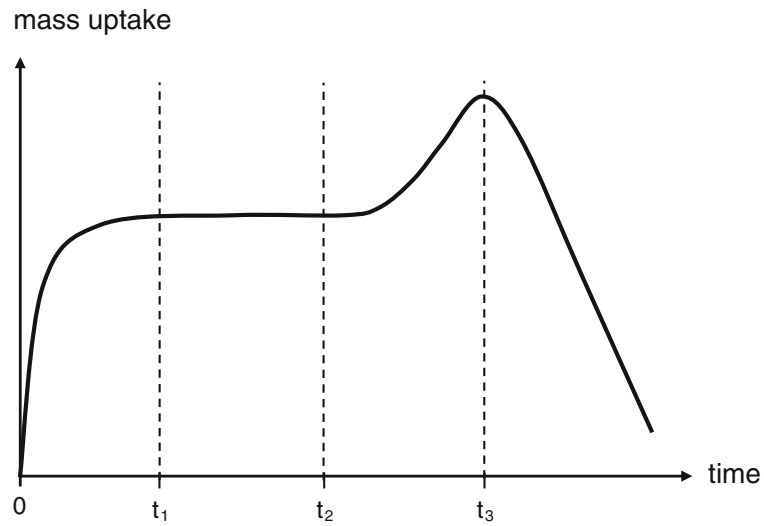


representative of the material stability. It can be called the induction time of cracking.

- At $t_{3}$, the cracks coalesce. A large part of the solutes responsible for osmosis is abruptly transferred to the bath, which explains the fast mass decrease after $t_{3}$.

In the former studies of the process, the authors supposed that the small molecules were mainly catalyst residues and other additives. These products are, however, in too small concentrations to reach the value of $8 \mathrm{mol.L} \mathrm{L}^{-1}$ calculated above. Various studies, in the 1980s-1990s showed the importance of certain matrix structural characteristics, as well the nature and concentration of ester groups [129, 130]. Mortaigne et al. [131] confirmed the influence of the ester nature, but showed also that the induction time of osmotic cracking is almost proportional to the reciprocal of the prepolymer molar mass, i.e. almost proportional to the concentration of polyester chain ends. Osmotic crack propagation was well understood but the mechanism of crack initiation remained unexplained. The hypothesis of the presence of micro-pores is not proven. Osmotic cracking can occur in highly homogeneous polymer glasses as, for instance, polycarbonate [132], where the presence of porosities is not obvious. Gautier et al. [128] proposed the following synthetic explanation: solutes can be effectively present but the most important part results from hydrolysis events near polyester chain ends that explains the result cited above of Mortaigne et al. [131]. Indeed random hydrolysis generates new chain ends and, then, contributes also to the process. These small molecules remain dissolved in the matrix until the time when their concentration becomes higher than their solubility threshold. Then, they demix and form highly hydrophilic micro-pockets able to initiate cracking. Then, the induction time of osmotic cracking would be the time at which the concentration of small molecules reaches its solubility limit. This reasoning leads to the following equation:

$$
\mathrm{C}=\mathrm{C}_{0}+2 \mathrm{aKb}_{0} \mathrm{t}+\mathrm{aK}^{2}[\mathrm{E}]_{0} \mathrm{t}^{2}
$$

where $\mathrm{C}$ is the solute concentration, $\mathrm{C}_{0}$ is the concentration of initially present water soluble molecules; $\mathrm{a}$ is a dimensionless parameter of the order of unity corresponding to the average number of hydrolysable groups close to the chain end in a dangling chain, $\mathrm{K}$ is the first-order rate constant of hydrolysis, $\mathrm{b}_{0}$ is the initial concentration of polyester chain ends, and $[\mathrm{E}]_{0}$ is the initial ester concentration.

The build-up of osmotic pressure is thus decomposed into three terms which suggest three ways for stabilization: minimizing catalyst concentrations $\left(\mathrm{C}_{0}\right)$; increasing the prepolymer molar mass, i.e. reducing $b_{0}$, but there is a limit imposed by the viscosity requirements for composite processing; decreasing the hydrolysis rate constant, which depends on ester reactivity and polymer hydrophilicity. Concerning a change of ester reactivity, it is possible to optimize the choice of the saturated (aromatic) diacid. For instance, it has been demonstrated, a long time ago, that isophthalates are more stable than orthophthalates. But, this optimization must have limited effects because the weakest point of these polyesters is the 
maleate unit. Replacement of maleic acid by another unsaturated diacid seems economically difficult. Minimizing hydrophilicity is possible, using bulky, nonpolar diols such as neopentyl glycol.

If the end of induction period corresponds to a critical concentration $\mathrm{C}_{\mathrm{L}}$ of small molecules, the induction time $t_{i}$ can be determined by solving the above equation:

$$
\mathrm{t}_{\mathrm{i}}=\frac{\mathrm{b}_{0}}{\mathrm{~K}[\mathrm{E}]_{0}}\left\{-1+\left[1+\frac{[\mathrm{E}]_{0}\left(\mathrm{C}_{\mathrm{L}}-\mathrm{C}_{0}\right)}{\mathrm{ab_{0 } ^ { 2 }}}\right]^{1 / 2}\right\}
$$

Since $[E]_{0}$ and $\left(\mathrm{C}_{\mathrm{L}}-\mathrm{C}_{0}\right) \gg \mathrm{b}_{0}$, and $\mathrm{C}_{\mathrm{L}} \gg \mathrm{C}_{0}$ one can reduce the above equation to:

$$
\mathrm{t}_{\mathrm{i}} \approx \frac{1}{\mathrm{~K} \sqrt{\mathrm{a}}}\left(\frac{\mathrm{C}_{\mathrm{L}}}{[\mathrm{E}]_{0}}\right)^{1 / 2}
$$

The diffusivity $\mathrm{D}_{\mathrm{s}}$ of small molecules is low compared to water diffusivity but not null. One sees that, if the characteristic time of diffusion $t_{D}=L^{2} / D_{s}$ is shorter than $t_{i}$, small molecules cannot accumulate in the matrix, they migrate in the bath and the critical concentration $\mathrm{C}_{\mathrm{L}}$ cannot be reached. In this case, blistering is suppressed.

\subsection{Consequences of Hydrolysis on Matrix Properties}

\section{Linear polymers}

The effect of random chain scissions on mechanical properties has been reviewed by Fayolle et al. [113].

The effect on elastic properties is very limited, the shear and Young's moduli remain almost constant in glassy amorphous polymers, a long time after embrittlement has occurred. In semi-crystalline polymers, a small modulus increase, linked to chemicrystallization, can be observed. Hydrolysis of PET sheets offers a good example: After 15 days in boiling water, the samples are stiffer than initially but their fracture behavior is very close to that of eggshells.

The most important effect of hydrolysis is thus a deep embrittlement linked to the destruction of the entanglement network in glassy polymers and semi-crystalline polymers having a limited crystallinity ratio such as PET or PA 11. In nonpolar polymers, there is another embrittlement mechanism linked to the decrease of interlamellar spacing, but there are no hydrolysable polymers in this latter category.

Studies of the molar mass dependence of toughness have revealed the existence of a discontinuity at a molar mass $\mathrm{M}_{\mathrm{D}}$ (Fig. 16).

This critical molar mass is clearly related to the entanglement molar mass $\mathrm{M}_{\mathrm{e}}$, typically $\mathrm{M}_{\mathrm{D}} \sim(2-10) \times \mathrm{M}_{\mathrm{e}}$. The high initial toughness is linked to the existence 
Fig. 16 General shape of the molar mass dependence of toughness $\left(\mathrm{G}_{1 \mathrm{C}}\right.$ is the critical rate of elastic energy release in mode I)

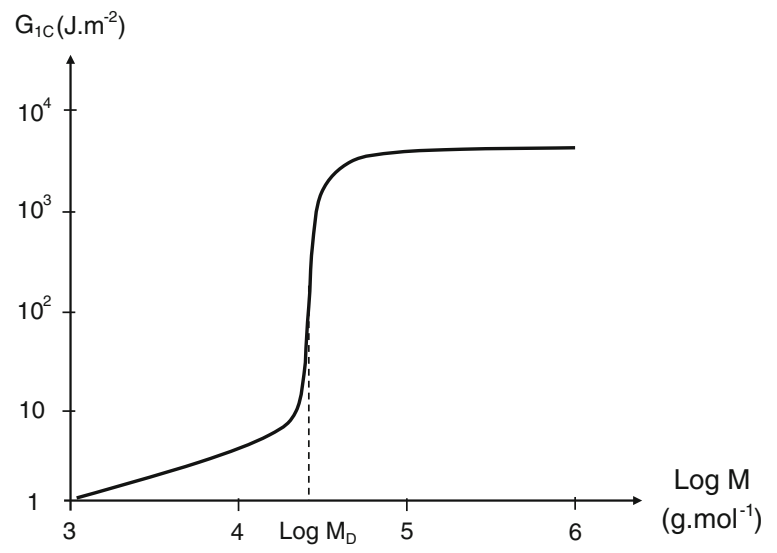

of plastic deformation involving chain drawing. This latter is only possible if the chains participate in a network. In amorphous linear polymers, the network structure is due to chain entanglements and these exist only when the chains have a length higher than a critical value corresponding to a small multiple of $\mathrm{M}_{\mathrm{e}}$. Hydrolysis destroys this entanglement network. When it reaches the state where the chains disentangle easily during stretching, i.e. when $M$ approaches $M_{D}$, the toughness decreases suddenly by 2 or 3 decades. As a result, ageing can be assimilated to a ductile-brittle transition. The characteristics of this transition constitute an ideal end-life criterion because it is almost independent of experimental parameters and corresponds to a deep change in fracture properties. Let us consider the simplest kinetic model:

$$
\frac{\mathrm{ds}}{\mathrm{dt}}=\mathrm{k}[\mathrm{W}][\mathrm{E}]_{0}
$$

Thus:

$$
\mathrm{s}=\mathrm{k}[\mathrm{W}][\mathrm{E}]_{0} \mathrm{t}
$$

The end-life criterion is:

$$
\mathrm{s}_{\mathrm{f}}=\frac{1}{\mathrm{M}_{\mathrm{D}}}-\frac{1}{\mathrm{M}_{\mathrm{n} 0}}
$$

The lifetime $t_{\mathrm{f}}$ is thus:

$$
\mathrm{t}_{\mathrm{f}}=\frac{1}{\mathrm{k}[\mathrm{W}][\mathrm{E}]_{0}}\left(\frac{1}{\mathrm{M}_{\mathrm{D}}}-\frac{1}{\mathrm{M}_{\mathrm{n} 0}}\right)
$$

Note that, $\mathrm{s}_{\mathrm{f}}<\mathrm{M}_{\mathrm{D}}^{-1}$ always, and generally, $\mathrm{M}_{\mathrm{D}} \geq 10 \mathrm{~kg} / \mathrm{mol}$. Thus, embrittlement occurs at a very low conversion of the hydrolysis reaction, that justifies the approximation made in the expression for degradation rate, except in rare cases where hydrolysis reaches its equilibrium at low conversion (case of PA 11). 
Fig. 17 Mass uptake against exposure time in distilled water for composites based on $50 \mathrm{w} \%$ glass $\mathrm{E}$ fibers and orthophthalic polyester matrix. Adapted from Jacquemet and Lagrange [77]

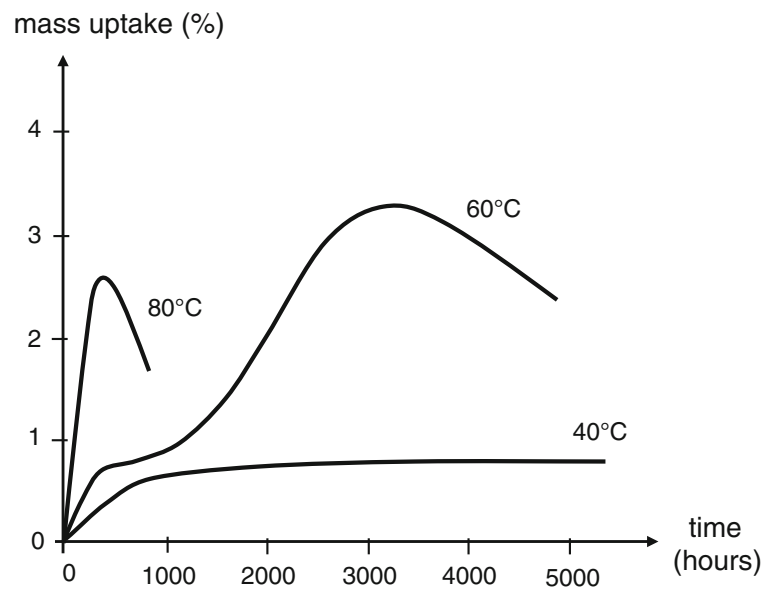

In polymers such as PA 11 , PET or PC, the critical molar mass $\mathrm{M}_{\mathrm{D}}$ is about $15 \mathrm{~kg} \cdot \mathrm{mol}^{-1}$ when the initial molar mass $\mathrm{M}_{\mathrm{n} 0}$ is generally in the $30-100 \mathrm{~kg} \cdot \mathrm{mol}^{-1}$. In other words, just a few scissions per chain are sufficient to induce embrittlement.

\section{Tridimensional polymers}

In polyester composites, hydrolysis effects can be observed on weight uptake curves as shown, for instance, by the behavior of glass E-orthophthalic polyester composites ([77], Fig. 17).

There is a great amount of published data on humid ageing of polyester composites, but they are not easy to interpret in terms of degradation mechanisms. There are also data about the influence of crosslink density on matrix mechanical properties [115], but they are not applicable to degradation studies. As a matter of fact, these studies consider ideal networks in which all the chains are assumed to have a small polydispersity.

In the case of ideal networks, a decrease of crosslink density results from an increase of the chain length: $v=\mathrm{M}_{\mathrm{e}}^{-1}$. In the case of degradation, the molar mass $\mathrm{M}_{\mathrm{e} 0}$ of EACs remains constant, but the number of EACs decreases. In the simplest case: $v=v_{0}-\mathrm{s}$. The consequences of a crosslink density decrease on rubbery elastic modulus are the same, in both cases: $\mathrm{E}=3 \mathrm{RT} \rho v$.

In contrast, there is little practical influence on elastic modulus in the glassy state. In the case of networks having a transition $\beta$ of low activity as, for instance, unsaturated polyesters or vinyl esters, there are only small modulus variations. In the case of networks having a transition $\beta$ of high activity, chain scissions induce an antiplasticization effect, i.e. a decrease in the activity of the $\beta$ relaxation and an increase of modulus on the glassy plateau between $\mathrm{T}_{\beta}$ and $\mathrm{T}_{\mathrm{g}}$. This phenomenon has not been observed in hydrolysis cases, but it has been shown in the case of oxidation of amine crosslinked epoxies [133].

The consequences of a crosslink density decrease on fracture properties of ideal and degraded networks are opposed: the toughness increases in the case of ideal 
networks [115], but decreases in the case of degraded networks. This is the reason why ideal networks are not good models for the study of relationships between structure and fracture properties of degraded networks. Unfortunately, to our knowledge, there is no physical theory predicting fracture properties of networks with broken chains. Model networks of degraded thermosets can, however, be synthesized as, for instance, in the case of unsaturated polyesters (UP) [131].

Let us consider an UP matrix based on a polyester prepolymer of molar mass $\mathrm{M}_{0}$. After ageing it has undergone $\mathrm{s}$ chain scissions per polyester mass unit. The degraded matrix cannot be distinguished from a virgin (model) polyester of molar mass $M$ such as:

$$
\frac{1}{\mathrm{M}}=\frac{1}{\mathrm{M}_{0}}+\mathrm{s}
$$

Networks based on polyester prepolymers of known molar mass can thus be used as model compounds for degraded networks based on initially longer prepolymers in order to appreciate degradation effects on mechanical properties and to calibrate crosslink density measurements, for instance, from rubber elastic modulus.

In initially brittle networks such as, for instance, polyester networks, fracture properties decrease progressively with the number of chain scissions. According to Vincent [134] or Seitz [135], the ultimate stress would be proportional to the number of chains crossing the fracture plane, that would give, for an initially ideal network of ultimate stress $\sigma_{\mathrm{R} 0}$ and EAC molar mass $\mathrm{M}_{\mathrm{e}}$ :

$$
\sigma_{\mathrm{R}}=\sigma_{\mathrm{R} 0}\left(1-2 \mathrm{sM}_{\mathrm{e}}\right)
$$

\subsection{Stress Effects on Hydrolysis}

Let us return to the hydrolysis mechanism shown in Sect. 4.1. There are two main steps: first, water addition to the hydrolysable group giving an unstable structure; second, rearrangement of this structure with a chain scission. One can suppose that, if the chain is under a tension $\sigma$, this must essentially affect the second step. If the rate controlling step is the first one, stresses are expected to have no direct influence on hydrolysis kinetics (an indirect influence can come from stress effects on water solubility and diffusivity seen previously). If, in contrast, the rate controlling step is the second one, the stress will accelerate hydrolysis. According to the simplest theory of stress assisted reactions, the hydrolysis rate $r$ would be linked to the stress by:

$$
\mathrm{r}=\mathrm{r}_{0} \exp \left(-\frac{\mathrm{H}-\mathrm{V} \sigma}{\mathrm{RT}}\right)
$$

where $\mathrm{H}$ is the activation energy of hydrolysis and $\mathrm{V}$ an activation molar volume expressing the sensitivity of the reaction to stresses. 
The problem, here, is that experimental studies of this phenomenon need to dispose of a method for precise measurement of the hydrolysis rate, that is generally easier on linear than on tridimensional polymers. The activation volume $\mathrm{V}$ must be high enough to have measurable effects at stress levels lower than yield stress, otherwise creep, damage or fracture would complicate the analysis in the case of isoptropic or quasi-isotropic samples. These problems do not arise in the case of highly oriented samples such as, for instance, aramid fibers which have very high yield stress values and can thus support hydrolytic ageing experiments under high tensile stress [136].

Experiments made on isotropic unreinforced polymers are very scarce. In the case of polycarbonate, for instance, measurable effects have been observed, but the stress dependence of hydrolysis rate does not obey the above law [137].

Experiments on composites in wet or aqueous media have often been reported in the literature. A classical way of presenting results consists in plotting the applied stress $\sigma$ against the logarithm of time to failure $\mathrm{t}_{\mathrm{f}}$. The problem, here, is to interpret highly scattered results. As a example, Philips [138] made a detailed study of this data scatter and obtained a plot having the shape of Fig. 18.

At high stress values, typically more than the half of instantaneous fracture strength, the dependence is linear, the slope lower than unity. It may be noted that this dependence is compatible with Eyring's law expressing the strain rate $\varepsilon$ ' as a function of stress and temperature:

$$
\varepsilon^{\prime}=\varepsilon_{0}^{\prime} \exp \left(-\frac{\mathrm{H}-\mathrm{V} \sigma}{\mathrm{RT}}\right)
$$

Considering that $\varepsilon=\varepsilon^{\prime} \times \mathrm{t}$ and that there is an ultimate strain $\varepsilon_{\mathrm{f}}$, one defines the time to failure $t_{\mathrm{f}}$ by:

$$
\mathrm{t}_{\mathrm{f}}=\frac{\varepsilon_{f}}{\varepsilon^{\prime}}
$$

Fig. 18 Stress normed by the instantaneous failure stress against $\log ($ time to failure) for polyester laminates according to Philips [138]

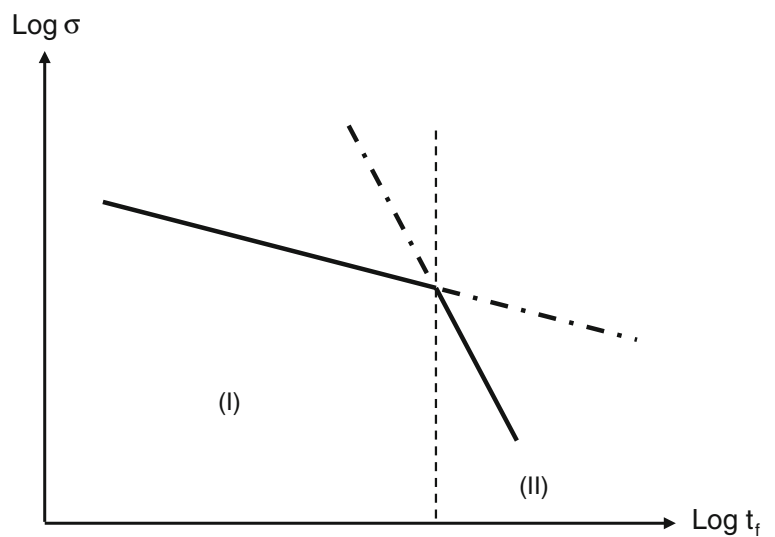




$$
\log \mathrm{t}_{\mathrm{f}}=\mathrm{A}-\mathrm{b} \frac{\sigma}{\sigma_{0}}
$$

with:

$$
\mathrm{A}=\log \frac{\varepsilon_{\mathrm{f}}}{\varepsilon_{0}^{\prime}}+\frac{\mathrm{H}}{\mathrm{RT}}
$$

and:

$$
\frac{\mathrm{b}}{\sigma_{0}}=\frac{\mathrm{V}}{\mathrm{RT}}
$$

In this stress/time domain, failure would only be due to physical processes (creep) and would be independent of environment. Beyond a certain time (about 20 days at $60{ }^{\circ} \mathrm{C}, 40$ days at $40{ }^{\circ} \mathrm{C}$, and 500 days at $20^{\circ} \mathrm{C}$ ), the absolute value of the slope $\mathrm{b}$ increases abruptly, showing that another failure mechanism takes place. At $23 \%$ of instantaneous ultimate stress, the lifetime is one month at $60{ }^{\circ} \mathrm{C}$, 11 months at $40{ }^{\circ} \mathrm{C}$, and 30 months at $20^{\circ} \mathrm{C}$. The second process can be resin plasticization, inducing a creep acceleration, and/or polyester hydrolysis. The effect of this latter presumably predominates at $60{ }^{\circ} \mathrm{C}$ and is responsible for the steep slope value.

\subsection{Hydrolytic Processes in the Interfacial Region}

Let us consider the results reported by Theberge [139] on humid ageing by immersion in boiling water for three thermoplastics: polycarbonate (PC), polyoxymethylene (POM), and impact modified poly(2-6 dimethyl oxyphenylene) (PPO), and their short glass fiber (30 w\%) composites (Table 11).

Polycarbonate undergoes hydrolysis. In the short term, the composite degrades faster than the matrix, which can be attributed to interfacial degradation, but, at long term, both the matrix and the composite are strongly degraded, which can be, at least in part, attributed to the matrix hydrolysis. More interesting are the results obtained on both non-hydrolysable polyethers, POM and PPO. In these cases, the

Table 11 Strength retention (SR) after immersion in boiling water for 100 and $1,000 \mathrm{~h}$ of three thermoplastics and their glass fiber composites. After Theberge [139]

\begin{tabular}{lccc}
\hline Polymer & Glass fiber $(\%)$ & SR $(\%)$ after $100 \mathrm{~h}$ & SR $(\%)$ after $1,000 \mathrm{~h}$ \\
\hline PC & 30 & 51 & 28 \\
PC & 0 & 100 & 28 \\
POM & 30 & 71 & 57 \\
POM & 0 & 100 & 98 \\
PPO & 30 & 84 & 65 \\
PPO & 0 & 100 & 100 \\
\hline
\end{tabular}


matrix is stable, even at long term, while the composite undergoes a significant degradation. The only possible explanation is that the composites fail by interfacial degradation. No information was available about interface/interphase, but this result clearly shows that composites based on non-hydrolysable matrices are ideal candidates for studies on hydrolytic degradation of the interfacial zone because it is the unique possible cause of mechanical property changes.

Despite about 40 years of intensive research, it remains difficult to have a clear and exhaustive vision of the role of the interface/interphase in humid ageing. Considering, first, the case of uncoupled fibers, one sees various possible causes of a specific attack of water in the interfacial region: first, the presence of interfacial voids allowing a fast penetration of water in deep layers (for instance [140]). Glass fibers have an alkaline character, which may be able to play a catalytic role on ester hydrolysis. Mortaigne [141] studied the hydrolysis of glass microspheres/ polyester composites at $100{ }^{\circ} \mathrm{C}$ and compared the apparent first-order rate constants of hydrolysis of samples containing 10, 30 or $60 \mathrm{w} \%$ coupled or uncoupled glass microspheres. The results are presented in Fig. 19.

Hydrolysis is accelerated in the presence of glass, which can be attributed to basic catalysis, and the coupling agent (of unknown nature) displays a limited but significant stabilizing effect, especially at high glass content. Thus, at least for the above two reasons: interfacial voids and catalytic effect of reinforcing agent (in the case of glass), coupling agents are expected to have a positive effect on the composite stability in humid ageing conditions. There is an impressive number of published works confirming this stabilizing role of coupling agents, for instance Kaelble et al. [142], Joshi [143], Woo and Piggott [144, 145], Di Benedetto and

Fig. 19 Pseudo first-order rate constant of polyester hydrolysis against mass fraction of coupled (c) and uncoupled $(\mathrm{u})$ glass microspheres of $50 \mu \mathrm{m}$ diameter and 1,600 kg.m ${ }^{-3}$ density

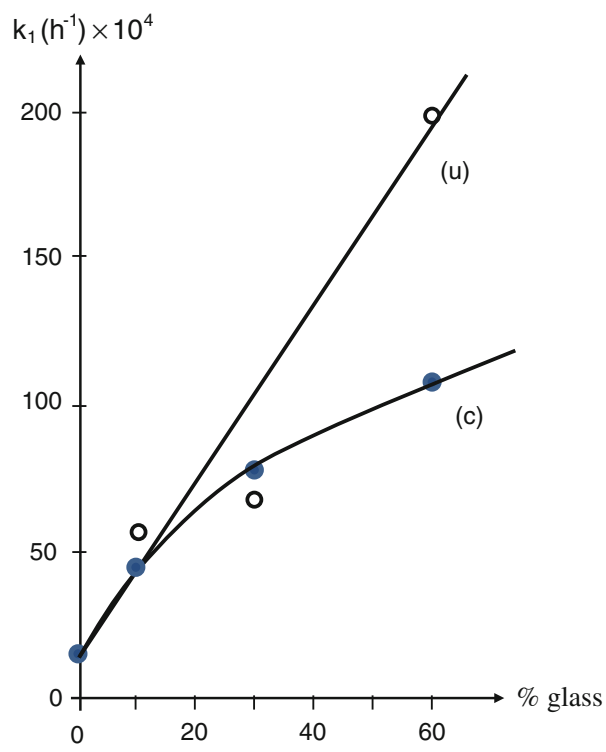


Lex [146], etc. However, despite this role, the interphase can remain the weakest zone of the composite because it is susceptible to undergo hydrolysis. This is now well recognized in the case of silane coupling agents where the interphase can be schematized as follows:

The coupling agent is a trialkoxy silane (Alk-O-) ${ }_{3} \mathrm{Si}-\mathrm{R}$ where -Alk is an alkyl group, generally $-\mathrm{CH}_{3}$ or $-\mathrm{C}_{2} \mathrm{H}_{5}$, and $-\mathrm{R}$ is a function able to establish a bond with the polymer through a reaction with a reactive group $\mathrm{Y}$ of this latter:

$$
\mathrm{Si}-\mathrm{R}+\mathrm{Y}-\text { Polym } \rightarrow \mathrm{Si}-\mathrm{R}^{\prime}-\text { Polym }+ \text { products }
$$

Hydrolysis of the $\mathrm{Si}-\mathrm{O}$ bonds of the coupling agent generates silanol groups able to condensate with the silanol groups present at the glass surface or with themselves:

Coupl-Si-O-Alk $+\mathrm{H}_{2} \mathrm{O} \rightarrow$ Coupl-Si-OH + Alk-OH (hydrolysis of coupling agent)

Coupl-Si-OH + Glass-Si-OH $\rightarrow$ Coupl-Si-O-Si-Glass $+\mathrm{H}_{2} \mathrm{O}$ (chemical bonding with glass fibers)

Coupl-Si-OH + Coupl-Si-OH $\rightarrow$ Coupl-Si-O-Si-Coupl $+\mathrm{H}_{2} \mathrm{O}$ (polycondensation of coupling agent).

The interphase can be then schematically represented by the model of Fig. 20.

One can distinguish three layers separated by diffuse boundaries. The intermediary layer (II) is made of a network resulting from the polycondensation of the coupling agent. In this layer, groups $-\mathrm{R}$ are non-reacted. The layer (II) is linked to glass by Si-O- bonds (layer (I)) and to polymer by $-\mathrm{R}^{\prime}-$ bonds (layer (III)). The extension of the latter depends on the diffusion conditions of the monomers used for crosslinking layer (II) [53]. Since, generally, the group -Y used to react with the coupling agent is also reactive in polymer crosslinking, one can expect a local perturbation of the polymer structure resulting from the local deficit of $-Y$ groups [56, 147]. This interphase structure has been described by various authors, among whom Ishida [148, 149] has been a prominent contribution.

Fig. 20 Schematization of the interphase in the case of glass fiber coupled by trialkoxysilane

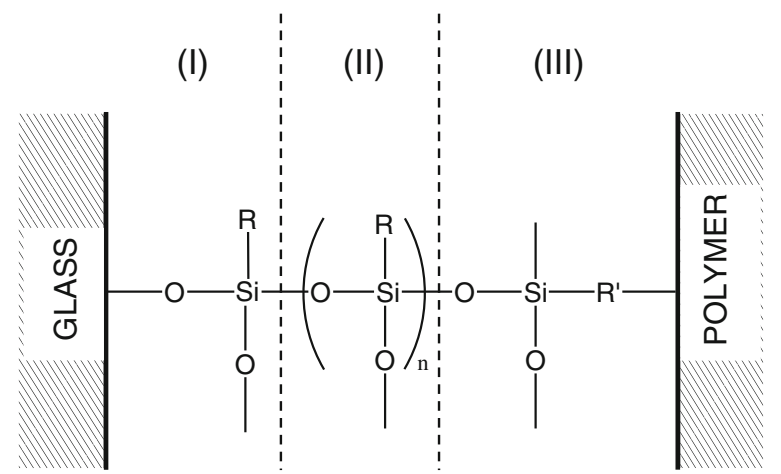


Table 12 Time to dissolution in water for networks resulting from the polycondensation of three distinct coupling agents. After Salmon et al. [58]

\begin{tabular}{lll}
\hline Network code & $\begin{array}{l}\text { Time to complete dissolution } \\
\text { at } 100{ }^{\circ} \mathrm{C}(\mathrm{h})\end{array}$ & $\begin{array}{l}\text { Time to complete dissolution } \\
\text { at } 65{ }^{\circ} \mathrm{C}(\mathrm{h})\end{array}$ \\
\hline $\mathrm{Am}$ & 0.08 & 1 \\
Ep & 35 & 300 \\
Alk & 8.000 & - \\
\hline
\end{tabular}

It was soon recognized that such interphases can undergo hydrolysis [55, 150-153]. There are now sophisticated methods to reveal structural changes in the interfacial zone of a fiber composite, but in general these methods lack sensitivity for quantitative measurements in order to determine the kinetic parameters of hydrolysis. Salmon et al. [58] prepared bulk samples of networks resulting from the polycondensation of common coupling agents based on triethoxy amino (Am), epoxy (Ep) or alkyl (Alk) silanes. It has been shown in paragraph 2.8 that the water equilibrium concentration varies in the order: Am $\gg \mathrm{Ep}>$ Alk. The diffusion coefficients at $20^{\circ} \mathrm{C}$ are comparable: $\mathrm{D} \sim(2 \pm 1) \times 10^{-12} \mathrm{~m}^{2} . \mathrm{s}^{-1}$. From gravimetric experiments, it was possible to estimate the time for complete network hydrolysis (total solubility in water). The results are reported in Table 12.

In such networks, the functional group of the coupling agent remains unreacted. Salmon et al. also studied model compounds resulting from the condensation with polymer reactive groups. As an example, the amino silane was reacted with an epoxide group (phenyl glycidyl ether (PGE)). The resistance of these compounds to hydrolysis was considerably better than the preceding ones, showing the importance of the reactive group, especially the primary amine in Am networks, in the reactivity with water. It appears thus that hydrolytic degradation in the interfacial zone must occur preferentially in zones (I) or (II) (Fig. 20), and that the choice of the reactive group (when several options exist) can be crucial. The authors checked the validity of their approach by comparing the stability of glass/ silane/glass joints immersed in distilled water at $60{ }^{\circ} \mathrm{C}$. The joint lifetime was 1-2 days for Am, 5-7 days for Ep, and more than 90 days for Alk. The hierarchy is respected, but the difference between Am and Ep is less marked. The authors showed, however, that transposition of these results to industrial fiber composites is not obvious, other components than silanes are present in the fiber sizing and can affect the hydrolysis behavior.

It can be noticed that, in composites, the interphase is confined. Water absorption and hydrolysis are expected to induce volume changes, but the latter are hindered, so that hydrostatic pressure must grow in the interfacial zone. Does this pressure affect the mechanical behavior ? Could it shift the hydrolysis equilibrium towards lower conversions? These questions, among many others, show that our current knowledge remains far from what would be needed for a non-empirical lifetime prediction in this domain. 


\section{Conclusion}

Research on composite durability began almost half a century ago. It was soon recognized that there are two main matrix categories. The first category includes the polymers which react chemically with water, for instance polyesters. Here, it is supposed that failure results from the following causal chain:

Polymer + water $\rightarrow$ water absorption $\rightarrow$ polymer hydrolysis

$\rightarrow$ degradation of the macromolecular backbone $\rightarrow$ embrittlement $\rightarrow$ failure.

It appeared that, in these polymers, kinetic modeling of hydrolysis would be the most important objective of research.

The second category includes the non-reactive polymers, for instance amine cured epoxies, for which failure results from the following causal chain:

$$
\begin{aligned}
\text { Polymer }+ \text { water } & \rightarrow \text { water absorption } \rightarrow \text { polymer swelling } \\
& \rightarrow \text { stress state } \rightarrow \text { failure. }
\end{aligned}
$$

In both categories, water concentration is an important quantity. Its prediction involves a series of research objectives relative to the mechanism(s) of water dissolution in the polymer, the role of thermodynamic parameters (temperature, hygrometry, stress state), and the solubility-structure relationships. Indeed, in thick samples, water does not invade instantaneously the whole volume, it is thus important to establish the kinetic laws of diffusion. This is especially important for the second category where swelling stresses are generated by water concentration gradients in the sample thickness. In this chapter, have shown that, in many aspects, water solubility and diffusivity in composite matrices remain largely open research areas.

In the case of the first category, the most critical questions are, in our opinion, those relative to embrittlement mechanisms, especially in networks: relationships between the network structure and fracture properties; role of degradation gradients; role of matrix mechanical properties in composite fracture.

In the case of the second category, the mechanical analysis of swelling effects has been the subject of sophisticated approaches profiting from the advances in mechanics of heterogeneous materials. Surprisingly, the swelling phenomenon itself has been the subject of few studies, one cannot consider that it is a fully elucidated mechanism, and it remains an open research area.

To summarize the above aspects, when the composite fails by matrix chemical degradation or by matrix swelling, there is sufficient knowledge to build reasonably non-empirical lifetime prediction models. Certain elements, for instance the prediction a priori of clustering or swelling ratio, remain out of reach, but can be replaced by empirical relationships. When the composite fails by its interfacial zone, we have now elements for a partial understanding of mechanisms, but we lack almost totally basic quantitative data to build non-empirical kinetic models able to predict failure. It seems to us that this domain requires considerable research efforts in the future. 


\section{References}

1. Lubin G, Donohue P (1980) Real life ageing of composites. In: 31st ANTEC, reinforced plastics/composites section, The Society of the Plastics Industry, paper 17E

2. McCall DW, Douglass DC, Blyler LL Jr, Johnson GE, Jelinski LW, Bair HE (1984) Solubility and diffusion of water in low-density polyethylene. Macromolecules 17(9): 1644-1649

3. MKacher I (2012) Vieillissement thermique des gaines PE et PVC de câbles électriques, PhD Thesis, ARTS ET METIERS ParisTech Paris, France

4. Li SZ, Chen RS (1995) NMR studies of water in polyimide films. J Polym Sci Part B Polym Phys Ed 33(3):403-409

5. Zhou J, Lucas JP (1999) Hygrothermal effects of epoxy resin. Part I: the nature of water in epoxy. Polymer 40:5505-5512

6. Popineau S, Rondeau-Mouro C, Sulpice-Gaillet C, Shanahan MER (2005) Free/bound water absorption in an epoxy adhesive. Polymer 46:10733-10740

7. Reid JD, Lawrence WH, Buck RP (1986) Dielectric properties of an epoxy resin and its composite I. Moisture effects on dipole relaxation. J Appl Polym Sci 31(6):1771-1784

8. Grave C, McEwan I, Pethrick RA (1998) Influence of stoichi- ometric ratio on water absorption in epoxy resins. J Appl Polym Sci 69(12):2369-2376

9. Lim RS, Nowick AS, Lee KW, Viehbeck A (1993) Sorption of water and organic solutes in polyimide films and Its effects on dielectric properties. J Polym Sci Polym Phys Ed 31: $545-555$

10. Illinger JL, Schneider NS (1980) Water vapor transport in an epoxy resin based on TGMDA and DICY. Polym Eng Sci 20:310-314

11. Cotugno S, Larobina D, Mensitieri G, Musto P, Ragosta G (2001) A novel spectroscopic approach to investigate transport processes in polymers: the case of water-epoxy system. Polymer 42(15):6431-6438

12. Brunauer S, Emmett PH, Teller E (1938) Adsorption of gasses in multimolecular layers. J Amer Chem Soc 60(2):309-319

13. Barrett EP, Joyner LG, Halenda PP (1951) The determination of pore volume and area distributions in porous substances. I. Computations from nitrogen isotherms. J Amer Chem Soc 73:373-380

14. Desvaux H, Gautier T, Le Goff G, Petro M, Berthault P (2000) Direct evidence of a magnetization transfer between laser-polarized xenon and protons of a cage-molecule in water. Eur Phys J D 12:289-296

15. Zimm BH, Lundberg JL (1956) Sorption of vapours by high polymers. J Phys Chem 60(4): $425-428$

16. Barrer R, Barrie J, Slater J (1958) Sorption and diffusion in ethyl cellulose. Part III. Comparison between ethyl cellulose and rubber. J Polym Sci 27:177-197

17. Merdas I, Thominette F, Tcharkhtchi A, Verdu J (2002) Factors governing water absorption by composite matrices. Compos Sci Technol 62:487-492

18. Tcharkhtchi A, Bronnec Y, Verdu J (2000) Water absorption characteristics of diglycidylether of butane diol-3,5-2,4-diaminotoluene networks. Polymer 41(15):5777-5785

19. Derrien K, Gilormini P (2007) The effect of applied stresses on the equilibrium moisture content in polymers. Scr Mater 56(4):297-299

20. Weitsman YJ (1987) Stress assisted diffusion in elastic and viscoelastic materials. J Mech Phys Solids 35(1):73-93

21. Weitsman YJ (2000) Effects of fluids on polymeric composites-a review. Compre Compos Mater 2:369-401

22. Adamson MJ (1980) Thermal expansion and swelling of cured epoxy resin used in graphite/ epoxy composite materials. J Mater Sci 15:1736-1745

23. Enns JB, Gilham JK (1983) Effect of the extent of cure on the modulus, glass transition, water absorptio, and density of an amine-cured epoxy. J Appl Polym Sci 28(9):2831-2846 
24. Gupta VB, Drzal LT, Rich M (1985) The physical basis of moisture transport in a cured epoxy resin system. J Appl Polym Sci 30(11):4467-4693

25. Johncock P, Tudgey GF (1986) Some effects of structure, composition and cure on the water absorption and glass transition temperature of amine-cured epoxies. Brit Polym J 18(5): 292-302

26. Barrie JA (1968) Water in polymers. In: Crank J, Park GS (eds) Diffusion in polymers, 4th edn. Academic Press, London, pp 259-313

27. Morel E, Bellenger V, Verdu J (1985) Structure-water absorption relationships for amine cured epoxy resins. Polymer 26:1719-1724

28. Van Krevelen DW, Te Nijenhuis K (2009) Properties of polymers. Their correlation with chemical structure. Their numerical estimation and prediction from additive group contributions, 4th edn. Elsevier, Amsterdam

29. Bellenger V, Verdu J, Morel E (1989) Structure properties relationships for densely crosslinked epoxy-amine system based on epoxide or amine mixtures. J Mater Sci 24:63-68

30. Bellenger V, Mortaigne B, Verdu J (1990) Water sorption in styrene crosslinked polyesters. J Appl Polym Sci 41:1225-1233

31. Bellenger V, Verdu J, Ganem M, Mortaigne B (1994) Styrene crosslinked vinylesters. II: water sorption, water diffusion and cohesive properties. Polym Polym Compos 2(1):17-25

32. Gaudichet-Maurin E, Thominette F, Verdu J (2008) Water sorption characteristics in moderately hydrophilic polymers. Part 1: effect of polar groups concentration and temperature in water sorption in aromatic polysulphones. J Appl Polym Sci 109(5):3279-3285

33. Pethrick RA, Hollins EA, McEwan L, Pollock A, Haymard D, Johncock P (1996) Effect of cure temperature on the structure and water absorption of epoxy/amine thermosets. Polym Int 39(4):228-275

34. Pimentel GC, McClellan AL (1960) Methods of detection: infrared and Raman Spectroscopy. In: Freeman WH (ed) The hydrogen bond. San Francisco, pp 67-141

35. Razumovskii LP, Zaikov GE (1985) Determination of the solubility and diffusion coefficients of water in aliphatic polyamides as a step to studying their hydrolytic stability. Polym Degrad Stab 12(1):1-12

36. Maxwell ID, Pethrick RA (1983) Dielectric studies of water in epoxy resins. J Appl Polym Sci 28:2363-2379

37. Muller-Plathe F (1998) Diffusion of water in swollen poly(vinyl alcohol) membranes studied by molecular dynamics simulation. J Membrane Sci 141(2):147-154

38. Starkweather HW (1975) Some aspects of water clusters in polymers. Macromolecules 8(4):476-479

39. Marais S, Métayer M, Nguyen QT, Labbé M, Saiter JM (2000) Difusion and permeation of water through unsaturated polyester resins-influence of of resin curing. Europ Polym $\mathrm{J}$ 36:453-462

40. Pitkethly MJ, Favre JP, Gaur U, Jakubowski J, Mudrich SF, Caldwell DL, Drzal LT, Nardin M, Wagner HD, Di Landro L, Hampe A, Armistead JP, Desaeger M, Verposet I (1993) A round-robin program on interfacial test methods. Compos Sci Technol 48:205-214

41. Elberaïchi A, Daro A, David C (1999) Water vapour transport in polyethylene oxide/ polymethyl methacrylate blends. Europ Polym J 35(7):1217-1228

42. Marque G, Neyertz S, Verdu J, Prunier V, Brown D (2008) Molecular dynamics simulation study of water in amorphous kapton. Macromolecules 41(9):3349-3362

43. Henderson SM (1952) A basic concept of equilibrium moisture content. Agric Eng 33(1): 29-32

44. Peleg M (1993) Assessment of a semi-empirical four parameter general model for sigmoid moisture sorption isotherms. J Food Proc Eng 16:21-37

45. Timmermann EO, Chirife J, Iglesias HA (2001) Water sorption isotherms of foods and foodstuffs: BET or GAB parameters? J Food Eng 48:19-31

46. Detallante V, Langevin D, Chappey C, Metayer M, Mercier R, Pineri M (2002) Kinetics of water vapor sorption in sulfonated polyimide membranes. Desalination 148(1):333-339 
47. Dewimille B, Bunsell AD (1982) The modelling of hydrothermal aging in glass fibre reinforced epoxy composites. J Phys D Appl Phys 15(10):2079-2091

48. Wong TC, Broutman LJ (1985) Moisture diffusion in epoxy resins. Part I: non-fickian sorption processes. Polym Eng Sci 25:521-528

49. Walter E, Ashbee KHG (1982) Osmosis in composites materials. Composites 13(4): $365-368$

50. McKague L (1977) The thermal spike effect on wet composites. In: Proceedings of conference on environental degradation of engineering materials, Blacksburg, USA, pp. 353-362

51. Thomason JL (1990) Investigation of composite interphase using dynamic mechanical analysis: artifacts and reality. Polym Compos 11(2):105-113

52. Chiang CH, Koenig JL (1984) Fourier transform infrared spectroscopic study of the adsorption of multiple amino silane coupling agents on glass surfaces. J Colloïd Interf Sci 83(2):361-370

53. Hoh KP, Ishida H, Koenig JL (1986) The diffusion of epoxy resin into a silane coupling agent interphase. In: Koenig JL, Ishida H (eds) Composite interfaces, Elsevier, New York

54. Ishida H, Koenig JL (1978) Fourier transform infrared spectroscopic study of the silane coupling agent/porous silica interface. J Colloïd Interf Sci 64(3):555-564

55. Ishida H, Koenig JL (1980) A fourier-transform infrared spectroscopic study of the hydrolytic stability of silane coupling agents on E-glass fibers. J Polym Sci Part B Polym Phys 18:1931-1943

56. Serier A, Pascault JP, Lam TH (1989) Modeling of interphase in composite materials: characterization of epoxy resin/aminosilane system. Makromol Chem Macromol Symp 25(1):85-90

57. Wolff V (1996) Influence de l'ensimage sur les propriétés mécaniques de tissus de verre enduits de résine phénolique ou de latex, $\mathrm{PhD}$ Thesis, University of Lille I, Lille, France

58. Salmon L, Thominette F, Pays M-F, Verdu J (1997) Hydrolytic aging of polysiloxane networks modelling the glass fiber epoxy-amine interphase. Compos Sci Technol 57:1119-1127

59. Flory PJ, Rehner J Jr (1943) Statistical mechanics of cross-linked polymer networks. II. swelling. J Chem Phys 11(11):521-526

60. Belan F, Bellenger V, Mortaigne B, Verdu J (1997) Relationship between the structure and hydrolysis rate of unsaturated polyester prepolymers. Polym Degrad Stab 56:301-309

61. McKague EL Jr, Reynolds JD, Halkias JE (1978) Swelling and glass transition relations for epoxy matrix material in humid environments. J Appl Polym Sci 22(6):1643-1654

62. Marque G, Verdu J, Prunier V, Brown D (2010) A molecular dynamics simulation study of three polysulfones in dry and hydrated states. J Polym Sci Part B Polym Phys 48:2312-2336

63. Hahn HT (1987) Hygrothermal damage in graphite/epoxy laminates. J Eng Mater Technol 109(1):3-11

64. Delasi R, Whiteside JB (1978) Effect of moisture on epoxy resins and composites. In: Vinson JR (ed) Advanced composite materials. Environmental effects, ASTM-STP 658, American Society for Testing and Materials, Philadelphia, pp 2-20

65. Hahn HT, Kim RY (1978) Swelling of composite laminates. In: Vinson JR (ed) Advanced composite materials. Environmental effects, ASTM-STP 658, American Society for Testing and Materials, Philadelphia, pp 98-120

66. Xiao GZ, Shanahan MER (1997) Water absortion and desorption in an epoxy resin with degradation. J Polym Sci, Part B: Polym Phys 35:2659-2670

67. Cohn D, Marom G (1978) A proposal for a coefficient of hygroelasticity. Polyym Eng Sci 18:1001-1005

68. Gazit S (1978) Dimensional changes in glass-filled epoxy resins as a result of absorption of atmospheric moisture. J Appl Polym Sci 22:3547-3558

69. Ishai O (1975) Environmental effects on deformation, strength, and degradation of unidirectional glass-fiber reinforced plastics. I. Survey. Polym Eng Sci 15(7):486-490

70. Kelley FN, Bueche F (1961) Viscosity and glass temperature relations for polymer-diluent systems. J Polym Sci 50:549-556 
71. Zhou J, Lucas JP (1999) Hygrothermal effects of epoxy resin. Part II: variations of glass transition temperature. Polymer 40:5513-5522

72. Carfagna C, Apicella A, Nicolais L (1982) The effect of the prepolymer composition of amino-hardened epoxy resins on the water sorption behavior and plasticization. J Appl Polym Sci 27(1):105-112

73. Sandorff PE, Tajima YA (1979) The experimental determination of moisture distribution in carbon-epoxy laminates. Composites 1:37-62

74. Ghi P, Hill DJT, Maillet D, Whittaker AK (1997) NMR imaging of the diffusion of water into poly(tetrahydrofurfuryl methacrylate-co-hydroxyethyl methacrylate). Polymer 38:3985-3989

75. Braun J, Klein MO, Bernarding J, Leitner MB, Mika HD (2003) Non-destructive, threedimensional monitoring of water absorption in polyurethane foams using magnetic resonance imaging. Polym Test 22(7):761-767

76. Shen CH, Springer GS (1976) Moisture absorption and desorption of composite materials. J Compos Mater 10(1):2-20

77. Jacquemet R, Lagrange A (1990) Aspects de la diffusion de l'eau de mer dans le vieillissement de matériaux composites à base de résines polyester. Composites 30(1):17-25

78. Belan F (1995) Amélioration de la résistance à l'hydrolyse de résines polyester, $\mathrm{PhD}$ Thesis, ENSAM Paris, France

79. Crank J (1990) The mathematics of diffusion. Clarendon Press, London

80. Derrien K, Gilormini P (2006) Interaction between stress and diffusion in polymers. In: Proceedings of DSL 2006 conference, defect and diffusion forum 258/260, Lisbon, Portugal, pp. $447-452$

81. Vaddadi P, Nakamura T, Singh RP (2003) Transient hygrothermal stresses in fiberreinforced composites: a heterogeneous characterization approach. Compos A 34:719-730

82. Vaddadi P, Nakamura T, Singh RP (2003) Inverse analysis for transient moisture diffusion through fiber-reinforced composites. Acta Mater 51:177-193

83. Valançon C, Roy A, Grandidier JC (2006) Modelling of coupling between mechanics and water diffusion in bonded assemblies. Oil Gas Sci. Technol (IFP) 61(6):759-764

84. Wu CH (2001) The role of Eshelby stress in composition-generated and stress-assisted diffusion. J Mech Phys Sol 49(8):1771-1794

85. Fahmy AA, Hurt JC (1980) Stress dependence of water diffusion in epoxy resin. Polym Compos 1:77-80

86. Neumann S, Marom G (1986) Free volume dependent moisture diffusion under stress in composite materials. J Mater Sci 21(1):26-30

87. Barrie JA, Machin D, Nunn A (1975) Transport of water in synthetic cis-1,4-polyisoprenes and natural rubber. Polymer 16:811-814

88. Hopfenberg HB, Frisch HL (1969) Transport of organic micromolecules in amorphous polymers. Polym Lett 7:405-409

89. Koros WJ, Paul DR (1978) $\mathrm{CO}_{2}$ sorption in poly(ethylene terephthalate) above and below the glass transition. J Polym Sci Part B Polym Phys 16(11):1947-1963

90. Stern SA (1994) Polymers for the gas separation: the next decade. J Membr Sci 94:1-65

91. Yang DK, Koros WJ, Hopfenberg HB, Stannet VT (1985) Sorption and transport studies of water in Kapton polyimide. J Appl Polym Sci 30(3):1035-1047

92. Cohen HH, Turnbull D (1959) Molecular transport in liquids and glasses. J Chem Phys 31:1164-1169

93. Bellenger V, Dahoui W, Morel E, Verdu J (1988) Packing density of the amine-crosslinked stoichiometric epoxy networks. J Appl Polym Sci 35:563-571

94. Thominette F, Gaudichet-Maurin E, Verdu J (2006) Effect of structure on water diffusion in moderately hydrophilic polymers. In: Proceedings of DSL 2006 conference on defect and diffusion forum 258/260, Lisbon, Portugal, pp 442-446

95. Carter HG, Kibler KG (1978) Langmuir-type model for anomalous moisture diffusion in in composite resins. J Compos Mater 12:118-131

96. Morgan RJ, O'Neal JE (1978) The durability of epoxies. Polym Plast Technol Eng 10(1):49-116 
97. Alfrey T, Gurnee EF, Lloyd WG (1966) Diffusion in glassy polymers. J Polym Sci Part C Polym Symp 12:249-261

98. Thomas NL, Windle AH (1982) A theory of case II diffusion. Polymer 23(4):529-542

99. Argon AS, Cohen RE, Patel AC (1999) A mechanistic model of case II diffusion of a diluent into a glassy polymer. Polymer 40(25):6991-7012

100. Barrer RM (1968) Diffusion and permeation in heterogeneous media. In: Crank J, Park GS (eds) Diffusion in polymers, 4th edn, Academic Press, London, pp 165-217

101. Kondo K, Taki T (1982) Moisture diffusivity of unidirectional composites. J Compos Mater 16(2):82-93

102. Roy S, Singh S (2009) Analytical modelling of orthotropic diffusivities in a fiber reinforced composite with discontinuities using homogenization. Compos Sci Technol 69(11-12): $1962-1967$

103. Roy S (2012) Moisture-induced degradation. In: Pochiraju KV, Tandon GP, Schoeppner GA (eds) Long term durability of polymeric matrix composites. Springer, New York, pp 181-236

104. Jacques B, Werth M, Merdas I, Thominette F, Verdu J (2002) Hydrolytic ageing of polyamide 11. I. Hydrolysis kinetics in water. Polymer 43(24):6439-6447

105. Ravens DAS (1960) The chemical reactivity of poly(ethyelene terephthalate). Heterogeneous hydrolysis by hydrochloric acid. Polymer 1:375-383

106. Serpe G, Chaupart N, Verdu J (1997) Ageing of polyamide 11 in acid solutions. Polymer 38(8):1911-1917

107. McMahon W, Birdsall HA, Johnson GA, Camilli CJ (1959) Degradation studies of polyethylene terephthalate. J Chem Eng Data 4:57-79

108. Merdas I, Thominette F, Verdu J (2003) Hydrolytic ageing of polyamide 11. Effect of carbon dioxide on polyamide 11 hydrolysis. Polym Degrad Stab 79:419-425

109. Ballara A, Verdu J (1989) Physical aspects of the hydrolysis of polyethylene terephthalate. Polym Degrad Stab 26:361-374

110. Saito O (1958a) On the effects of high energy radiation to polymers. I. Crosslinking and degradation J Phys Soc (Japan) 13(2):198-206

111. Saito O (1958b) On the effects of high energy radiation to polymers. II. End-linking and gel fraction. J Phys Soc (Japan) 13(12):1451-1464

112. Launay A, Thominette F, Verdu J (1994) Hydrolysis of poly(ethylene terephthalate): a kinetic study. Polym Degrad Stab 46(3):319-324

113. Fayolle B, Richaud E. Colin X, Verdu J (2008) Review: Degradation-induced embrittlement in semi-crystalline polymers having their amorphous phase in rubbery state. $\mathrm{J}$ Mater Sci 43:6999-7012

114. Miyagi A, Wunderlich B (1972) Etching of crystalline poly(ethylene terephthalate) by hydrolysis. J Polym Sci Part A2 Polym Phys 10:2073-2083

115. Pascault J-P, Sautereau H, Verdu J, Williams RJJ (2002) Thermosetting polymers. Marcel Dekker, New York

116. Flory PJ (1953) Principles of polymer chemistry. Cornell University Press, New York

117. Di Marzio EA (1964) On the second-order transition of rubber. J Res Nat Bur Stand Sect A Phys Chem 68:611-617

118. Rivlin RS (1948a) Large elastic deformations of isotropic materials. I, II and III. Phil Trans Roy Soc (London) A240:459-525

119. Rivlin RS (1948) Large elastic deformations of isotropic materials. IV. Further developments of the general theory. Phil Trans Roy Soc (London) A241:379-397

120. Bellenger V, Mortaigne B, Grenier-Loustalot MF, Verdu J (1992) Structure-property relationships for styrene crosslinked polyesters. I. Network structure and rubbery elastic modulus. J Appl Polym Sci 44(4):643-651

121. Bellenger V, Ganem M, Mortaigne B, Verdu J (1995) Lifetime prediction in the hydrolytic ageing of polyesters. Polym Degrad Stab 49(1):91-97

122. Derombise G, Schoors V, Vouyovitch L, Davies P (2010) Degradation of aramid fibers under alkaline and neutral conditions: relations between the chemical characteristics and mechanical properties. J Appl Polym Sci 116(5):2504-2514 
123. Golike RC, Lasoski SW (1960) Kinetics of hydrolysis of polyethylene terephthalate films. J Phys Chem 64:895-898

124. Ashbee KHG, Franck FL, Wyatt RC (1967) Water damage in polyester resins. Proc Roy Soc A300:415-419

125. Ashbee KHG, Wyatt RC (1969) Water damage in glass fibre/resin composites. Proc Roy Soc A312:553-564

126. Steel DJ (1967) Trans J Plast Inst 35:429

127. Van't Hoff $\mathbf{J}$ (1888) The function of osmotic pressure in the analogy between solutions and gases. Philos Mag 26(5):81-105

128. Gautier L, Mortaigne B, Bellenger V, Verdu J (1999) Osmotic cracking nucleation in hydrothermal-aged polyester matrix. Polymer 41(7):2481-2490

129. Burrell PP, Herzog DJ, McCabe RT (1987) A study of permeation barriers to prevent blisters in marine composites and a novel technique for evaluating blister formation. In: Proceedings of 42 nd annual conference of composite institute, the society of the plastics industry, paper $15 \mathrm{E}$, Feb 2-6

130. Curry B (1987) The effect of gel coat composition on osmotic blister formation. In: Proceedings of 42 nd annual conference of composite institute, the society of the plastics industry, paper $15 \mathrm{~A}$, Feb $2-6$

131. Mortaigne B, Bellenger V, Verdu J (1991) Vieillissement hygrothermique de composites verre/ polyester insaturés réticulés par le styrène, Rev Sci Techn Defense (Paris) 4ème trim., 76

132. Robeson LM, Crisafull ST (1983) Microcavity formation in engineering polymers exposed to hot water. J Appl Polym Sci 28:2925-2936

133. Rasoldier N, Colin X, Verdu J, Bocquet M, Olivier L, Chocinski-Arnault L, Lafarie-Frenot MC (2008) Model systems for thermo-oxidised epoxy composite matrices. Compos Part A 39:1522-1529

134. Vincent PI (1972) A correlation between critical tensile strength and polymer crosssectional area. Polymer 13:558-560

135. Seitz JT (1993) The estimation of mechanical properties of polymers from molecular structure. J Appl Polym Sci 49:1331-1351

136. Morgan RJ, Pruneda CO, Butler N, Kong FM, Caley L, Moore RL (1984) The hydrolytic degradation of Kevlar 49 fibers. In: Proceedings of 29th national sampe symposium, Society for the Advancement of Material and Process Engineering, Reno, Nevada, , pp 891-900, April 3-5

137. Ghorbel I, Akélé N, Thominette F, Spiteri P, Verdu J (1995) Hydrolytic aging of polycarbonate 2: hydrolysis kinetics, effect of static stresses. J Appl Polym Sci 55(1): 173-179

138. Philips MG (1983) Prediction of long term stress-rupture life for glass fiber-reinforced polyester composites in air and in aqueous evironements. Composites 14(3):270-275

139. Theberge JE (1970) In: Proceedings of 25th Annual technical conference on reinforced plastics, composites division, The Society of the Plastics Industry, paper 2D, Washington DC

140. Wu WL, Orts WJ, Majkrzak CJ, Hunston DL (1995) Water-adsorption at a polyimide/ silicon wafer interface. Polym Eng Sci 35(12):1000-1004

141. Mortaigne B (1989) Vieillissement hydrolytique de polyesters insaturés réticulés par le styrène, $\mathrm{PhD}$ Thesis, ENSAM Paris, France

142. Kaelble DH, Dynes PJ, Maus L (1976) Hygrothermal ageing of composite materials. Part 1 : Interfacial aspects. J Adhes 8(2):121-144

143. Joshi OK (1983) The effect of moisture on the shear properties of carbon fibre composites. Composites 14(3): 196-200

144. Woo M, Piggott M (1987) Water absorption of resins and composites, Part II: diffusion in carbon and glass reinforced epoxies. J Compos Technol Res 9:162-166

145. Woo M, Piggott M (1988) Water absorption of resins and composites: IV. Water transport in fiber rein- forced plastics. J Compos Technol Res 10:20-24

146. Di Benedetto AT, Lex PJ (1989) Evaluation of surface treatments for glass fibers in composite materials. Polym Eng Sci 29(8):543-555 
147. Serier A, Pascault JP, My LT (1991) Reactions in aminosilane-epoxy prepolymer systems. I. Kinetics of epoxy-amine reactions. J Polym Sci, Part A: Polym Chem 29:209-218

148. Ishida $H$ (1984) A review of recent progress in the studies of molecular and microstructure of coupling agents and their functions in composites, coatings and adhesive joints. Polym Compos 5(2):101-123

149. Ishida $H$ (1985) Structural gradient in the silane coupling agent layers and its influence on the mechanical and physical properties of composites. In: Ishida H, Kumar G (eds) Molecular characterization of composite interfaces. Plenum Press, New York, pp 25-51

150. Hoh KP, Ishida H, Koenig JL (1990) Multi-nuclear NMR spectroscopic and proton NMR imaging studies on the effect of water on the silane coupling agent/matrix resin interface in glass fiber-reinforced composites. Polym Compos 11(3):192-199

151. Johanson OK, Stark FO, Vogel GE, Fleishman RM, Flaningham OL (1968) The physical chemical nature of the matrix - glass fiber interface. In: Schwatrz E (ed) Fundamental aspects of fiber reinforced plastic composites. Interscience Publisher, New York

152. Rosen MR, Goddard ED (1980) FDT: a technique for direct study of water attack at the silane-fiber interface. Polym Eng Sci 20:413-425

153. Schradder ME, Block A (1971) Tracer study of kinetics and mechanism of hydrolytically induced interfacial failure. J Polym Sci Part C Polym Lett 34:281-291

154. Husman G (1976) Characterization of wet composite laminates. In: Proceedungs of Mechanical Composite., Air Force Materials Laboratory, Non Metallic Materials Division, Dayton, Ohio

155. McKague EL Jr, Halkias JE, Reynolds JD (1975) Moisture in composites: the effect of supersonic service on diffusion. J Compos Mater 9:2-9

156. Damian C, Escoubès I, Espuche E (2001) Gas and water transport properties of epoxyamine networks: influence of crosslink density. J Appl Polym Sci 80(11):2058-2066

157. Sacher E, Susko JR (1979) Water permeation of polymer films. I. Polyimide. J Appl Polym Sci 23:2355-2364 